PATIENT SAFETY EVENTS DURING CRITICAL CARE TRANSPORT

by

\title{
SCOTT SWICKARD
}

Submitted in partial fulfillment of the requirements for the degree of

Doctor of Philosophy

Frances Payne Bolton School of Nursing

\section{CASE WESTERN RESERVE UNIVERSITY}

August, 2016 


\title{
CASE WESTERN RESERVE UNIVERSITY
}

\section{SCHOOL OF GRADUATE STUDIES}

\author{
We hereby approve the thesis/dissertation of \\ Scott Swickard \\ Candidate for the degree of Doctor of Philosophy *. \\ Committee Chair \\ Dr. Chris Winkelman PhD \\ Committee Member \\ Dr. Mary Kerr PhD \\ Committee Member \\ Dr. Andrew Reimer PhD \\ Committee Member \\ Dr. Frederic Hustey MD \\ Date of Defense
}

June 24, 2016

*We also certify that written approval has been obtained for any proprietary material contained therein. 
Dedicated to my wife, with whom all things are possible; without whom, all things are meaningless. 
Table of Contents

$\begin{array}{ll}\text { List of Tables } & 7\end{array}$

$\begin{array}{lr}\text { List of Figures } & 8\end{array}$

$\begin{array}{lr}\text { Abstract } & 9\end{array}$

$\begin{array}{ll}\text { Chapter } 1 \text { Introduction of Problem Statement } & 11\end{array}$

- Introductory Statement 11

- Framework 12

- Purpose Statement 14

- Context / Background 14

- Problem Statement 20

- Theoretical Base $\quad 21$

- Research Questions 25

- Definition of Terms 25

- Assumptions 30

Chapter 2 Review of the Literature 32

- Literature related to Patient Safety Events

In health care $\quad 33$

○ In critical care $\quad 42$

In intra-facility transport 44

○ In inter-facility transport $\quad 54$

$\begin{array}{ll}\text { Chapter } 3 \text { Methodology } & 69\end{array}$

- Introduction 69 
- Research Design $\quad 70$

- Variables of Interest 72

- Patient Characteristics / Pre-transport Variables 73

- Hypothetical Moderators $\quad 81$

- Dependent Outcome Variables 84

- Setting 86

- $\quad$ CCT Devices $\quad 88$

- $\quad$ CCT Modes of Transport $\quad 88$

- Population and Sample $\quad 89$

- Sample: Sources of Data 91

- Sample: Inclusion / Exclusion Criteria 93

- Estimating Sample Size 94

- Instrumentation 95

- Data collection procedures 95

- Plan for Random Selection of Control Cases 96

- $\quad$ Missing Data 96

- Data Validation and Cleaning 97

- Data analysis 98

- Human Subjects Protection 99

$\begin{array}{lr}\text { Chapter } 4 & 101\end{array}$

- Primary Analyses 103

- Secondary Analyses 114

$\begin{array}{lr}\text { Chapter } 5 & 122\end{array}$ 
- Limitations

- Implications for Nursing

- Conclusions

Appendices

130

Bibliography

137 
List of Tables

Table 1 - Summary of relevant intra-facility published studies

Table 2 - Summary of existing transport triage instruments

Table 3 - Summary of relevant inter-facility studies cited

Table 4 - Descriptive Statistics 1 103

Table 5 - Types and Frequencies of PSE During CCT 104

Table 6 - Collinearity Diagnostics 105

Table 7 - Between Group Comparisons 106

Table 8 - PSE by Components of Stability 107

Table 9 - PSE by Components of Vulnerability 108

Table 10 - PSE by Components of Complexity 108

Table 11 - PSE by Components of Predictability 109

Table 12 - PSE by Components of Resiliency 110

Table 13 - Biserial Correlations of Patient Characteristics 111

Table 14 - Summary of Regression Results 112

Table 15 - Moderation by Nursing Competencies of Lead Clinician 113

Table 16 - Moderation by Environmental Factors 114

Table 17 - Descriptive Statistics 2

Table 18 - Significant Results of Secondary Analysis 116

Table 19 - Regression Results All Pre-transport Variables 116

Table 20 - Duration of Transport as a Function of Mode of Transport $\quad 120$ 
List of Figures

Figure 1 - Research Model

14,130

Figure 2 - Theoretical Framework of Predictor Variables

24,131

Figure 3 - CONSORT Diagram

102,132

Figure 4 - PSE per Duration of Transport (in minutes)

Figure 5 - PSE per Duration of Transport (quartiles)

Figure 6 - Adverse Events per Time Quartile

119

Figure 7 - Patient Safety Event Record

Figure 8 - Combined Data Collection Record 


\title{
Patient Safety Events During Critical Care Transport
}

\author{
Abstract \\ by \\ SCOTT SWICKARD
}

\section{Purpose Statement}

The purpose of this retrospective chart review was to investigate the type and frequency of patient safety events (PSE) during critical care transport (CCT) between hospitals and explore the patient characteristics, nursing competencies, and environmental factors impact on PSE.

\section{Research Questions}

Research questions were:

1. What are the types and frequencies of patient safety events that occur when registered nurses (RNs) and advanced practice nurses (APNs) are lead clinicians in ground, rotor and fixed-wing vehicles?

2. What is the impact of the patient characteristics of stability, vulnerability, complexity, predictability, and resiliency on frequency of patient safety events?

3. Do the nursing competencies of caring practices and clinical judgment, have a mediating or moderating role on the frequency PSE? 
4. Do modifiable environmental factors (i.e., time outside of the ICU and mode of transport) influence the frequency of PSE?

\section{Method}

This was a descriptive, comparative review of 5 months of records at a quaternary academic medical center. Inclusion criteria were all inter-hospital transports via ground, rotor, and fixed wing transport. Cases with PSE reported were compared to randomly selected non-PSE cases (ratio 1 PSE: 8 non-PSE cases). Logistic regression was used to determine relationships among the variables of interest with the occurrence of PSE.

\section{Results}

The rate of PSE was $2.65 \%$ among all qualifying cases. A total of 440 cases were reviewed and entered into the database (48 with PSE: 392 without PSE). Adverse events were the most common type of PSE (1.88\%), and new or recurrent hypoxia was the most frequent type of adverse event. The patient characteristic of stability was significant $(\mathrm{p}=0.083$, OR $1.059,95 \%$ CI $0.993-1.113)$. Secondary analyses supported the association of hypoxia, a component of stability, with PSE. The nursing competency of clinical judgment, as measured by experience in years of transport employment of the lead clinician, was identified as a potential moderator of hypoxia-related PSE. Duration of transport demonstrated the most consistent relationship with PSE in secondary analysis.

\section{Conclusion}

Hypoxia, defined as new or recurrent decrements in peripheral oxygenation, emerged as a new consideration for evaluating patients risk for CCT PSE. 


\section{Chapter 1: Introduction of Problem Statement}

\section{Introductory statement}

Nightingale's timeless parsimonious writings referred to nursing as being responsible for the health of another (Marriner-Tomey \& Alligood, 2002; Nightingale, 1860). It is axiomatic that patient safety events (PSE), defined as any event, incident, or condition that resulted in patient harm, or could have resulted in patient harm, diminish the propensity for a positive execution of that responsibility. The identification and occurrence of adverse events, particularly patient safety events, has received increased attention in health care. However, there is little information about this aspect of health care among patients who receive Critical Care Transport (CCT) in the United States (U.S.). While elimination of all adverse events in health care may be impossible, it is essential that patient safety events are measured, preventable error is identified, and strategies to avoid situations that contribute to patient harm are developed and used to deliver consistent high quality health care.

There is theoretical and empiric support for this investigation of patient safety events during CCT. There are also practical, clinical reasons to build an understanding of the factors that influence the type and frequency of patient safety events. Specifically, a mid-level theory, the American Association of Critical Care Nurses' Synergy Model for Patient Care, suggests that matching nursing competencies with patient needs promotes positive outcomes. Data from health care studies and CCT literature indicates that adverse events and other events 
consistent with patient safety event terminology occur at an alarming rate.

Clinically, analysis following patient safety events are recognized by healthcare administrators as opportunities to improve delivery of care.

This chapter provides an overview of the theoretical and conceptual issues considered during the development of a project to investigate patient safety event occurrence during CCT in a single site. The first several sections of Chapter 1 informs the reader of the purpose of this research, provide the problem statement and describe theoretical support. The next several sections give a brief overview of the literature, state the specific research questions, and define the essential terminology of the study. The chapter concludes with an explanation of the assumptions and significance of this inquiry.

\section{Framework}

Patient safety events have become increasingly well-defined in the literature. Particularly in hospital or acute care settings, common taxonomy and definitions have been adopted in both literature and practice. For this project, patient safety events were defined using standard taxonomy as adopted by the National Patient Safety Goals, and commonly used in acute care settings. This concept is further developed later in the chapter and defined in Chapter 3.

Investigation into pre-transport risk for patient safety events such as physiologic factors (e.g., unstable blood pressure or dysrhythmias) or therapeutic support requirements (e.g., artificial airway, vasopressor use, or delivery of high levels of oxygen) are key elements of the Synergy Model and may be related 
directly to specific patient characteristics. These factors also have support from CCT empiric reports about patient safety events.

Investigation into nurse competencies or environmental factors such as the level of education or experience of CCT clinicians or duration or mode of transport, and are also factors identified in the CCT research literature that may be associated with type (e.g., severity or harm to patient) and frequency of patient safety events. These factors were emphasized in this investigation. The population of patients who are transported between hospitals have variations of both time (duration of transport) and mode of transportation (e.g., ground or air vehicles) in practice. Inter-facility CCT teams have a wide range of education and experience (i.e., paramedic, registered nurse [RN], advance practice nurse [APN] and physician [MD]). In this study, the nurse competencies of licensure level of lead clinician, and years of experience of the lead clinician and environmental factors of duration and mode of transport, were hypothesized to be moderating variables, altering the strength of relationships between pre-transport risk associated with patient characteristics and adverse events. The factors that influence patient safety events and their hypothesized relationships are illustrated in Figure 1. This model is derived from the AACN Synergy Model for Patient Care with Patient Characteristics in that model as the referent to Physiologic and Therapeutic Support factors; Clinician experience and level of clinician referent to Characteristics of the Clinician, and Patient Safety events referring to Patient Outcomes. Duration and Mode of Transport are additional factors that are supported in the empiric literature. 


\section{Figure 1 - Research Model}

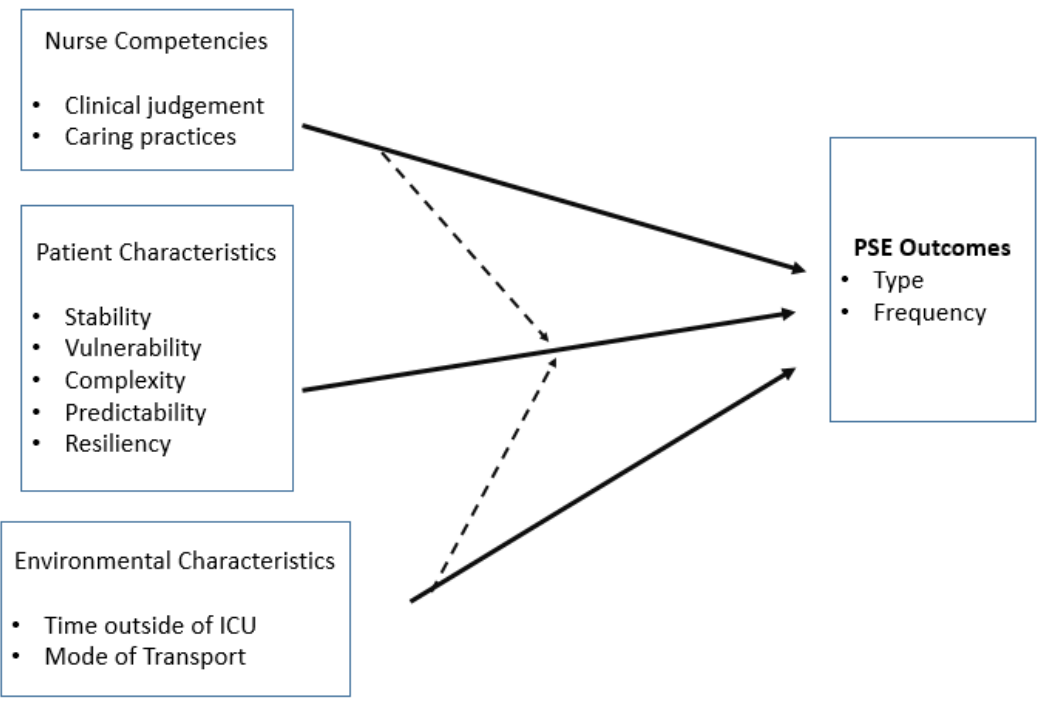

Research Model Based on Adaptation of AACN Synergy Model

*Solid lines indicate direct relationships

**Dotted lines indicate potential moderating or mediating relationships

\section{Purpose Statement}

The purpose of this research was to investigate the type and frequency of patient safety events during critical care transport (CCT) between hospitals, explore the impact of stability, vulnerability, complexity, predictability, and resiliency on the outcome of patient safety events (PSE), examine if the nurse competencies of clinical judgment and caring practices or the environment influenced the frequency of PSE, and investigate if environmental factors similarly influenced frequency of PSE.

\section{Context / Background}

Patient safety events, including adverse events, sentinel events, no-harm events, near misses, and hazardous conditions, occur at alarming rates in health 
care (Commission, 2015; Griffin FA, 2009; Kohn, Corrigan, Donaldson, \& Institute of Medicine (U.S.). Committee on Quality of Health Care in America., 2000). The errors and events can be the result of an individual's action (or inaction) but, more often, they are the result of contextual or system defects such as poor design, faulty maintenance or inadequate staffing (Thomas \& Petersen, 2003). In 1999, the Institute of Medicine (IOM) published To Err Is Human: Building a Safer Health System (Kohn, Corrigan, Donaldson, \& Institute of Medicine (U.S.). Committee on Quality of Health Care in America., 1999). Citing data from original studies, the American Hospital Association, and the Centers for Disease Control, this landmark report shocked the United States health care consumer and provider alike, revealing that between 44,000 and 98,000 hospitalized Americans die each year as a result of medical errors alone (Association, 1999; Prevention, 1999). The financial cost associated with these errors was estimated to be more than $\$ 37$ billion annually with $\$ 17$ billion of these costs deemed preventable. As alarming as these numbers were, follow up studies citing limitations in original study design suggested that the actual rate of adverse events may be significantly higher. Using a 'Global Trigger Tool' designed by the Institute for Healthcare Improvement, findings by Classen et al (2011) indicated that the adverse event rate may be ten times higher and involve nearly one third of all hospital admissions.

The IOM reported that the intensive care unit (ICU), operating room, and emergency department (ED) had higher rates of adverse events than other inpatient areas, and the consequences of the events were more significant (Kohn, 
Corrigan, Donaldson, \& Institute of Medicine (U.S.). Committee on Quality of Health Care in America, 2000). Critical Care Transport is a specialty area of intensive care that includes additional aspects of the operating room (procedures) and the ED (triage and time sensitive interventions). For example, during CCT, patients who require an artificial airway are at increased risk for dislodgement during transfer to the transport cot, while being loaded and unloaded from the transport vehicle, and during transport across uneven road surfaces or during air turbulence.

There are nearly 1.6 million patients transported from one healthcare institution to another annually (Reimer, Schiltz, Koroukian, \& Madigan, 2016). Regionalization of care, the development of specialized treatment centers, and the continuing evolution of definitive care systems have all contributed to the rapid expansion in inter-facility transport in recent years. The majority of CCT is between hospitals and the trend for increased inter-hospital transfers using CCT is expected to continue. The volume of CCT patients makes it imperative that risk for and occurrence of patient safety events be evaluated.

Not only are CCT patients potentially at great risk for patient safety events, the consequences are likely to be serious. To extend the previous exemplar, an unexpected loss of the airway may mean respiratory (and patient) distress; hypoxemic cell, organ or tissue damage; and the need for re-intubation with its attendant risk for complications. Reports from both the IOM (2000) and Classen (2011) reveal that areas with higher case-mix indices have higher rates of adverse events. Case-mix index (CMI) is a proxy measure for severity of illness in 
a given patient population. The Centers for Medicare \& Medicaid Services (CMS) measures CMI by dividing the diagnosis-related group (DRG) weight for a given diagnosis or set of diagnoses by the number of patients in the group (Services, 2015). While the Centers for Medicare and Medicaid Services report shows the national average case mix for all inpatient hospitals to be just 1.4 (CMS, 2012), the case mix indices of CCT teams are likely to be much higher as the majority or patients transported are destined for a tertiary medical center for specialty care when too critically ill to be effectively treated at local or regional facilities.

Several researchers have investigated rates of various combinations of quality measures and patient safety events in CCT. Two Canadian studies, Singh and colleagues $(2009,2014)$ looked at what they referred to as "critical events" during inter-hospital CCT. Singh defined a critical event as death, performance of an intra-transport major resuscitative procedure (further defined as eight specific airway procedures and eight specific cardiac procedures), hemodynamic deterioration (defined as specific aberrations of systolic blood pressure, mean arterial pressure, or initiation of an intra-transport vasopressor), inadvertent endotracheal extubation, or respiratory arrest (Singh, MacDonald, Bronskill, \& Schull, 2009). Results from this study indicated that critical events occur during air medical transport at a rate of at least one event in $5.1 \%$ of transports.

In a follow up study, Singh and colleagues (2014) examined critical events during CCT using ground transport alone. Critical events in this study were defined similarly, though not exactly, to their previous study. They reported 
a critical event rate of $6.5 \%$, or at least one critical event occurring in $6.5 \%$ of all ground transports.

In both studies by Singh et al., the authors found that level of clinician had a potential moderating effect. However, the levels of clinician in these investigations were paramedics prepared at differing levels, such as primary care paramedics, advanced care paramedics, and critical care paramedics. Singh found that increased education level of the paramedic was inversely related to the frequency of critical events (Singh et al. 2009, 2014).

Paramedics are not the lead or primary clinicians in the standard crew configuration of CCT teams globally, and constitute a rare staffing model in the United States specifically. The most recent report on crew composition and salaries in CCT states that $100 \%$ of air medical and $97 \%$ of ground CCT teams include a registered nurse (RN) (Greene, 2014). From a regulatory perspective, any U.S. CCT organization accredited through the Commission for Accreditation of Medical Transport Systems (CAMTS) is required to have a RN or physician as the primary caregiver on any CCT mission (Systems, 2012). To emphasize this point, CAMTS defines CCT as “...the transport of a patient, from a scene or a clinical setting, whose condition warrants care commensurate with the scope of practice of CCT professionals. (i.e., physician or registered nurse)" (Systems, 2012, p. 7). Many individual states define CCT simply as critical care needs of the patient beyond the scope of a paramedic.

The literature is replete with findings that support an association between the level of clinician and the occurrence of patient safety events, both within and 
outside of CCT. In a series of studies from the Netherlands, an MD, nurse, or both were aboard 100\% of transports (Droogh et al., 2012; Ligtenberg et al., 2005; Wiegersma, Droogh, Zijlstra, Fokkema, \& Ligtenberg, 2011). These investigators focused on patient safety events related to equipment used during inter-facility transport. They found patient safety event rates decreased from $34 \%$ to $12.5 \%$ after adding a Mobile Intensive Care Unit staffed with higher levels of clinicians experienced in transport of critically ill patients. This series of studies also concluded that critically ill patients arrived at the receiving facility in a more stable condition when a physician was present during transport rather than the nurse alone.

The licensure level of the CCT clinician might play a moderating role in reducing patient safety events that result in patient harm. This becomes much more valuable if there is a relationship established between certain pre-transport conditions and the probability of intra-transport adverse events. When pretransport factors alert the dispatch or triage clinician to high risk for adverse events, it may be possible to vary the level of clinician assigned in order to mitigate the potential for patient safety event occurrence. For example, should it be determined that patients who are hemodynamically unstable, require mechanical ventilation, and have 3 or more lines are at increased risk of a patient safety event, and should it also be found that the increased risk can be partially or completely mitigated through appropriate team selection, it would then be possible to examine if patients experience less adverse events through application of improved triage and crew resource management. 
Several studies have investigated pre-transport predictors of intra-transport patient safety events during inter-facility transport. Singh and colleagues (2009, 2014) found pre-transport hemodynamic instability and mechanical ventilation to be associated with higher likelihood of specific critical events. Additionally, duration of transport, level of paramedic, and mode of transport were significantly associated with critical events. Looking specifically at intra-transport adverse events in mechanically ventilated patients, Seymour (2008) found an independent relationship between the presence of a vasopressor infusion and the frequency of adverse events.

Intra-facility transport studies also suggest pre-transport variables influence patient safety events. Rates of patient safety events during intra-facility transport are reported as high as 67.9\% (Papson, Russell, \& Taylor, 2007). Doring and colleagues (1999) found increased frequency of "technical mishaps" with increased number of invasive lines, increased number of intravenous infusions, and greater time out of the intensive care unit (ICU). Papson (2007) also found relationships with numbers and types of supportive equipment and the rate of patient safety events, as well as an inverse relationship with level or experience of the accompanying staff. Lahner (2007) similarly found positive relationships between pre-transport mechanical ventilation and vasopressor support and the frequency of intra-facility transport patient safety events of critically ill patients.

\section{Problem statement}


Critical care transport is a growing specialty for delivering care to patients and inter-hospital transfer is a high volume occurrence in the U.S. Standardized nomenclature now exists to describe patient safety events but this approach has not consistently been used in CCT between U.S. hospitals. The role of the RN and APN in patient safety events or mitigating harm from adverse events has not been studied in the U.S. inter-facility CCT population.

\section{Theoretical base}

The American Association of Critical Care Nurses' (AACN) middle range theory, the Synergy Model for Patient Care, provided the theoretical basis for this research. The Synergy Model suggests that the nurse creates the environment for the care of the patient, and that the environment affects what the nurse can do (Hardin \& Kaplow, 2005). It is also very reminiscent of Nightingale's deep concern for assuring the patient had a healthy environment in which to heal (Alligood \& Marriner-Tomey, 2010; Nightingale, 1860, 1863).

The AACN Synergy Model for Patient Care was developed by an expert panel of critical care nurses in the 1990's to elevate the level of certified nursing practice beyond tasks to a patient-need driven system (Hardin \& Kaplow, 2005). It posits that critically ill patients have eight characteristics that need to be addressed in care: resiliency, vulnerability, stability, complexity, resource availability, participation in care, participation in decision-making, and predictability. Likewise, in order to meet the needs for care related to those characteristics, nurses may be described according to eight characteristics: clinical 
judgment, advocacy, caring practices, collaboration, systems thinking, response to diversity, clinical inquiry, and facilitation of learning. Each characteristic, both patient and nurse, lie on a categorical level described as a 1,3 , or 5 (one indicates the patient or nurse has the LEAST quantity of the characteristic; five indicates the patient or nurse has the MOST quantity of the characteristic). The Synergy Model suggests that when the patient needs and nurse competencies match, synergy develops and outcomes are optimized.

It is important to recognize how the essential elements of this research related to the theoretical base in the Synergy Model for Patient Care. A substruction of the patient characteristics found in the Synergy Model for Patient Care allowed each of the pre-transport variables of interest to be directly related to a concept in the theoretical model (See Figure AA below). AACN defines stability as the ability to maintain a steady-state equilibrium (AACN, 2015). Vital signs were used to refine this concept. Measures of abnormal heart rate, blood pressure, oxygen saturation, level of consciousness, and positive end-expiratory pressure (in mechanically ventilated patients) were used to operationalize the concept of stability in this study. Vulnerability is defined by AACN as a susceptibility to stressors, and was operationalized here through presence of mechanically assisted ventilation or non-invasive positive pressure ventilation (NPPV). Complexity is defined in the Synergy Model as the entanglement of two or more systems, and systems may include body systems, families, or therapies. Number of cardiac assist devices, number of invasive lines, number of total infusions, number of vasoactive infusions, and number of tubes and drains were 
used to operationalize the concept of complexity. Predictability is defined as the ability to predict a certain trajectory of events, and was operationalized here as associated with their diagnostic category. Resiliency is defined by AACN as the individual's ability to return to their previous level of functioning, and was operationalized through measurements of age.

Only two nursing competencies were examined in this study: caring practices and clinical judgement. Caring practices is defined as nursing activities that promote a compassionate, supportive, and therapeutic environment for the patient, and was operationalized here as experience in the role of a tertiary level critical care transport provider. Where a level 1 clinician simply maintains a safe physical environment, the level 5 seasoned and experienced clinician anticipates hazards and avoids them. Clinical judgement is defined in the model as critical thinking, combining nursing skills learned both formally and informally to command a global grasp of the situation. Clinical judgment was operationalized here as licensure level of the clinician, differentiating the formal licensure level of the RN and the APN.

Environmental factors were also examined, congruent with the nursing meta-paradigm and with the Synergy Model. According to the Synergy Model, the nurse creates an environment for the provision of care, and that environment has a direct impact on what the nurse can do (Hardin \& Kaplow, 2005). The concept of environment was operationalized by considering two environmental factors that impact CCT. The first factor was the mode of transport, defined as ground, rotor or fixed wing. Mode of transport, as reviewed in chapters 1 and 2 
has specific and empiric support for inclusion in CCT investigations. The second environmental factor was the time outside the ICU, measured in minutes. Again, this factor has both theoretic and empiric support in CCT literature.

Outcome measures of the Synergy Model included physiologic changes, the presence or absence of complications, and the extent to which treatment objectives were successfully obtained (Peterson \& Bredow, 2009). Prevention of complications, whether related to the patient's illness or as a result of medical care, is central to the Synergy Model. Outcome was operationalized in this study as the occurrence of a Patient Safety Event.

\section{Figure 2 - Theoretical Framework of Predictor Variables}
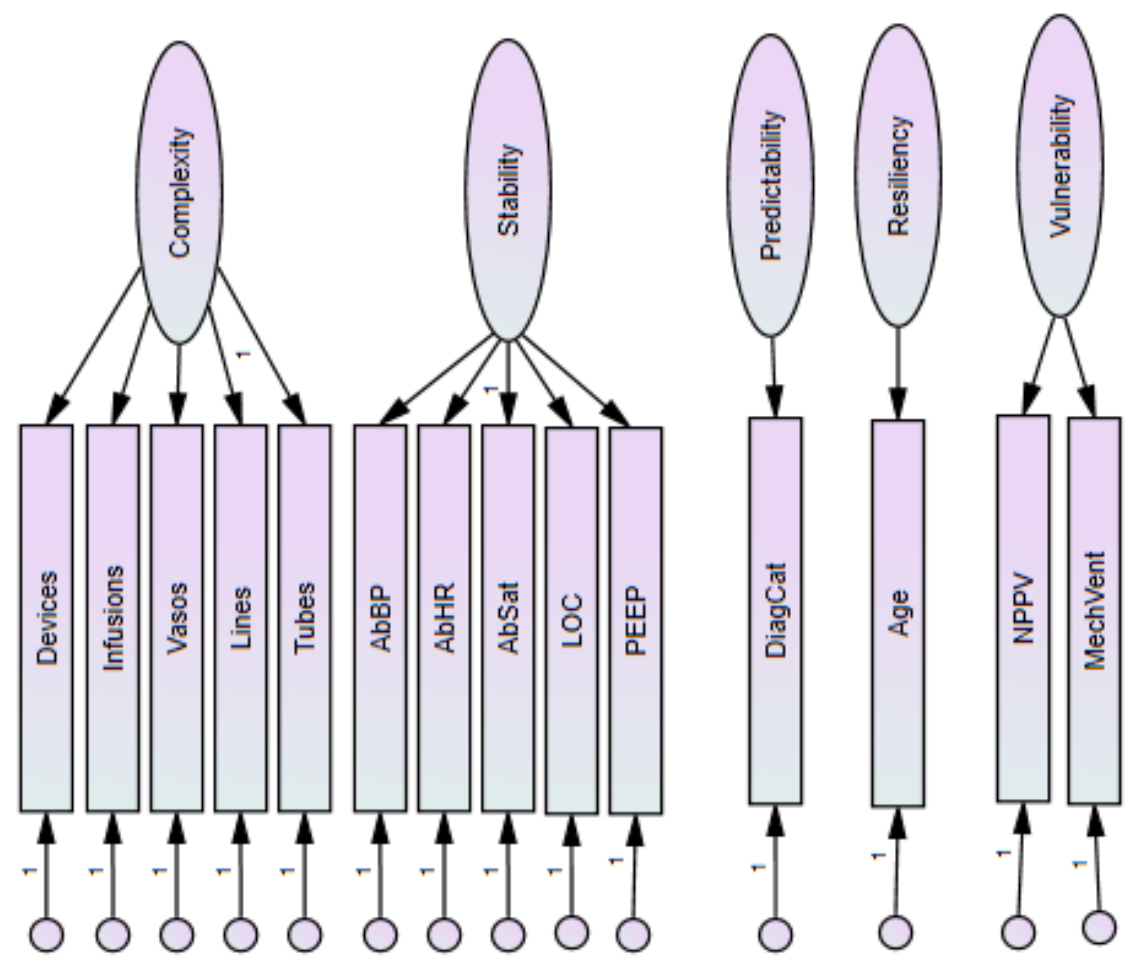


\section{Research Questions}

Using a retrospective descriptive correlational design, data was collected from a single site facility that uses all modes of transport (ground, rotor and fixed wing) and has CCT teams lead by either RN or APN clinicians. The specific aims of this project were:

1. What are the types and frequencies of patient safety events that occur during inter-facility CCT at a single site that uses RNs and APNs as lead clinicians in ground, rotor and fixed-wing vehicles?

2. What is the impact of the patient characteristics of stability, vulnerability, complexity, predictability, and resiliency on frequency of patient safety events?

3. Do the nursing competencies of caring practices and clinical judgment, have a mediating or moderating role on the frequency PSE?

4. Do modifiable environmental factors (i.e., time outside of the ICU and mode of transport) influence the frequency of PSE during interfacility transport?

\section{Definition of Terms}

There are several terms used in this study that require definition. These terms include critical care transport (CCT), physiologic factors, therapeutic support requirements, mode of transport, duration of transport, licensure level of clinician, years of lead clinician experience, and patient safety events (e.g., 
adverse events, sentinel events, no-harm events, near-misses, and hazardous conditions).

Critical care transport is an ill-defined term with significant variations in meaning ("The Critical Care Transport Standards Project," 2012). Literally, CCT is the movement of a critically ill or injured patient from one geographic location to another. This literal translation has been the source of significant ambiguity in its use. The Association for Critical Care Transport (ACCT), in collaboration with several other industry organizations, recently sought to better define the terminology in order to proceed with regulatory advisement using a consistent frame of reference. Their definition consists of the provision of medical care to a patient in need of inter-facility transport by a defined CCT team in which the initiation or maintenance of certain pharmacologic or technological interventions are or may be necessary and without which, patient harm or demise may result ("The Critical Care Transport Standards Project," 2012). ACCT goes on to define a critical care patient and a CCT agency. Use of the term "Critical Care Transport (CCT)" in this document refers to the ACCT definition that focuses on the provision of critical care and the welfare of the patient, rather than the literal definition that focuses on the simple provision of transportation.

For this study, CCT referred to all ground and air transport between hospitals where critical care is needed and provided. It did not include prehospital scene transports nor did it include rendezvous with EMS at a hospital helipad prior to evaluation by a physician at that facility such as in cases of ST elevation myocardial infarction (STEMI) recognized in the field, or specialized 
pre-hospital treatment of acute stroke patients via a specialized stroke treatment unit.

Stability is often measured as a function of certain physiologic parameters. These factors typically include specific vital signs, particularly blood pressure, heart rate, oxygen saturation, and level of consciousness. This study measured stability as a function of these parameters, plus the level of positive endexpiratory pressure (PEEP) being used to maintain oxygen saturation levels. Where appropriate, physiologic measures followed ranges established and validated in the Modified Early Warning Score (MEWS).

Vulnerability was measured in this study as a function of the patient's airway status, and the degree to which the patient was vulnerable as a result of mechanical support requirements to maintain normal oxygen saturation levels. The presence of mechanical ventilation, or non-invasive positive pressure ventilation (NPPV) were used as measurements of vulnerability.

Complexity is a function of the entanglement of multiple systems, pharmacologic agents, and technology used to maintain or improve homeostasis. In this study, complexity was measured as a function of (1) the number of cardiac support devices, (2) intravenous infusions, (3) vasoactive infusions specifically, (4) intravascular lines, and (5) various tubes and drains.

Predictability was conceptualized as the degree to which the patient's course during transport could be predicted. Predictability was measured in this study using the patient's diagnostic category. Diagnostic category referred to the primary diagnosis for which the patient was transferred. The CCT team in this 
study transports patients with a wide range of diagnoses, but larger percentages come from cardiovascular and neurologic diagnoses. Diagnostic category was measured at the nominal level including five broad categories: (1) primary cardiac diagnoses (including acute vascular disorders of the aorta), (2) primary medical diagnoses, (3) complex neurological diagnoses, (4) complex surgical diagnoses, and (5) trauma. Age was measured as the patient age in years at the time of transport.

Resiliency was measured in this study as a function of patient age in years at the time of transport.

The nursing competencies of caring practices and clinical judgment were measured in this study as a function of licensure level (RN or APN) and years of lead clinician experience. Licensure level of clinician referred to the level of nursing practice defined by the Ohio Board of Nursing and was allocated to the lead clinician. The lead clinician has primary responsibility for care of the patient, and is present during care (not via phone). The highest licensure level was either a RN (Licensed by the state of Ohio) or an APN (has a certificate of authority from Ohio). Experience of the lead clinician was measured in whole number years. Experience was determined by the total years of experience in critical care transport at the tertiary level and applied only to the lead clinician responsible for that patient's care.

Environmental factors associated with transport may have a significant impact on the patient, and was measured in this study as a function of the mode of transport utilized, and the duration of time outside the controlled environment of 
the ICU. Mode of transport in CCT referred to the primary powered mechanism by which the patient was transported from the referring facility to the receiving facility. It included transport by ground or by air. Ground transport was defined as the inter-facility transport of a patient using surface transport vehicles (i.e. Mobile Intensive Care Unit) alone. Air transport was divided into two categories: rotor wing (RW) transport via helicopter and Fixed Wing (FW) transport via jetpowered airplanes. Duration of transport was a measure of CCT team involvement with the patient. Duration of transport was defined as beginning when the patient was removed from their hospital room at the referring facility until arrival at the hospital room at the receiving facility. This interval was measured in minutes (and included the ground transport time when ground and air are combined).

One aspect of critical care literature that has been inconsistent is the terminology related to adverse events. Hospitals that receive federal reimbursement are uniformly subject to the requirements of the Centers for Medicare and Medicaid Services (CMS), or The Joint Commission as a proxy for adherence to CMS guidelines. The Joint Commission, and all hospitals that are subject to those requirements, use a common terminology to describe adverse events, and their relationship to patient safety and quality of care. This study conformed to that terminology to maintain consistency of event reporting from referring facility, through transport, and at the receiving facility, creating a seamless patient safety monitoring system between facilities. 
The term patient safety event is the all-inclusive term used by The Joint Commission to include all aspects of care that might compromise patient safety. A patient safety event, as defined by the Joint Commission, is any "event, incident, or condition that could have resulted or did result in harm to a patient" (Commission, 2015). It includes the following terms: adverse event, sentinel event, no-harm event, near miss, and hazardous condition. Each of these terms are defined below and follow The Joint Commission definitions.

An adverse event is a patient safety event that results in harm to a patient (Commission, 2015). A sentinel event is a specific type of adverse event that results in death, permanent harm, or severe temporary harm to the patient. A noharm event is a patient safety event that affects the patient, but does not cause harm to the patient. A near miss is a patient safety event that occurs, but is intercepted before affecting the patient. A hazardous condition is any circumstance or condition that increases the probability of an adverse event. Each patient safety event is further detailed in data collection as one of these categories.

\section{Assumptions}

The underlying assumption of this study was that the overarching goal of CCT is to maintain or improve the condition of a critically ill patient who is geographically or temporally separated from a needed diagnostic center or definitive treatment. It was further assumed that $\mathrm{CCT}$ clinicians encounter patient safety events during the course of their work and patient safety events are barriers to achieving the goal of optimal care. Some clinicians may have been reluctant to 
provide full disclosure of events, perhaps because these events may be viewed as individual error. This study, however, did not identify individuals. No personal information from patients or staff were used for analysis or reporting. Individual clinicians were not named at any time in the study, nor were reports used in workperformance evaluation. While self-report of concerning and adverse events was a common practice in the proposed setting, it may be that there was a culture of not reporting all types of events. It may be that examining patient safety events in general reduced the challenges around self-reporting since the terms "patient safety event" did not have the negative implications of the terms error or adverse event. 


\section{Chapter 2: Review of the Literature}

In chapter 1, the case was introduced for investigation into PSE during CCT, association of those events to common patient characteristics operationalized by measurement of certain pre-transport conditions, and identification of potential moderating factors that influence the occurrence of PSE during inter-facility transport. During the course of that introduction, numerous concepts were discussed briefly in order to fully describe the purpose and research questions.

Current research should be grounded in the previous scholarly work of others (Bryant, 2004). The purpose of Chapter 2 is to explore the existing literature related to the concepts identified in Chapter 1, gain a thorough understanding of what is known about these concepts in general and in related areas, and explicate how they are applicable to the present research in interfacility transport.

This literature review is organized into broad categories, moving conceptually from the more general to the more specific. It begins with literature related to patient safety events in health care, followed by literature related to patient safety events in critical care, literature related to patient safety events in the related area of intra-facility transport of critically ill patients, and finally literature related to patient safety events in the inter-facility transport of critically ill patients. The review ends with a focus of assessing risk of PSE in inter-facility 
CCT and identifying moderating factors that were theorized to mitigate that risk for this project.

\section{Literature related to Patient Safety Events in Health Care}

The dependent outcome variable in this study was patient safety events in the setting of CCT. It is essential that we define patient safety events explicitly, determine what it includes and what it does not include, and understand where this definition fits into the larger program of patient safety in health care. Most literature related to patient safety refers specifically to adverse events. Adverse events are defined differently between studies, but tend to have a common theme of actual patient harm. The study described here examined all patient safety events, defined according to standards of The Joint Commission, adverse events are just one type of patient safety event. In this chapter, to maintain accuracy of reporting the findings of individual studies, terminology used by the authors in each is used. When the terminology cannot be used because of variations in data end points, the original vocabulary is used.

As discussed briefly in Chapter 1, the landmark publication To Err is

Human: Building a Safer Health System provided illumination into the magnitude of patient safety events in health care. The understanding that medical professionals could inadvertently cause harm to our patients predates the IOM by many hundreds of years. Though the exact origin is disputed, the bioethical provision for doing no harm has been central dogma in medicine for generations (Smith, 2005). Primum non nocere - first, do no harm - has been widely 
attributed to Galen of Pergamon in the second century (Ilan \& Fowler, 2005). Nightingale understood the concept applied equally to nurses and health care facilities when she wrote in 1863 in the third edition of Notes on Hospitals that "It may seem a strange principle to enunciate as the very first requirement in a hospital that it should do the sick no harm" (Nightingale, 1863, p. iii). Today, the American Nurses' Association Code of Ethics includes the provision of nonmaleficence, referring to causing no harm, whether intentional or exposing to risk of harm (Silva, 1983).

From the 1940's through the 1970's, society looked to find ways to prevent major accidents in high-profile industries such as aviation and nuclear power, but the routine adverse events happening in health care remained largely undisclosed as they largely affected people on an individual basis (Reason, 1995). A Harvard review of more than 30,000 medical records in New York began to uncover the magnitude of patient safety events happening as a result of health care interventions (Brennan \& Leape, 1991; Brennan et al., 1991). Defining adverse events solely as injuries to a patient as a result of negligence or substandard medical management, Brennan et al (1991) found the frequency of adverse events in hospitals to be $3.7 \%$ (95\% confidence interval [CI] $3.2 \%-4.2 \%$ ). Extrapolating their findings and generalizing to the larger health care system in the United States, Reason (1995) projected the impact on American hospitalized patients was between 1,000,000-3,000,000 people. Limitations to the Harvard study were around generalizability: data were from hospitals in a single state, from a single year, and the authors defined adverse events uniquely. 
In a second report, Australian investigators found an adverse event rate of $16.6 \%$ (CI $15.2 \%$ to $17.9 \%$ ) in Australian admissions, defining an adverse event as an unintended injury or complication which results in disability, death, or prolonged hospital stay and is caused by health care management" (Wilson et al., 1995). It is not clear that delivery of care in Australian hospitals is equivalent to U.S. hospitals. For example, scope of nursing practice differs in these two countries, affecting delivery of care. (Cook, Brower, Cooper, Brochard, \& Vincent, 2002; Coombs, Chaboyer, \& Sole, 2007)

A third report by Thomas et al (2000) reported on adverse events in Utah and Colorado. The authors defined an adverse event similarly to the Harvard investigators as "an injury caused by medical management (rather than the disease process) that resulted in either a prolonged hospital stay or disability at discharge" (Thomas et al., 2000, p. 263). Medical management was further described as either negligent or deviating from a standard of care, using a legalistic definition to link management to the injury. Using these criteria, they found an adverse event rate of $2.9 \%(95 \% \mathrm{CI} 2.7 \%-3.1 \%)$. This study used the narrowest scope in determining adverse events and was limited by the regional site enrollment.

All three studies were retrospective record reviews, and patient harm had to occur to meet inclusion criteria. These studies were limited by the necessity for the error to be documented in the medical record. As with all types of research, retrospective chart review has both advantages and disadvantages. The primary advantage of retrospective research designs are relative reduced time and effort in data collection compared to prospective designs. In retrospective designs, follow- 
up has already occurred, saving time over waiting for an effect (Hulley, 2007). Disadvantages of this research design include lack of control over subject selection and measurements, and lack of control of variables, making inferences of causality more difficult (Burns \& Grove, 2009; Hulley, 2007)

Among the three studies just cited, the range of adverse event frequencies ranged from a minimum $2.7 \%$ (Thomas et al., 2000) to $17.9 \%$ (Wilson et al., 1995). Each of these studies had slightly different methodologies, slightly different definitions of an adverse event, and limited an adverse event to those events that caused physical harm, disability, or death. The mortality rate caused by adverse events ranged from $4.9 \%$ (Wilson et al., 1995) to $13.6 \%$ (Brennan et al., 1991). This rate might roughly correspond to a sentinel event rate under standards set by The Joint Commission.

Largely as a result of the previously described studies, the IOM commissioned the Quality of Healthcare in America Committee to further investigate adverse events in hospitals and develop a strategy to improve the quality of health care in America over the following decade (Kohn et al., 2000). The resultant 312-page report found that between 44,000 and 98,000 Americans die each year as a result of medical errors. This result was extrapolated from the volume of annual U.S. hospital admissions and reported mortality rates in smaller studies. The financial implications of these adverse events were estimated at between $\$ 17$ billion and $\$ 29$ billion annually.

The IOM report was much more than an estimation of the incidence of medical error resulting in death in US hospitals. The report addressed the 
variation and limitations of the definitions of adverse events and explored the types of errors and the subtle differences between terms such as mistakes, lapses, and slips. The IOM report included a discussion of what is known about causes of mistakes, including those directly attributable to human error and those more directly attributable to system design.

The IOM report also described error reporting mechanisms, and the inherent limitations in systems that can lead to dramatic under-reporting of error. To illustrate the potential degree of under-reporting in a retrospective chart review, a 1981 prospective observational study with a slightly wider definition of "adverse event" reported that $36 \%$ of patients had some form of iatrogenic illness (Steel, Gertman, Crescenzi, \& Anderson, 1981). Another example, using a broader definition of adverse events than the landmark studies already cited, had a finding of a $45.8 \%$ adverse event rate among a patient population limited to two ICUs and a surgical service. (Andrews et al., 1997).

A recurrent challenge in interpreting the findings of studies reporting hospital-based adverse events has been the variation in definition of error and adverse event. Since this is the dependent outcome variable of the study explicated in this dissertation, it is crucial that we understand fully the terminology used and define it precisely. The IOM report set out a definition of each of these terms:

"An error is defined as the failure of a planned action to be completed as intended (i.e., error of execution) or 
the use of a wrong plan to achieve an aim (i.e., error of planning).

An adverse event is an injury caused by medical management rather than the underlying condition of the patient. An adverse event attributable to error is a 'preventable adverse event'.

Negligent adverse events represent a subset of preventable adverse events that satisfy legal criteria used in determining negligence (i.e., whether the care provided failed to meet the standard of care reasonably expected of an average physician qualified to take care of the patient in question)." (Kohn et al., 1999, p. 28).

In describing adverse events that result in harm, it is also important to distinguish between latent and active errors. The IOM report uses examples of high-profile accidents that were not the result of a single person or problem, but rather that of a system designed to result in the failure that eventually happened. Examples cited include the Three-Mile Island nuclear accident as described by Reason (1990) and the Challenger disaster as described by Vaughan (1996). While active errors happen at the point of patient contact and are often recognized immediately, latent errors are organizational, and the error in planning, structure maintenance, design, installation, or decision-making may be far removed from the point of result of the error (Kohn et al., 2000; Reason, 1990, 1995). 
Much of the IOM's description and basis for discussion of latent and active error refer back to Reason who wrote on the topic in the early 1990 's. Reason would later gain notoriety for his publication and illustration describing the process by which large accidents happen as the "Swiss Cheese Model" (Reason, 2000). Reason highlighted the temporal differences between active and latent errors and their negative consequences on safety. While active errors have immediate consequences, latent errors may take many years before manifesting in a negative event (Reason, 1990). Active errors are the result of unsafe actions committed by those at the front-line, which he referred to as the "sharp end", while latent errors were borne of the poor decisions made away from the point-of care. It is easy to understand the increased difficulty in making causal inferences in areas of latent failure. The following figure from Reason (1995) shows the distanced relationship between decisions made at the organizational level to accidents and incidents at the point-of care:

In addition to significant reference to the work of Reason in looking at accidents, the IOM also relied heavily on the work of Charles Perrow. Perrow's 1984 assessment of the Three-Mile Island nuclear incident, among other disasters, found that most major catastrophes were not the result of a single blunder, but rather a sequence of smaller, trivial events (Perrow, 1984). This pattern is particularly true as systems become increasingly complex. Health care, in every sense of the word, is a highly complex system. In his book, Perrow speaks at 
length of the role of "organizations and management in preventing failures - or causing them" (Perrow, 1984, p. 9).

Based heavily on the arguments made by Perrow, and further by Reason's 1990 work related to the human interface of error, the IOM cited two properties of systems that could impact the rate of accidents: complexity and coupling (Kohn et al., 2000). Complex systems have many parts and processes, each interacting uniquely with the other parts. There is significant interdependency among the parts of the system, and likewise each part is specialized to deliver a particular part of the overall product (Kohn et al., 2000). Increasing complexity predisposes to unintended and unforeseen interactions that Perrow referred to as "interactive complexity" (Perrow, 1984, p. 4) Coupling refers to the degree of dependence of one part of the system on another part or parts. A system that is highly reliant on one part of the system $\mathrm{X}$ to complete a task before another part $\mathrm{Y}$ can do its task is referred to as highly coupled. Anyone who has watched a patient bleeding profusely while waiting at an emergency department registration desk to give their name, address, and a plethora of additional information in order to generate a medical record number before they can be permitted to see a nurse before they can be permitted to see a doctor before they can get treatment to stop the bleeding can validate that health care, even at the point of entry, is highly coupled.

Since the IOM report, much has been done to validate and investigate the many aspects of the report. Not all the progress and investigation has been positive however. Following an earlier 1999 version designed to detect adverse medication reactions in electronic medical records, the Institute for Healthcare 
Improvement (IHI) designed a Global Trigger Tool for detection of adverse events. This tool, with a second edition published in 2009, provides a universal method and common framework to address the issue identified throughout the literature of asynchronous definitions of adverse events, and provided a sampling method designed to quickly and reliably report the adverse event rate in hospitals (Griffin FA, 2009). Using this tool, Classen and colleagues (2011) found the adverse event rate in hospitals may be $1000 \%$ higher than reflected in the earlier IOM document. The Global Trigger Tool, used on a sampling of three large US tertiary care centers, found at least one adverse event occurred in one-third of hospital admissions.

It should be noted here that the Global Trigger Tool is designed to only capture events that occurred as the result of the direct action of a caregiver (Griffin FA, 2009). Substandard care, or lack of care, is not captured here, nor are the sequelae. It should also be noted that events that occur, but do not cause harm, are not captured here, and there is no attempt to determine if a given event is preventable. The adverse event rate was higher than previous studies in New York and Utah / Colorado because it did not have a prerequisite for resultant major disability or to be determined as preventable.

James (2013) provided a review and summation of four studies using the Global Trigger Tool to assess the current rate of adverse events and errors in the U.S. health care system 30 years after the data collection used to form the IOM report. Using these studies as the basis for extrapolation of patient harm, James 
projected there were $210,000-400,000$ preventable deaths annually and the rate of serious harm may be 10-20 times the rate of preventable deaths.

Following the IOM report in 2000, The Joint Commission established the National Patient Safety Goals (NPSG) program (Commission, 2015). Advised by a multi-disciplinary expert panel called the Patient Safety Advisory Group, The Joint Commission identifies emerging and continuing patient safety issues and disseminates ways to address them in the form of National Patient Safety Goals, and other methods such as Sentinel Event Alerts, performance measures, and educational materials. Many National Patient Safety Goals directly target prevention of patient safety events, and utilize the patient safety event terminology used here. There is consensus that standardizing safety event terminology is essential in identifying, tracking, and preventing adverse events (Chang, Schyve, Croteau, O'Leary, \& Loeb, 2005; Kaplan, Battles, Van der Schaaf, Shea, \& Mercer, 1998).

\section{Literature related to patient safety events in critical care}

The IOM report noted specific areas such as critical care and emergency departments have higher rates of adverse events compared to other, less complex, areas of the hospital (Kohn et al., 2000). Since that report, the predominant literature related to adverse events in critical care has been related to specific disease processes or therapeutic modalities common to critical care, rather than looking generally at critical care. Since CCT is a highly specialized division of 
critical care, it is reasonable to understand adverse events in the context of critical care.

One example of a current report compared the outcomes of universal glove and gown use for all patient care in an Intensive Care Unit (ICU) with the use of gloves and gown only with patients known to have antibiotic resistant infections (standard precautions) (Croft et al., 2015). Using a the Global Trigger Tool, the authors found no statistical difference in adverse event rates between the universal glove and gown use group and the standard precautions group (46.3 events per 1000 patient-days versus 56.5 per 1000 patient-days).

Similarly, many studies looked at high-risk areas of critical care such as medication administration. One of the most frequent type of adverse events reported involves the administration of medications. As such, Adverse Drug Event reporting systems have evolved and the literature contains assessments of those systems. There is a recent retrospective record review that reported nearly $300 \%$ more adverse drug events when screened using the ICU transfer summary (33 per 1000 patient-days) rather than the hospital discharge summary (13 per 1000 patient-days) (Anthes, Harinstein, Smithburger, Seybert, \& Kane-Gill, 2013). A 2011 cross-sectional study reported on the types of adverse events, their frequencies, and their results (Reis \& Cassiani, 2011). Although this Brazilian study reported findings as $33 \%$ of admissions to ICU rather than as a factor of adverse events per 1000 patient-days as seen in other studies, it described the types of adverse drug events, their frequency by drug, and the resulting types of harm. Nephrotoxicity was the primary adverse reaction and fentanyl and 
midazolam the top two causes of adverse drug reactions found in this study.

Fentanyl and midazolam, incidentally, are both commonly used drugs in CCT.

Using information from the Harvard Work Hours and Health Study, and supported by the Agency for Healthcare Research and Quality (AHRQ), Rothschild and colleagues (2005) reported a rate of 80.5 adverse events per 1000 patient-days in the critical care departments of a tertiary university hospital in a prospective 1-year observational study. They found 36.2 preventable adverse events per 1000 patient-days, and 149.7 serious errors per 1000 patient-days (Rothschild et al., 2005).

Using the Global Trigger Tool, adapted for use with the medical record of ICU patients, Resar and colleagues (2006) found an adverse event rate in 54 academic and community hospitals at a rate of 11.3 events per 100 patient days, and 16.4 events per 100 ICU days, supporting the view that critical care has more patient safety events. There was at least one adverse event in $55 \%$ of patient ICU medical records.

Ringdal and colleagues (2016) found that nurses' perceptions of removing the patient from the ICU for testing or other purposes was highly stressful to the patients, increasing risk for adverse event both for that patient, and for potentially for the remainder of patients in the ICU. During intra-facility transport, staff not accompanying the patient were left to care for more patients, widening the scope of potential error beyond the patient being transported.

Literature related to patient safety events in intra-facility transport 
The intra-facility transport of critically ill patients has similarities to the inter-facility transport of critically ill patients. For example, patient diagnosis, hemodynamic instability, use of vasopressors and portable medical devices, and time away from the ICU are common to both intra- and inter-facility transport. There may be significant differences between the two transport arenas in areas such as education of accompanying clinicians, average duration of transport, and purpose of transport.

Intra-facility transport, often referred to as intra-hospital transport, is the movement of a patient from one location in a hospital to another location within the same facility. Emergency Department (ED) patients are frequently transported to other locations both within and outside the ED for diagnostic testing or to other inpatient units (Papson et al., 2007). Likewise, critically ill patients in the ICU also frequently require transport out of the relative security of the ICU, most commonly for diagnostic testing (Doring et al., 1999; Kue, Brown, Ness, \& Scheulen, 2011).

Intra-facility transport is accomplished in a variety of ways, using a variety of equipment with a variety of clinicians accompanying the patient. For example, critically ill patients may be transported via a specially designed transport stretcher (Fanara, Manzon, Barbot, Desmettre, \& Capellier, 2010), or an ED stretcher or ICU bed (Lahner et al., 2007).

The number and variety of clinicians that accompany the patient on the "road trip" varies considerably from patient to patient, institution to institution, and even country to country. Most references to the attending staff in intra- 
facility transport include a RN (Doring et al., 1999; Kue et al., 2011; Papson et al., 2007; Voigt, Pastores, Raoof, Thaler, \& Halpern, 2009). Only one study was located that explicitly stated that a RN was not in attendance in accordance with hospital policy, unless transporting a pediatric patient (Lahner et al., 2007). In studies based in the U.S., physician attendance is rare (Doring et al., 1999; Voigt et al., 2009), but in non-US studies, physician attendance during transport was common (Fanara et al., 2010; Lahner et al., 2007; Papson et al., 2007; ParmentierDecrucq et al., 2013; Schwebel et al., 2013; Venkategowda, Rao, Mutkule, \& Taggu, 2014). In addition, additional staff may accompany transported patients based on the specific patient needs. For example, when patients are mechanically ventilated, a respiratory therapy technician is frequently present (Doring et al., 1999; Voigt et al., 2009).

In at least one U.S. facility, an internal CCT team was created exclusively for intra-facility transports (Kue et al., 2011). This team was comprised of a specially trained $\mathrm{RN}$, paramedic, and emergency medical technician. The intrafacility transport team was based on the facility's inter-facility transport team who had documented success in safe patient care while outside of the critical care unit.

Destinations of intra-facility transport are commonly suites or departments that have diagnostic imaging and specialized therapeutic intervention, such as radiology, cardiac catheterization laboratory or electrophysiology laboratory. Some studies that examined patient safety events during intra-facility transport specifically exclude those transports going to the surgical suites, as these patients 
were felt to have a potentially different set of risks for patient safety events than the standard ED and ICU populations (Schwebel et al., 2013).

Duration of time spent outside of the ICU has been implicated as a factor in the frequency of adverse events. Of those studies that specifically measured time outside the ICU, transport durations ranged from 8 minutes to more than 2 hours, with means averaging 40-60 minutes (Doring et al., 1999; Lahner et al., 2007; Parmentier-Decrucq et al., 2013). One study measured multiple aspects of time related to intra-facility transports out of the ICU, from time of day to day of week, but did not look specifically at duration of the transport (Voigt et al., 2009)

Equipment used in intra-facility transport is designed to maintain patients with equivalent resources necessary for pharmacotherapeutic and hemodynamic maintenance and interventions, and hemodynamic monitoring as the patient was receiving prior to transport (Ott, Hoffman, \& Hravnak, 2011; Quenot et al., 2012). Most critically ill patients have cardiac monitoring, at least one intravenous infusion, and many are mechanically ventilated. The US Food and Drug Administration approved portable ventilators and drug infusion devices in 2001 (Fanara et al., 2010; Lovell, Mudaliar, \& Klineberg, 2001), significantly improving the ability to move mechanically ventilated patients.

Nine authors have recently investigated the presence of patient safety events in intra-facility transport within the critically ill population. The frequency of patient safety events varies widely from study to study, in part due to inconsistency in definitions (Parmentier-Decrucq et al., 2013). The frequency of adverse events in recent studies ranges from 22\% (Gillman et al., 2006) to 68\% 
(Papson et al., 2007). A 2009 study found that $44 \%$ of ICU patients undergo intra-facility transport at least once during their stay in the ICU, and 55\% of those patients transported get transported more than once (Voigt et al., 2009).

Frequency of intra-hospital transport increases with increased length of ICU stay, presence of mechanical ventilation, and use of vasopressors (Voigt et al., 2009).

Studies that investigated adverse events during intra-facility transport of the critically ill and also associated factors have contradictory results. Kue (2011) and Lahner (2007) both found increased rates of adverse events with increased patient acuity while Doring (1999) and Parmentier-Decrucq (2013) did not. Although Parmentier-Decrucq found no association between acuity level and adverse events, they did find a correlation for the necessity to stabilize the patient prior to transport or change therapy for transport with the rate of adverse events. One could argue that the necessity to stabilize or alter treatment in order to transport is a proxy for instability prior to transport. Doring (1999) found a correlation with adverse events and duration of time outside the ICU, while Lahner (2007) found no such association. Reasons that these studies have contradictory findings may include differences in patient populations, differences in acuity levels, differences in measurement of an adverse event, and differences in accompanying staff. For example, Doring's (1999) patient population included neuro ICU patients with an arterial line, while Lahner (2007), who had very different findings, specifically excluded patients from the cardiac ICU or neuro ICU. 
Although authors did not measure the same items constituting pharmacologic or mechanical support, most studies reported a significant, positive correlation between numbers or types of therapeutic support with the adverse event rate. Mechanical ventilation was consistently identified as a factor in adverse events (Kue et al., 2011; Lahner et al., 2007), and more specifically increased ventilatory support as measured by increased requirement of positive end-expiratory pressure (PEEP) greater than $5 \mathrm{~cm} \mathrm{H} 2 \mathrm{O}$ (Lahner et al., 2007; Parmentier-Decrucq et al., 2013). The Therapeutic Index Scoring System, or TISS-28, is a validated instrument used for quantifying the therapeutic requirements of a patient, and thus is used for assessment of nursing manpower requirements in ICU's (Miranda, de Rijk, \& Schaufeli, 1996). Doring (1999) found a positive correlation between technical mishaps during transport and number of infusions, but the correlation between adverse events and higher TISS28 scores did not reach statistical significance $(p=0.201$ with $n=35)$. Other authors reported correlations between adverse events and numbers of infusions (Parmentier-Decrucq et al., 2013), ventilatory support (Lahner et al., 2007; Papson et al., 2007; Parmentier-Decrucq et al., 2013), and invasive lines with frequency of adverse events (Papson et al., 2007).

Level of clinician licensure making up the transport team was not purposely examined in any intra-facility transport study reviewed but two studies found incidental relationships with the level or experience of the accompanying staff with adverse events. Papson (2007) found an inverse relationship with the experience of the accompanying physician and adverse event rate, and 
Venkatagowda (2014) associated the lower rate of adverse events in that Australian study to use of an intensivist leading the transport team rather than resident physicians or nursing staff. Conversely, Doring (1999) found no correlation of adverse events with number or type of escorting staff, but a physician was only present during one transport, and no other form of licensed independent provider (LIP) was used for comparison. The following table summarizes the nine predominant studies used in this literature review of intrafacility transport. 
$\underline{\text { Table } 1 \text { - Summary of relevant intra-facility studies }}$

\begin{tabular}{|c|c|c|c|c|c|c|}
\hline Author & Country & $\mathrm{N}$ & Design & $\begin{array}{l}\text { Levels of } \\
\text { Clinicians }\end{array}$ & Results & Comments \\
\hline Doring, Kerr & US & 35 & $\begin{array}{l}\text { Prospective within } \\
\text { subjects repeated } \\
\text { measures }\end{array}$ & $\begin{array}{l}\mathrm{RN}+/-\mathrm{RN}, \\
\mathrm{RT}, \mathrm{MD}, \mathrm{NA}\end{array}$ & $\begin{array}{l}\text { No statistically significant } \\
\text { physiologic changes; } 40 \% \\
\text { had at least } 1 \text { technical } \\
\text { mishap; more infusions } \\
\text { related to more technical } \\
\text { mishaps; Increased time } \\
\text { out of ICU related to } \\
\text { increased technical mishaps }\end{array}$ & \\
\hline Papson & Australia & 339 & $\begin{array}{l}\text { Prospective } \\
\text { Observational Study }\end{array}$ & $\begin{array}{l}\text { Physician } \\
+/- \text { RN }\end{array}$ & $\begin{array}{l}67.9 \% \text { of transports had } \\
\text { UEs; Almost half of UEs } \\
\text { were equipment problems; } \\
\text { UE rate inversely } \\
\text { proportional to experience } \\
\text { of physician }\end{array}$ & $\begin{array}{l}\text { High threshold } \\
\text { inclusion } \\
\text { criteria, but low } \\
\text { threshold } \\
\text { qualifying as a } \\
\text { UE (i.e. IV line } \\
\text { tangle, ECG } \\
\text { artifact) }\end{array}$ \\
\hline Schwebel & France & 3006 & $\begin{array}{l}\text { Prospective } \\
\text { multicenter cohort }\end{array}$ & Physician & AE rate $37.4 \%$ & $\begin{array}{l}\text { DOV AEs here } \\
\text { are POST- } \\
\text { transport } \\
\text { complications, } \\
\text { not INTRA- } \\
\text { transport AEs. }\end{array}$ \\
\hline
\end{tabular}




\begin{tabular}{|c|c|c|c|c|c|c|}
\hline $\begin{array}{l}\text { Parmentier- } \\
\text { Decrucq }\end{array}$ & France & 262 & $\begin{array}{l}\text { Prospective } \\
\text { Observational Study }\end{array}$ & Physician & $\begin{array}{l}\text { AE rate } 45.8 \% \text {; patient- } \\
\text { related rate } 26 \% \text {; Serious } \\
\text { AE rate } 16.8 \% \text {; Equipment- } \\
\text { related - } 32.8 \% \text {; Predictive } \\
\text { for intra-transport AE -Fluid } \\
\text { challenge for transport (OR } \\
\text { 6.5), PEEP >6 (OR 2.28), } \\
\text { sedation before transport } \\
\text { (OR 1.85), TX modification } \\
\text { for transport (OR 2.8), } \\
\text { norepinephrine infusion } \\
\text { (OR 4.4); SAPS II or SOFA } \\
\text { day of IHT not-predictive }\end{array}$ & $\begin{array}{l}\text { Increased } \\
\text { experience of } \\
\text { physician } \\
\text { related to } \\
\text { decrease in } A E \\
\text { rate; Increase in } \\
\text { equipment- } \\
\text { related AE and } \\
\text { increase in time } \\
\text { outside of ICU } \\
\text { related to } \\
\text { higher patient- } \\
\text { related } A E\end{array}$ \\
\hline Lahner & Austria & 226 & $\begin{array}{l}\text { Prospective } \\
\text { observational study }\end{array}$ & Physician & $\begin{array}{l}\text { Physiologic deterioration in } \\
30 \% \text { adults, } 60 \% \text { pediatrics; } \\
\text { increased frequency with } \\
\text { catecholamine support, } \\
\text { mechanical ventilation, esp. } \\
\text { PEEP }>5 ; 1 \% \text { - displaced } \\
\text { ETT, CT, or vent failure; } \\
4.2 \%-7.8 \% \text { in emergencies } \\
\text { vs } 2.4 \% \text { in scheduled } \\
\text { transports }\end{array}$ & $\begin{array}{l}\text { Transported in } \\
\text { ICU bed without } \\
\text { changing pumps }\end{array}$ \\
\hline Fanara & France & & Lit review & $\mathrm{N} / \mathrm{A}$ & $\begin{array}{l}\text { Global AE range } 22 \%-68 \% \text {; } \\
\text { clinical events range } 3 \%- \\
54 \% \text {, materials and } \\
\text { environment AE range } 33 \%- \\
61 \%\end{array}$ & \\
\hline
\end{tabular}




\begin{tabular}{|c|c|c|c|c|c|c|}
\hline Voigt & US & 413 & $\begin{array}{l}\text { Retrospective chart } \\
\text { review }\end{array}$ & $\begin{array}{l}\mathrm{MD}, \mathrm{RN},+/- \\
\mathrm{RT}\end{array}$ & $\begin{array}{l}\text { Increased LOS in ICU } \\
\text { correlates with increase } \\
\text { rate of IHT; Increased SOI } \\
\text { (as measured by } \\
\text { mechanical ventilation, } \\
\text { vasopressors) more likely to } \\
\text { get IHT }\end{array}$ & \\
\hline Kue & $\begin{array}{l}\text { US } \\
\text { (Hopkins) }\end{array}$ & 3383 & $\begin{array}{l}\text { Retrospective chart } \\
\text { review }\end{array}$ & $\begin{array}{l}\text { RN, PM, } \\
\text { EMT }\end{array}$ & $\begin{array}{l}\text { Serious adverse event rate } \\
1.7 \% \text {; increased acuity } \\
\text { correlated with increased } \\
\text { AE rate }\end{array}$ & $\begin{array}{l}\text { Excluded } \\
\text { technical } \\
\text { mishaps } \\
\text { (equipment- } \\
\text { related) }\end{array}$ \\
\hline Venkategowda & India & 254 & $\begin{array}{l}\text { Prospective } \\
\text { observational study }\end{array}$ & Physician & $\begin{array}{l}\text { Major Unexpected Events } \\
(U E)=37 \% \text { of UE; Minor UE } \\
=11 \% \text { of UE; Miscellaneous } \\
\text { UE }=64 \% \text { of UE; Total UE } \\
\text { rate } 25 \%\end{array}$ & $\begin{array}{l}\text { UE are common, } \\
\text { but frequency } \\
\text { and impact can } \\
\text { be decreased by } \\
\text { increased level } \\
\text { of clinician } \\
\text { (physician) with } \\
\text { appropriate } \\
\text { interventions }\end{array}$ \\
\hline
\end{tabular}


Literature related to patient safety events in inter-facility transport

Critical care transport was defined for purposes of this work in chapter 1. Based on the definition proposed by the Association for Critical Care Transport (ACCT), the definition of CCT is limited to inter-facility transport, specifically excluding pre-hospital scene response, and further specifies for inclusion the requirement of certain technological or pharmacologic supports to maintain homeostasis and prevent patient deterioration. Inter-facility transport of critically ill patients may be literally accomplished via any form of locomotion. Commonly in the United Sates this is accomplished via ground Mobile Intensive Care Unit (MICU), helicopter (also known as rotor wing transport $[\mathrm{RW}]$ ), or fixed wing aircraft (FW) such as a jet or propeller-driven airplane. In an annual survey of CCT agencies across the United States, Greene reports most recently that $60 \%$ of full-time dedicated CCT vehicles are rotor wing, $27 \%$ are Mobile ICU, and 13\% are fixed wing aircraft (Greene, 2014). It should be noted that this proportion of dedicated full-time vehicles does not imply that this is the relative proportion of inter-facility transport volume.

Most CCT agencies are hospital-based (66\%) (Greene, 2014). The average interfacility / scene transport ratio is $75 \% / 25 \%$ across the country, with the percentage of inter-facility transport increasing over the past decade (Greene, 2014). Ground transport teams consist of a registered nurse (RN) in $97 \%$ of teams, an Emergency Medical Technician - Paramedic (EMT-P) in 89\% of teams, and an Advanced Practice Provider, either nurse practitioner (APN) or physician assistant, in $6 \%$ of teams. For rotor wing 
transports, the compositions are $100 \%$ RN, $85 \%$ EMT-P, $4 \%$ APN, and $4 \%$ physician. For fixed wing transports, $100 \%$ of respondents included an RN, 77\% included an EMTP, and 6\% included an APN (Greene, 2014).

As early as 1989, Kanter and Tompkins (1989) recognized that the frequency of adverse events during inter-facility transport of pediatric patients required careful consideration of the risks of transport with standard transport teams. It is extremely common to find a reference to benefits of transport outweighing the risks in inter-facility transport literature, and several investigators have conducted limited observational studies or retrospective chart reviews to investigate the type or frequency of adverse event during transport as a measurement of those risks.

Frequency of unexpected events during transport ranged from 6.5\% (Singh et al., 2014) to $34 \%$ (Ligtenberg et al., 2005). Comparison of rates between studies is complicated, primarily due to differences in definitions and terminology. For example, in sequential studies by Singh, the term 'critical event' was used, and was defined as a death, major resuscitative event, inadvertent displacement of the endotracheal tube, or respiratory arrest in the earlier work in rotor wing inter-facility transport (Singh et al., 2009). In the later work, however, Singh (2014) defined critical event similarly, though not identically, as new hemodynamic instability, new respiratory instability, or death during ground-based inter-facility transport. It should be noted that these critical events do not attempt to differentiate critical events that resulted from the normal progression of the patient's critical illness from those critical events that were the result of the health care system. 
Terminology and definitions that were used to describe the type of patient safety event were far more variable between authors. As mentioned, Singh et al used the term critical event (Singh et al., 2014; Singh et al., 2009). Edge and colleagues (1994) focused on morbidity and adverse events. Kanter (1989), Flabouris (2006), Droogh (2012), and Patterson (2014) used the term adverse event. A series of studies conducted in the Netherlands on the topic used the terminology of critical thresholds or vital thresholds in discussing adverse events (Droogh et al., 2012; Ligtenberg et al., 2005; Wiegersma et al., 2011).

The literature of patient safety events in CCT has not generally adhered to standardized terminology related to safety events. Rather, the predominant studies have mixed Quality measures and Safety measures in variable proportions. Singh (2009, 2014) explicated his dependent outcome variables most clearly. Of the twenty listed "critical events" during transport, only two were patient safety events, while 18 events were quality indicators, and may or may not be the result of the normal course of the patient's underlying illness, making it difficult to determine if "critical events" were patient safety events. Droogh (2012) reported a 15.5\% rate of "technical events" related to equipment, all of which appear to qualify at least as a hazardous condition under this study. These "technical events" however do not capture all events qualifying as a patient safety event in the current study, and the generalizability of the Mobile ICU team in the Netherlands using a different patient population, different equipment, and differently prepared staff is unknown. 
Definitions of these terms, and their specific measurement parameters to qualify as an event, have informed the development of this proposed project. Flabouris (2006) obtained data using a standardized incident reporting form that permitted free-text entry. Post-hoc analysis allowed for the description of 39 types of adverse events categorized among 4 broad categories of adverse events including equipment problems, patient care problems, transport operations problems, and interpersonal communication problems. Some events are poorly defined, such as a single dichotomous response for "patient deterioration", or "difficulty with patient transfer". This study used only incident reports as a basis for categorizing the actual events, thus calculating an adverse event rate among the total transport cases was not possible.

Singh's (2009) detailed description of adverse events were specific to meet inclusion criteria: death, major resuscitative procedure, hemodynamic deterioration, inadvertent endotracheal extubation, or respiratory arrest. Major resuscitative procedures were well-defined, and included:

- Airway procedures

○ Needle thoracostomy

- Needle or surgical cricothyrotomy

○ Nasotracheal intubation

O Orotracheal intubation

- Removal of foreign object

O Other advanced life support airway

○ Laryngeal mask airway 
- Ascherman chest seal

- Cardiac procedures

- Cardiopulmonary resuscitation or chest compressions

- Cardioversion

- Carotid sinus massage

○ Precordial thump

○ Manual defibrillation

○ Automatic defibrillation

- Transcutaneous pacing

- Administration of dextrose or glucagon

Hemodynamic deterioration was also specific and well-defined, including:

- Systolic blood pressure $<80 \mathrm{mmHg}$ (millimeters of mercury)

- Mean arterial pressure $<60 \mathrm{mmHg}$

- In-flight administration of a (non-specific) vasopressor

Ligtenberg (2005), in contrast, defined adverse event as a departure from the pretransport condition of the patient beyond a predetermined critical threshold in the following categories:

- $\quad$ Arterial $\mathrm{pH}$

- Oxygen saturation

- $\quad$ PCO2 (partial pressure of arterial carbon dioxide)

- $\quad$ PO2 (partial pressure of arterial oxygen)

- Systolic blood pressure 
- Diastolic blood pressure

- Heart rate

- Temperature

- Serum lactate

- Hemoglobin

- Serum glucose level

- Serum bicarbonate level

Noting the commonality of equipment-related adverse events, Droogh and colleagues narrowed the focus to include only events related to equipment (Droogh et al., 2012). Technical mishaps are a common finding, but were not included as adverse events by Singh (2009) or Ligtenberg (2005). In the equipment-based study, 20 specific technical related events occurred, coming from 5 categories including gas supply, electrical system, MICU ambulance, equipment, and trolley (Droogh et al., 2012).

Fried and colleagues (2010) also looked at equipment-related issues during interfacility transfer, but found only a $1 \%$ rate when limited to total equipment failure. They documented an $18 \%$ unsecured equipment rate, the only place where this risk factor was noted in the literature. Although the $1 \%$ rate of equipment-related adverse events captured only complete failure, (resulting in a very low rate), the study population included all inter-facility transfers. Only $28 \%$ of those transfers were deemed critical care by parameters defined by the study authors. Droogh and colleagues (2012) found a purely equipment-related technical event rate of $15.5 \%$. 
Using different measures, Singh and colleagues (2009) found a critical event rate of $5.1 \%$ that included no equipment-related or technical events. Interestingly, MacDonald and colleagues (2008) used a more standardized definition of adverse event and found an adverse event rate of just $1.15 \%$ during air medical transport using data from the same organization as Singh. Ligtenberg and colleagues (2005) found a 34\% adverse event rate looking purely at changes in physiologic parameters from pre-transport baseline.

For the proposed project, a patient safety event rate of $5 \%$ to $25 \%$ is hypothesized to occur, based on review of inter-facility reports and the broadest definitions of adverse events. This range is wide due to the lack of similar studies. While previous studies included clinical deteriorations that were likely to be part of the patient's illness and would not be included here, they did not include areas such as near misses and hazardous conditions which may be subjective and difficult to predict quantitatively. A pre-study survey conducted in June and July 2015 found a patient safety event rate of $17 \%$ using similar proposed terminology, predominantly consisting of miscommunications, delays, and hazardous conditions.

\section{Rationale for the selection of pre-transport variables}

The American College of Emergency Physicians (ACEP) provides standards and guidelines for inter-facility transport and guidelines for physicians acting as medical directors for agencies who provide such services. In a 2006 position statement regarding inter-facility transport, ACEP posited that the patient's condition and the patient's 
potential for intra-transport complications should dictate the services provided during inter-facility transport (Physicians, 2006). The nature of this statement implies that there are certain physiologic factors that should be known prior to transport that increase risk of deterioration or adverse event during transport. It also implies that those risk factors should be the basis for services provided during transport. Thus there is an implied relationship then between pre-transport conditions constituting risk, and varying the level of services provided during transport to mitigate that risk.

Several studies that looked at adverse events during inter-facility transport also made some attempt to correlate findings with pre-transport conditions. The findings in those studies that looked at pre-transport indicators shared significant commonalities with those researchers who looked at intra-facility transport of critically ill patients. The most prominently reported predictor of intra-transport adverse events was pre-transport hemodynamic instability. Pre-transport hemodynamic instability or physiologic derangement was found by Kanter (1989), Singh (2009), and Singh (2014) to be predictive of intra-transport adverse or critical events. Both studies by Singh (2009, 2014) found duration of transport to be a predictor of critical or adverse events, but Kanter (1989) and Ligtenberg (2005) did not find duration of transport to be a significant factor.

In intra-facility transport, higher TISS-28 scores or specific interventions such as mechanical ventilation and infusions, particularly vasoactive medications, were found to be positively correlated with adverse event rates (Doring et al., 1999; Kue et al., 2011; Lahner et al., 2007; Parmentier-Decrucq et al., 2013). There is a similar finding among 
inter-facility studies. Kanter specifically found the TISS-28 to be predictive of intratransport equipment-related adverse events at a ratio of more than 4 to 1 (13\% $\mathrm{AE}$ for TISS $>10,3 \%$ for TISS $<10$ ) with $n=117$, where Doring (1999) found positive correlation but did not find statistical significance with $n=35$. As in intra-facility transport, mechanical ventilation was also found to be independently associated with increased rates of adverse events during transport (Singh et al., 2014; Singh et al., 2009)

Factors relating specifically to the transport team were also common factors found to be associated with the frequency of adverse events. Edge (1994) found a reduction in adverse events specifically related to adding a specialty retrieval team, compared to standard ambulance teams. Ligtenberg (2005) reported the necessity of a specialized team for retrieval to improve an abysmal $34 \%$ adverse event rate, then reported, in cooperation with Wiegersma (2011) that the rate had dropped to $12.5 \%$ despite higher mean APACHE 2 scores with the addition of a specialized transport team. It should also be noted that Ligtenberg (2005) lamented that a search of the literature for pre-transport indicators to determine when a Mobile ICU was needed, versus standard ambulance, proved fruitless. Both studies by Singh $(2009,2014)$ reported independent associations of level of transport staff with adverse event rates. This finding is consistent with those found by Papson (2007) and Venkatagowda (2014) in intra-facility transport, except the Singh studies used varying levels of paramedics, and the intra-facility studies used varying experience and specialization of physicians.

In both intra-facility transport studies and inter facility transport studies, two factors, level of clinician during transport and duration of transport, were found to have 
independent associations with the dependent outcome variable, frequency of adverse events. Unlike the patient factors such as hemodynamic instability and various means of pharmacologic or technologic support that are a factor of the patient independent of the transport, transport-related issues such as level of clinician and duration of transport occur temporally after the patient-related factors. In several studies, increasing level of clinician was found to decrease or eliminate the increased risk associated with pretransport conditions such as acuity. In other studies, when level of clinician is suitably high, duration of transport becomes insignificant, but where level of clinician is low or variable, duration of transport is a factor.

Fairchild and MacKinnon discussed the role of moderation and mediation in statistical analysis (Fairchild \& MacKinnon, 2009). They described moderation as occurring when "...the prediction of a dependent variable, Y, from an independent variable, X, differs across levels of a third variable, Z" (Fairchild \& MacKinnon, 2009, p. 4). Therefore, given any set of predictor variables that can be shown to predict the dependent outcome variable, Patient Safety Events, any third factor that can be shown to affect the frequency of those events given that set of pre-transport variables at different levels of the third factor is a moderator variable. Although not a single study mentioned in this literature review used the term moderation, level of clinician and duration of transport by the above definitions are moderating factors.

Understanding the relationship between pre-transport factors and intra-transport outcomes, several expert clinicians have attempted to formulate instruments to predict risk in order to facilitate transport and mitigate increased risks. Lee (2008) tested the 
TISS-28 (described previously) and the Modified Early Warning Score (MEWS). Markakis (2006) developed and reported on the Risk Score for Transport Persons (RSTP). Swickard (2014) developed and reported on the Transport Triage Tool, to predict physiologic deterioration during transport. The TISS-28 looks exclusively at patient interventions, and the MEWS looks solely at hemodynamics. The RSTP uses a combination of intervention and hemodynamic measures. The Transport Triage Tool allows the user to subjectively assess levels of patient predictability, stability, complexity, resiliency, and vulnerability to form a composite number correlating to pre-transport risk, then uses that value to assign a level of clinician. Lee found neither the TISS-28 nor the MEWS to satisfactorily predict intra-transport deterioration. Markakis' instrument performed slightly better. The Transport Triage Tool outperformed the other instruments, but inter-rater and intra-rater reliability testing is currently suboptimal and the instrument is being refined (personal communication, Scott Swickard, June 2015). Table 2 summarizes the psychometric properties of the existing instruments to assess risk during inter-facility transport. Data regarding the Transport Triage Tool comes from a DNP thesis study that has not yet been published.

\section{Table 2 - Summary of inter-facility transport triage instruments}

\begin{tabular}{|c|c|c|c|c|}
\hline & TISS-28 & MEWS & RSTP & TTT \\
\hline Inter-rater reliability & & & & 0.92 \\
\hline Sensitivity & 0.21 & 0.96 & 0.71 & 0.68 \\
\hline Specificity & 0.92 & 0.37 & 0.73 & 0.79 \\
\hline
\end{tabular}




\begin{tabular}{|c|c|c|c|c|}
\cline { 2 - 4 } PPV & & & 0.25 & 0.84 \\
\hline NPV & & & 0.95 & 0.6 \\
\hline Youden Index & 0.133 & 0.329 & 0.45 & 0.47 \\
\hline AUROC & 0.53 & 0.71 & 0.74 & \\
\hline Likelihood Ratio & & & 2.63 & 3.24 \\
\hline
\end{tabular}

Logic, theory and prior empirical evidence support that the dependent outcome variable, patient safety events, has predictor variables that can be quantitatively measured. Pre-transport factors are associated with patient safety events and these factors consistently include patient physiology and therapeutic support devices. The literature also supports a moderating role for both clinician characteristics and transport factors. Some research suggests a relationship between mode of transport and frequency of patient safety events. This relationship, however, is based on findings in the Netherlands and elsewhere where flight is not common due to terrain and weather conditions. The author hypothesizes that mode of transportation is a spurious relationship and that the relationship of mode of transport needs additional investigation. In the proposed project, licensure level of clinician and / or experience may reduce the strength of the relationship between mode of transport and patient safety events and the author hypothesized that the relationship would become insignificant when the characteristics of the clinician or duration of transport are considered. 
The review of literature supports including physiologic and therapeutic support requirements as pre-transport variables that are associated with patient safety events in inter-facility CCT. Further the review of empiric literature indicates that licensure level of clinician, lead clinician experience, duration of transport, and mode of transport are potentially moderators of the relationship as illustrated in Figure 1. This model guided the proposed study.

\section{Figure 1. Research Model}

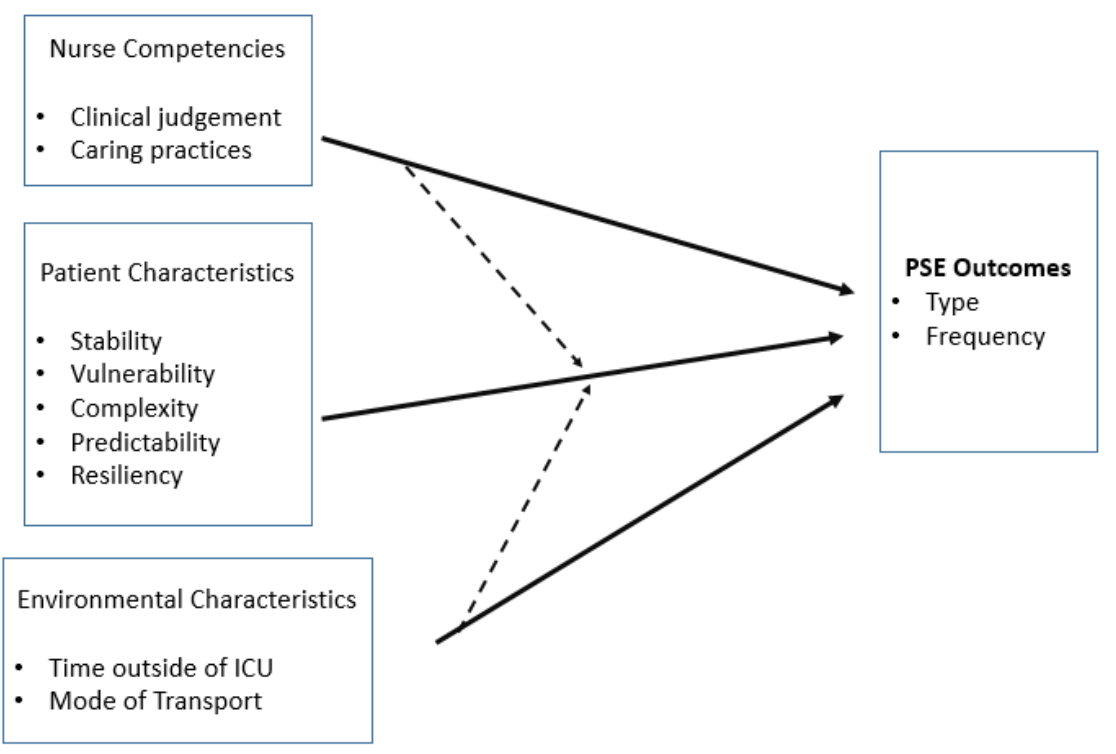

Research Model Based on Adaptation of AACN Synergy Model 


\section{$\underline{\text { Table } 3 \text { - Summary of inter-facility studies cited }}$}

\begin{tabular}{|c|c|c|c|c|c|c|c|}
\hline Author & Country & $\mathrm{N}$ & Design & Mode & Levels of Clinicians & Results & Comments \\
\hline Durairaj & US & 3,347 & $\begin{array}{l}\text { Retrospective cohort } \\
\text { study }\end{array}$ & Unknown & Unknown & $\begin{array}{l}\text { Mortality } 25 \% \text { compared to } 21 \% \text { for patients admitted } \\
\text { directly }\end{array}$ & $\begin{array}{l}\text { Only mention of transport-related } \\
\text { factors or events is distance travelled }\end{array}$ \\
\hline Ligtenberg & Netherlands & 100 & $\begin{array}{l}\text { Prospective within } \\
\text { subjects repeated } \\
\text { measures }\end{array}$ & Ground & $\mathrm{RN}+\mathrm{RN}$ or physician & AE rate $34 \%$ & $70 \%$ of Ues felt to be preventable \\
\hline Flabouris & Australia & 125 & $\begin{array}{l}\text { Incident report } \\
\text { review }\end{array}$ & $F W, R W, G$ & $\begin{array}{l}\text { Various comb of } \\
\text { MD, RN, PM }\end{array}$ & $\begin{array}{l}\text { Incidents related to equipment (37\%), patient care } \\
\text { (26\%), transport operations ( } 11 \%) \text {, interpersonal } \\
\text { communication }(9 \%) \text {, planning or preparation ( } 9 \%) \text {, } \\
\text { retrieval staff ( } 7 \% \text { ) and tasking }(2 \%) \text {. Incidents } \\
\text { occurred during patient transport to the receiving } \\
\text { facility }(26 \%) \text {, at patient origin }(26 \%) \text {, during patient } \\
\text { loading }(20 \%) \text {, at the retrieval service base }(18 \%) \text { and } \\
\text { receiving facility ( } 9 \%) . \text { Harm was documented in } 59 \% \\
\text { of incidents with one death. }\end{array}$ & $\begin{array}{l}\text { Review of incident reports, making } \\
\text { actual AE rate undetectable }\end{array}$ \\
\hline Singh & Canada & 19228 & Retrospective Cohort & RW, FW & $\begin{array}{l}\text { Advanced care } \\
\text { paramedics, critical } \\
\text { care paramedics }\end{array}$ & $\begin{array}{l}\text { Female OR } 1.3 \text {, pre-transport assisted ventilation OR } \\
\text { 3.0, pre-transport hemodynamic instability OR } 3.2 \text {, } \\
\text { FW transport OR } 1.5 \text {, duration of transport OR } 1.02 \text { per } \\
\text { 10-minute increment, scene calls OR } 1.7 \text {, level of } \\
\text { clinician OR } 0.6 \text {, critical event rate } 5.1 \%\end{array}$ & Only level of clinician is paramedics \\
\hline \begin{tabular}{|l|} 
Wiegersma \\
(Droogh)
\end{tabular} & Netherlands & 74 & \begin{tabular}{|l|}
$\begin{array}{l}\text { Propsective } \\
\text { observational study }\end{array}$ \\
\end{tabular} & Ground & MD?, RN vs RN & $\begin{array}{l}\text { Decerease in similarly measured events from } 34 \% \text { to } \\
12.5 \% \text { despite higher APACHE2 scores }\end{array}$ & \\
\hline Droogh & Netherlands & 353 & $\begin{array}{l}\text { Retrospective chart } \\
\text { review }\end{array}$ & Ground & $\begin{array}{l}\text { Not stated. MD } \\
\text { presumed }\end{array}$ & Equipment-related AE $15.5 \%$ & \\
\hline Singh & Canada & 5144 & $\begin{array}{l}\text { Retrospective cohort } \\
\text { study }\end{array}$ & Ground & $\begin{array}{l}\text { Advanced care } \\
\text { paramedics, critical } \\
\text { care paramedics }\end{array}$ & $\begin{array}{l}\text { Level of clincian OR } 1.6 \text {, mechanical ventilation OR } \\
\text { 1.7, baseline hemodynamic instability OR 3.7, critical } \\
\text { event rate } 6.5 \%\end{array}$ & $\begin{array}{l}\text { Again, only level of clinician is } \\
\text { paramedics }\end{array}$ \\
\hline
\end{tabular}




\section{Summary and conclusion}

Empirical evidence has informed us that adverse events occur in health care at alarming rates, and that they occur more commonly in critical care areas. Critical care transport is a highly specialized area of critical care that also reports high rates of adverse events, but published research to date have lacked generalizability to CCT teams common in the United States, and definitions of adverse events have not been consistent or conformed to standards set by The Joint Commission. Certain patient characteristics which may be measured as pre-transport factors may increase risk for intra-transport adverse events and the appropriate selection of transport team (licensure level or experience of lead clinician) and mode or duration of transport can be used to anticipate or mitigate increased risk. There is, however, no existing research to examine the type and frequency of patient safety events using standard taxonomy that examines these relationships in the setting of a crew configuration and setting common to the United States. The purpose of this study was to provide that information as an observational study. 
Chapter 3: Methodology

\section{Introduction}

Chapter 1 introduced the concept of patient safety in CCT, and highlighted the magnitude of this problem in the U.S. health care system. It described key formative literature related to patient safety in $\mathrm{CCT}$, and provided a rationale for developing the proposed study. The purpose of this research was to investigate the type and frequency of patient safety events during critical care transport between hospitals and to examine the relationships between selected variables and CCT patient safety events. This study occurred at a single site with an established CCT team. Chapter 2 provided an analysis of the relevant literature. Going from the general to the specific, the literature review began with a discussion of patient safety events in health care and why they are an important and necessary topic for research. Next, empiric literature about patient safety events in critical care was examined and evaluated, including the transport of critically ill patients within the same facility (intra-facility transport). Finally, literature related to patient safety events in the context of the inter-facility transport of critically ill patients was detailed. There is insufficient information in U.S. inter-facility CCT reports to be confident that the incidence of patient safety events is known and that factors associated with their type (e.g., severity) and frequency have been appropriately investigated.

The following research questions were examined: 
1. What are the types and frequencies of patient safety events that occur during inter-facility CCT at a single site that uses RNs and APNs as lead clinicians in ground, rotor and fixed-wing vehicles?

2. What is the impact of the patient characteristics of stability, vulnerability, complexity, predictability, and resiliency on frequency of patient safety events?

3. Do the nursing competencies of caring practices and clinical judgment, have a mediating or moderating role on the frequency PSE?

4. Do modifiable environmental factors (i.e., time outside of the ICU and mode of transport) influence the frequency of PSE during interfacility transport?

In this Chapter 3, the method for the current study is detailed. First, research design and rationale for choosing that design are described. The setting, sample, and rationale for sample size is then explained. The procedure for data collection, the data collection spreadsheets, the operational definition of variables and the plans for data analysis are described. A section on human subjects' protection illustrates steps taken to ensure ethical practices in research were followed.

\section{Research Design}

Study designs can be described according to their relationship with time retrospective looks at events in the past and prospective looks forward in time. Studies can also be described by their relationship to the degree of control of variables by the researcher. Descriptive studies lack any manipulation by the researcher, while quasi- 
experimental and experimental designs have increasing amounts of variable control by the researcher respectively. This study design was a non-experimental retrospective correlational study. To describe the choice of this study design, each element is detailed. Each decision was based on the research questions, the type of data to be collected to answer the research questions, the degree of control of the variables, and an assessment of the ideal method of answering the research questions with the given data.

The current research questions fall into two categories:

- Descriptive - Descriptive studies "explore the lay of the land" (Hulley, 2007, p. 5), allowing the researcher to describe the phenomenon of interest and its relative frequency.

Describing the patient safety events that occur during transport (dependent outcome variables) by type and frequency.

- Correlational - Correlational studies explore and describe the relationships between variables of interest (Burns \& Grove, 2009)

- Correlating pre-transport factors with frequency of certain patient safety events

- Correlating pre-transport factors with type of patient safety events

- Investigating whether level of licensure of lead clinician (RN/APN), experience of the lead clinician in CCT, time outside of the ICU (in minutes), or mode of transport (ground, rotor wing, fixed wing) act as moderating variables, influencing the direction or magnitude of association between the pre-transport variables and patient safety events 
Given these research questions and the limited state of knowledge about patient safety events in U.S. CCT, a retrospective descriptive correlational study design was used. No attempt was made to manipulate any study variable in any way, and there was no treatment or intervention used in this study. No random assignment of mode or clinician occurred, although these variables could be manipulated in future studies to better determine their effects on patient safety events. All data was collected as it occurred naturally during the study period. This study had the advantage of occurring naturally in a unique setting; a setting that include APNs as lead clinicians.

Retrospective review has the disadvantage of potential missing data. Experientially, patient safety events that do not reach the patient (e.g., "near misses") or do not cause harm have a high probability of not being documented in the medical record. Many of the studies cited previously had a retrospective design and authors consistently acknowledged limitations of record review. (Flabouris et al., 2006; Singh et al., 2014; Singh et al., 2009). Unique to this setting was the concurrent collection of PSE as a matter of record to improve quality. Thus, there was a source for collecting clinician reports of potential and actual PSE during CCT.

\section{Variables of Interest}

The dependent variable was the occurrence of Patient Safety Events are linked to Patient Outcomes in the AACN Synergy Model. The pre-transport predictor variables are linked conceptually to the Patient Characteristics in the AACN Synergy model, as described in Figure 2. There were 14 pre-transport variables in this study. 
There were four hypothesized moderator variables. Two moderators, level of lead clinician licensure and lead clinician experience, are linked conceptually to the nursing competencies in the AACN Synergy Model. The other two moderators, time outside the ICU and mode of transport, are linked to environment of care as described in the Synergy Model.

The current study links to Jaynes (2013) blueprint for industry research through investigation of the relationship between education and outcome, and indirectly evaluating the relationship of air transport (compared to ground) to outcome of safety events. Each of the 19 (23 if type of PSE is counted separately) variables is described and operationally defined below.

\section{Patient Characteristics / Pre-transport Variables}

Based on findings from completed research in patient safety events during transport, this study included 14 pre-transport predictor variables as measures of the 5 patient characteristics identified in the Synergy Model:

- Stability

- This was defined as the sum of values described below: SBP + HR + Hypoxia + LOC + PEEP. The score could range from 0-51, assuming a maximum PEEP of 30 (could be $0-66$, assuming a maximum PEEP of 45)

- Abnormal blood pressure 
- Defined as any documented systolic blood pressure (SBP) less than $90 \mathrm{mmHg}$ or greater than $160 \mathrm{mmHg}$ in the two hours prior to transport or upon arrival of the transport team

- Recorded as the highest or lowest value in the two hours prior to transport

- Coded following MEWS guidelines:

- $\quad 0=90-160 \mathrm{mmHg}$

- $1=70-89$, or $161-200 \mathrm{mmHg}$

- $2=0-69$, or $\geq 201 \mathrm{mmHg}$

- Ordinal level of measurement

- Abnormal heart rate

- Defined as any documented heart rate less than 51 beats per minute or greater than 100 beats per minute in the last two hours before transport

- Recorded as the highest or lowest documented value in the two hours prior to transport

- Coded following MEWS guidelines:

- $\quad 0=51-100$ beats per minute $(\mathrm{bpm})$

- $\quad 1=41-50$, or $101-110 \mathrm{bpm}$

- $2=\leq 40$, or $11-129 \mathrm{bpm}$

- $3=\geq 130 \mathrm{bpm}$

- Ordinal level of measurement 
- Hypoxia

- Defined as any documented pulse oximetry reading less than $90 \%$, regardless of inspired fraction of oxygen $(\mathrm{FiO} 2)$ in the last two hours prior to transport

- Recorded as the lowest value in the two hours prior to transport

- Coded following MEWS guidelines:

- $\quad 0=90-100 \%($ revised to $93-100 \%)$

- $1=80-89 \%$ (revised to $80-92 \%$ )

- $2=70-79 \%$

- $3=60-69 \%$

- $4=<60 \%$

- Ordinal level of measurement

- Altered level of consciousness

- Defined as deviations from maximum level of consciousness as measured by the Modified Glasgow Coma Scale (GCS) at time of initial patient assessment by transport team

- Recorded as the value documented upon initial assessment of the transport team subtracted from 15 (maximum GCS score).

- Ratio level of measurement

○ Positive End-Expiratory Pressure (PEEP)

- Only applicable to mechanically ventilated patients 
- Defined as a current PEEP setting measured in centimeters of water $(\mathrm{cm} \mathrm{H} 2 \mathrm{O})$

- Recorded as the level of PEEP documented to be present at the time of initial assessment by the transport team

- Ratio level of measurement

- Vulnerability. Scored as additive of the factors below with a range of $0-2$

- Mechanical ventilation

- Defined as the presence of an artificial airway and use of positive pressure ventilation by either manual or mechanical ventilation device at the time of initial assessment by the transport team

- Coded as Not Present (0) or Present (1)

- Dichotomous nominal level of measurement

- Noninvasive Positive Pressure Ventilation

- Defined as use of continuous positive pressure airway pressure with or without pressure support breaths at the time of initial assessment by the transport team

- Coded as Not Present (0) or Present (1)

- Dichotomous nominal level of measurement

Complexity. Scored as additive for number of devices (anticipated to be $0-2$ ) + number of infusions (anticipated to be $0-10$ ) + number of vasoactive infusions 
(anticipated to be 0-6) + number of other invasive lines (anticipated to be $0-8$ ) for a range of $0-26$ as the score.

- Total number of cardiac assist devices

- Defined as the presence of any mechanical or electrical cardiac assist device, regardless of manufacturer, including ventricular assist devices (left, right, or biventricular), extracorporeal membrane oxygenation (ECMO), Intra-Aortic Balloon Pump (IABP), or external electrical pace generator (including transvenous or transcutaneous) at the time of initial assessment by the transport team

- Recorded as the numeric total number of cardiac assist devices in place

- Ratio level of measurement

- Total number of intravenous infusions

- Defined as the total number of continuous or intermittent infusions, contained in any intravenous administration infusion bottle or bag, infusing at the time of initial assessment by the transport team. Does not include intravenous push medications.

- Recorded as the numeric total of applicable infusions documented as present at the time of initial assessment by the transport team 
- Ratio level of measurement

- Total number of vasoactive infusions

- Defined as the number of any continuous intravenous infusions whose purpose is to affect the blood pressure, either positively or negatively, by any mechanism of action. Examples include primarily norepinephrine, epinephrine, dopamine, vasopressin, sodium nitroprusside, and Nicardipine. This category also included continuous intravenous inotropic or chronotropic medications, either positive or negative, if used for purposes of their cardiovascular effect (e.g. dobutamine or esmolol).

- Recorded as the numeric total of applicable infusions documented as present at the time of initial assessment by the transport team

- Ratio level of measurement

- Total number of invasive lines, including peripheral intravenous lines

- Defined as the number of vascular access lines used for monitoring or medication administration. Includes any centrally inserted intravenous line (including pulmonary artery catheters), peripherally inserted central lines, osseous, or arterial lines. Includes ventriculostomy. Each line, regardless of number of ports, is considered a single line. Excludes vascular access lines for CV support. 
- Recorded as the numeric total of applicable lines documented at the time of initial assessment by the transport team

- Ratio level of measurement

- Total number of invasive tubes and drains

- Defined as the total number of tubes and drains inserted into the patient prior to arrival of transport team. Examples include but are not limited to tracheal tubes, enteral tubes, urinary drainage tubes, fecal drainage tubes, surgical drains, and thoracostomy tubes.

- Recorded as the numeric total of applicable tubes and drains documented as present at the time of initial assessment by the transport team

- Ratio level of measurement

- Predictability There is no score-this is a nominal descriptive factor.

○ Diagnostic category

- Defined as category of the patient's primary diagnosis as known at time of transport request

- Coded as Primary Cardiac diagnosis (including aortic syndromes) [1], Complex Medical diagnosis [2], Primary Neurological Diagnosis [3], Complex Surgical Diagnosis [4], or Trauma [5]

- Nominal level of measurement 
- Resiliency. The range of this score was anticipated to be 14-100.

$\circ$ Patient age

- Defined as age of the patient in years at time of transport as recorded in the patient record.

- Recorded as a whole number

- Ratio level of measurement

Some patient characteristics have multiple pre-transport variables associated with them, but each patient characteristic within the theoretical model may only have one empirical referent. To remedy this, a composite scoring system was devised to allow each patient characteristic to refer to a single measurement. Stability, Vulnerability, and Complexity are each measured as a sum composite score of the associated pre-transport variables. Resiliency and Predictability each had a single associated pre-transport variable and were measured by that unaltered variable alone.

\section{Hypothesized Moderators}

Several researchers reported a relationship between intra-transport events and licensure level of the lead clinician, experience of the lead clinician, time outside of the ICU, and/or mode of transport. These factors occurred temporally after the transport process is initiated and were hypothesized here to have a moderating effect on the frequency of patient safety events. A moderator variable is a third variable that partitions the independent variable into subgroups that better explain the domains of the independent variable / dependent variable relationship (Baron \& Kenny, 1986). 
This study hypothesized that nursing competencies may affect the frequency of PSE. Specifically, increasing licensure level of the lead clinician during transport may have an antagonistic moderator effect on the frequency of patient safety events during transport. This hypothesis was based on findings in other studies citing decreases in all events as the licensure level of the clinician increases (Papson et al., 2007; Singh et al., 2014; Singh et al., 2009; Venkategowda et al., 2014). Likewise, this study hypothesized that increasing total experience of the lead clinician would have an antagonistic moderator effect on the frequency of patient safety events during transport.

This study hypothesized that two modifiable environmental factors might also affect PSE. Environmental factors were defined as time outside of the ICU and mode of transport. Time outside of the ICU was hypothesized to have an enhancing moderator effect on the frequency of patient safety events. Though the literature is replete with studies linking mode of transport to positive and negative outcomes, this study hypothesized that mode of transport would be insignificant when placed in context with patient characteristics, and act as a spurious relationship. The nursing competencies and environmental factors are defined below.

- Nursing Competencies

- Caring Practices

- Level of clinician licensure

- Defined as the level of nursing licensure of the highest credentialed caregiver on the transport team 
- Coded as either RN (2) or ANP (3). Paramedics (coded as 1 in secondary caregiver data records) lead no transports on this team. Physicians lead teams, however, occur and those cases were excluded as they do not happen frequently enough to reach a sufficient sample size for inclusion.

- Ordinal level of measurement

- Clinical Judgment

- Experience of lead clinician

- Defined as the numeric total of years of tertiary level inter-facility transport experience of the lead clinician

- Measured as the sum of whole number years of experience of the lead clinician on the transport at a tertiary level. Does not include the experience of the second caregiver or any third parties that may supplement the team, such as Respiratory Therapy Technicians, perfusionists, or Emergency Medical Technicians that may drive the Mobile ICU.

- Ratio level of measurement

- Environmental factors

- Time outside of the ICU (duration of transport) 
- Defined as the total time, in minutes, from leaving the patient's location at the sending facility until reaching the new location at the receiving facility.

- Recorded as the whole number arrived at by subtracting the departure from referring bedside time from time of arrival at receiving bed

- Coded as a whole number

- Ratio level of measurement

○ Mode of transport

- Defined as the primary mode of transport utilized to transport the patient from the sending facility to the receiving facility.

- Measured as Mobile ICU (1), rotor wing (2), or fixed wing (3)

- Nominal level of measurement

\section{Dependent Outcome Variables}

All health care facilities accredited by The Joint Commission use a common taxonomy to describe patient safety events. This study used measures of patient safety events consistent with standards at both referring and receiving facilities, and thus the dependent outcome variable of this study, patient safety events, maintained taxonomy and definitions consistent with terminology used by The Joint Commission (Commission, 2015), including:

- $\quad$ Patient Safety Event (PSE) 
- Defined as any event, incident, or condition that resulted, or could have resulted, in patient harm

- Measured as a sum of cases that included adverse events (including sentinel events), no harm events, near misses, and hazardous condition events

- This value was used to report frequency

There are five types of PSE, including: adverse event, sentinel event (a subcategory of adverse event), a no-harm event, a near miss event, and a hazardous condition.

- Adverse Event (AE)

- Defined as a patient safety event that actually resulted in harm to a patient

○ Coded as Not Present (0) or present (1)

○ Dichotomous nominal level of measurement

- $\quad$ Sentinel Event (SE)

- Defined as a specific type of adverse event that results in death, permanent harm, or severe temporary harm to the patient

○ Coded as Not Present (0) or present (1)

○ Dichotomous nominal level of measurement

- No-Harm Event (NHE)

- Defined as a patient safety event that affects the patient, but does not cause harm to the patient

○ Coded as Not Present (0) or present (1) 
○ Dichotomous nominal level of measurement

- Near Miss (NM)

○ Defined as a patient safety event that occurs, but is intercepted before affecting the patient

○ Coded as Not Present (0) or present (1)

- Dichotomous nominal level of measurement

- Hazardous Condition (HC)

- Defined as any circumstance or condition that increases the probability of an adverse event

○ Coded as Not Present (0) or present (1)

○ Dichotomous nominal level of measurement

These data were captured from a post-transport report completed by one of the transporting clinicians within 48 hours of inter-facility CCT. The report was originally created by the site CCT Quality Improvement committee to identify opportunities to sustain or improve the care delivered during CCT.

\section{Setting}

This setting for this study was a single multi-modal CCT agency. This transport agency cared for more than 500 critically ill patients per month, with more than 400 per month that meet the stated inclusion criteria, covering a broad range of diagnoses and patient acuity levels. The CCT team was based from a large quaternary, international hospital system based in the Midwestern United States. This agency offered CCT 
services both within the system of 10 affiliated local hospitals and externally to other local and regional hospitals. Transports occurred in ground Mobile Intensive Care Unit (MICU), rotary wing helicopter (RW), and fixed wing jet aircraft (FW). Most transports were within the local Midwest area and the 10 local system facilities or other local facilities requiring tertiary services not available within their own facility or system. The mix of transport modes in 2015 was $75 \%$ Mobile ICU, $25 \%$ helicopter, and $<1 \%$ fixed wing (personal communication Scott Swickard, May 2016).

The source of data was records completed by members of the CCT team. These records were completed regardless of the study.

Staff of the CCT team included physician medical directors, acute care nurse practitioners (ACNPs), RNs, and critical care paramedics. Most staff members during the study period were rotated through all modes of transport and were not exclusive to any single mode, except where specified below. Staff members were assigned to a given mode of transport for each shift, but may have been moved from one transport modality to another as needed to match patient needs with most appropriate level of care available and transport mode most appropriate to the circumstances. All staff members received similar orientation and recurrent education in CCT despite different educational preparations and different roles. All staff members were required to have a professional certification within one year of hire, appropriate to their specific professional role. Registered Nurses and APNs may have had one or more certifications, including Certified Emergency Nurse (CEN), Certified Critical Care Nurse (CCRN), Certified Transport Registered Nurse (CTRN), or Certified Flight Registered Nurse (CFRN). 
Paramedics were certified as Certified Flight Paramedic (FP-C) or Certified Critical Care Paramedic (CCP-C).

An RN specializing in transport triage and communications coordinated all transports. This RN Clinical Coordinator was included in the phone conversation between the referring and receiving physicians, and received clinical information at that time. If the patient was accepted and a bed was immediately available, the Clinical Coordinator dispatched a team via transport mode requested by the referring physician. If the referring physician did not request a specific mode of transport, the Clinical Coordinator determined an appropriate mode and team in consultation with one of the on-duty ACNPs, the Clinical Operations Manager, or the Medical Director.

\section{CCT Devices}

All equipment used in transport was identical across all modes of transport, and were routinely interchanged. All durable medical equipment was less than ten years old, and most was less than five years old. Major medical equipment used during most transports included:

- Propaq MD cardiac monitor or Propaq X (Zoll Medical, Chelmsford, MA)

- Revel portable ventilator (CareFusion, San Diego, CA)

- Sigma Spectrum Infusion Pump (Baxter Healthcare, Deerfield, IL)

- CardioSave intra-aortic balloon pump (Maquet Corp, Rastatt Germany) 
Medical supplies used in all transports were identical, and came from the same hospital-based supply chain system. Supply purchase and distribution was universal across all modes of transport and all locations. There were no substantive differences in medical supplies.

\section{CCT Mode of Transport}

During the study period, Ground Mobile ICU transport utilized a dedicated Mobile ICU transport team and dedicated Mobile ICU trucks. Mobile ICUs were box-style ambulances with Ford F350 chassis and were 5 or less years old. There were three identically equipped and identically functional Mobile ICUs for generally adult patient populations. There was a single dedicated pediatric Mobile ICU that was not part of the study due to the different primary patient population. There was a dedicated Mobile Stroke Treatment Unit, differently staffed and equipped, that primarily responded to 9-1-1 calls having the potential to be acute strokes. Transports from that truck were also excluded from this study due to differences in patient population, staffing, and equipment. The patient cot was a Stryker MX Pro with no modifications on all Mobile ICU vehicles. The cot was center mounted allowing access to the patient from all sides. Standard crew configuration for a Mobile ICU included a RN and an Emergency Medical Technician - Paramedic. An Emergency Medical Technician - Basic was used as a driver for the vehicle, but was not involved in direct patient care. When patient circumstances necessitated, this team was supplemented with an APN (certified as an Acute Care Nurse Practitioner). Mobile ICUs had a general operating range of 80-100 miles each way, but 
went further when patient need necessitated using this team rather than a team closer to the patient. Liquid oxygen was used during transport, and portable E cylinder oxygen was used between Mobile ICU and patient origin and destination. Every vehicle had functional electrical inverter systems with sufficient electrical outlets to charge and power all medical devices without requiring battery use for extended time periods.

Rotor wing transports utilized three Sikorsky S76 helicopters during the study period. All were approximately ten years old, and had identical configurations in both medical compartment and aviation specifications. The patient compartment could hold one patient on a modified Stryker cot and four crew. All flights utilized two pilots who were IFR-certified and night-vision goggles certified. Standard crew configuration on rotor wing flights consisted of an APN and a RN. The APN was occasionally replaced by one of the physician medical directors, and/or a $\mathrm{RN}$ was replaced by a paramedic. All rotor wing flights included either a MD or ACNP. Normal operating range of a rotor wing transport was 150-200 nautical miles each way. Longer transports were possible, but rare, and generally required stops for fueling. Average speed of this aircraft was 160-180 miles per hour. Liquid oxygen was used in flight, and portable E cylinders were used between the aircraft and the patient origin or destination. All aircraft were equipped with onboard electrical inverter systems with sufficient electrical outlets to charge and power all medical devices without use of battery power for extended periods of time. During the study period, an alternate back-up aircraft was occasionally used as the primary aircraft were being upgraded. This aircraft was a Bell 412 with a differently configured patient compartment, but all elements present in the primary aircraft were maintained. 
Airframe was not a recorded data field, so variations related to use of a different airframe could not be excluded.

Fixed wing (FW) transports utilized a small fleet of Cessna Citation V Ultras. All aircraft had jet propulsion engines. Cabin pressure was maintained at or near 6,000 feet unless the patient condition warranted a lower altitude cabin pressure. All aircraft used a modular patient stretcher system (Med-Pac, Lake Park, MN) with integrated AC power, vacuum, and modified M-cylinder with aviation grade oxygen. All fixed wing transports had intrinsic ground transport segments between the patient origin and the airport, and again from the destination airport to the receiving facility. The transport team provided patient care during all legs of every transport, including the ground transport portions.

\section{Sample: Sources of Data}

There were two sources of data records used for this study. The first record was a clinician report of potential and actual patient safety events and other adverse occurrences completed by the lead or supporting clinician following each transport. This form was completed electronically and during the study period was a routine part of documentation used by the staff for quality improvement and for national reporting purposes as part of an initiative of the Air Medical Physicians Association (AMPA). AMPA quality metrics for adult patient transports included 28 separate items, including nine metrics covering patient safety events (see Figure 5). The following items cover the PSE that comprised the dependent outcome variable of this study: 
- 9 - Unplanned dislodgement of therapeutic devices during transport?

(Examples - IO, IV, central venous line, arterial line, advanced airway, chest tube, and tracheostomy tubes. This does NOT include IVs that infiltrate without obvious dislodgement.) [Adverse event]

- 10 - Hypoxia during transport? (Defined as the pulse ox reading dropping below $90 \%$. However, if the patient is chronically low or is $<90 \%$ when contact is made, the patient is ONLY included when the saturation is corrected to be $>90 \%$ and falls again.) [Adverse event]

- 21 - Transport-related patient injuries? [Sentinel event]

- 22 - Transport-related crew injuries? [Sentinel event]

- 23 - Adverse drug event during transport? [Adverse or sentinel event]

- 24 - Medical equipment failure during transport? (Examples: IV pumps, ventilator malfunction, monitor, empty medical gas tanks, etc.) [Adverse event]

- 25 - Patient near-miss or precursor adverse events?

(Near-miss events are deviations from generally accepted performance standards that occurred but did not "reach" the patient. Precursor adverse events are deviations from generally accepted performance standards that reach the patient but result in NO harm or minimal, temporary patient harm. Excluded are injuries and deaths related to the medical/surgical conditions themselves. Examples: patient falls, loose pieces of transport equipment that 
fall and strike the patient, injuries suffered in a transport vehicle accident, etc.) $[$ Near-miss event]

- 26 - Hazardous Condition? (Any circumstance or condition that increases the probability of an adverse event) [Hazardous condition]

- 28 - Medication administration error during transport? [Adverse event]

The second record used was the patient transport medical record completed by CCT staff for each inter-facility transport. This documentation included the flow sheet, narrative notes, and demographic patient data. No Health Insurance Portability and Accountability Act (HIPAA) or staff (individual) identifying data were collected for this study (see Human Subjects below). However, during data collection, the event record was linked to the patient's medical record. This linkage data only existed until data collection was complete and was eliminated following preliminary analysis to determine data collection accuracy and completeness.

\section{Sample Inclusion and Exclusion criteria}

The study sample included records of inter-facility transports by the CCT team in the single site setting over the study period. The sample did not include other activities or transports by the CCT agency such as pre-hospital responses (e.g., scene trauma), prehospital STEMI rendezvous, Medical Emergency Response Team (MERT) responses or intra-facility services, or Mobile Stroke Treatment Unit transports as these efforts, while completed by CCT staff, are not inter-facility transports, and may represent different 
patient safety risks and events than inter-facility transports. Transports led by physicians (MDs) were excluded due to the small number of these transports. Medical escort transports by a single clinician were excluded. Pediatric transports, defined as those transports of patients less than 14 years of age and / or transported by a specialty pediatric team, were excluded from the study.

\section{Estimating sample size}

This was a descriptive study. In general, 10 subjects (transports) were required for each variable in order to have sufficient sample size to support conclusions in a descriptive study (2013). There were 19 discrete variables; thus a minimum of 200 transports with complete data was needed.

G-Power analysis (version 3.1.9.2, Universitat Kiel, Germany) using an a priori alpha $=0.05$, power $=0.80$, effect size 0.05 (lowest incidence of the dependent variable cited in the literature), and 18 pre-transport measures of patient characteristics and moderator variables, indicated a minimum sample size of 157 was needed for logistic regression analysis.

Sample size calculations with an intervention require an estimate, generally from the literature, of effect size. A priori sample size was set at 100 PSE based on effect size in the literature and in a pre-study survey. The actual rates of PSE differed significantly from these a priori estimates, and sample size was adjusted in accordance with committee agreement. Eight control cases were randomly selected from transports with no reported 
PSE for every one transport with a PSE. Controls cases were evenly distributed across each 2-week period of the study.

\section{Instrumentation}

The primary method of data collation used in this study was a principle-investigator derived Microsoft Excel (Microsoft Corp) spreadsheet to collect data from each of the two records. It was capable of import into the Statistical Program for the Social Sciences (SPSS) for data analysis. This spreadsheet had all variables of interest, separated by type of variable (columns) and each case (rows) and is illustrated in Figure 8. Color-coding was used to separate pre-transport variables from moderator variables and dependent outcome variables. All data was transcribed from the transport records to the data collection sheet by the primary investigator (PI). Members of the PI's academic dissertation committee reviewed the data collection sheet for accuracy, supporting the validity of this investigator-developed tool.

The PI maintained validity and reliability with a concurrent diary to develop and follow decisions about data extraction, record interpretation, and concurrent events that may influence the records (such as accreditation visits, staff turnover/orientation, epidemic outbreak, or distressing events such as a transport vehicle crash.

\section{Data collection procedures}

Sequential entries in the Critical Care Transport log were used to form the framework for the sampling and data collection process. This log was completed on all 
patient transport requests, regardless of type or mode, and included all transport requests whether completed or not. The Air Medical Physicians Association (AMPA) metrics portion was a required field for clinician documentation, beginning in August 2015, and included a record of PSE, the dependent outcome variable. Entries from this log were collected weekly. Using integrated filters, all entries meeting inclusion criteria were entered chronologically in the data collection spreadsheet, using the unique medical record number and the date of service as identifiers. (These identifiers were deleted prior to data analysis; see human subjects' protection).

Collection of data points pertaining to the pre-transport and moderating variables required manual review of the transport medical records. These records contained information for each data point and were supplemented by the History of Present Illness or other narrative notes to complete data collection.

\section{Plan for Random Selection of Control Cases}

Paper records of transports were divided into two week periods in the Transport Office. The PI selected 40 charts from each box to achieve a ratio of 8 non-PSE cases for each of the 48 cases with reported PSE While epidemiological approaches suggested that a ratio of 1 PSE case to 5 non-PSE cases were sufficient to meet statistical assumptions, the PI oversampled non-PSE cases to assist with data validation and to assure a thorough description of common characteristics of patients, lead clinician, and environmental factors in this setting. No attempt was made to select PSE or non-PSE cases based on 
time of day, patient characteristics, lead clinician or environmental factors involved in transport. Only those cases from each two-week period were included.

\section{Missing Data}

Transports with incomplete AMPA metrics were planned to be excluded. Initial vital signs recorded by transport team in the transport medical record were considered the last vital signs of the referring facility. Abnormal vital signs meeting inclusion criteria prior to transport team arrival were only considered present if documented in the transport medical record. No attempt was made to investigate medical records of referring facilities.

\section{Data Validation and Cleaning}

The PI conducted a pilot study to determine the feasibility of the study plan, promote reporting of patient safety events in a safe environment, and develop data collection instruments. Data validation was planned to be re-entry of every $20^{\text {th }}$ patient care record, collected at least 2 -weeks after the original data entry. Data cleaning was planned as examination of summary data to ensure values were within anticipated range and averages. For example, the host facility is well-known for cardiovascular and cardiothoracic surgical services, so it was anticipated these diagnoses would constitute a high percentage of overall transport volume. The host facility recently acquired a Level 1 trauma center, and was just beginning to transport trauma patients, so volume of trauma patents was expected to be relatively low. The host transport department does not offer 
services below critical care, so transport to destinations other than intensive care units and emergency departments was expected to be low or non-existent.

To further validate the integrity of the data, the dual approach of rechecking administrative data acquired through the adverse event reporting system with a secondary verification through chart review was planned. As demonstrated by Maass and colleagues (2015), nearly three times as many adverse events can be detected through chart review than by administrative data alone.

Data analysis

Data collected in the Data Collection Spreadsheet were imported into the Statistical Package for the Social Sciences database (SPSS, IBM Corporation). Graphical and descriptive analyses were conducted for every variable. The histograms were examined to determine that the data entered matched the appropriate codes assigned for the variable. Homoscedasticity was examined via scatterplots and frequency distribution. If the data were skewed and appeared to violate the assumption of normality, the data were transformed.

Question 1 was analyzed using descriptive statistics to describe the frequency and percentage of each PSE event. Question 2 was answered using simultaneous entry logistic regression to determine which of the patient characteristics were associated with the dichotomous outcome of PSE. Questions 3 and 4 were answered by examining the mediation or moderation effects of nursing competencies and environmental factors on 
the relationship between patient characteristics and PSE outcomes. A series of a logistic and linear regression analyses between the patient characteristics, nursing competencies, environmental factors, and outcome variables were conducted. After testing for the assumptions of regression (variables vary, no influential cases, constant error variance, normality of error, and no multicollinearity) all variables were simultaneously entered into the regression equation to determine a significant increase in Nagelkerke's r-square, a non-significant Homer and Lemeshow, and significant omnibus test of the new model. The independent and moderator variables were run in Block 1, and each potential moderator was entered into Block 2 in combination with each predictor variable. A significant interaction effect was used to determine the presence of moderation in the variables of interest. Mediation was tested by serial regressions with and without the variables of interest to determine changes in significance.

\section{Human Subjects' Protection}

Institutional Review Board approval was obtained from the host facility (and reciprocated by Case Western Reserve University IRB) prior to the initiation of research activities under expedited review. The rights of all participants were protected throughout this observational study.

It is important to note that a supervisory relationship, though in most cases not a direct report relationship, existed between the PI and the clinicians involved in the study. This relationship required special consideration to ensure that the rights of these clinicians were not violated. The host organization maintained active Safety and Quality 
programs, and each program reported through the PI during the study period. While the proposed study added more comprehensive data to the reports already received by the PI concerning patient safety and quality, it was consistent with this information. To further protect clinicians, identifiable data was not used in the database that was developed for this study.

Participants in nursing research have several specific rights delineated by the American Nurses Association ("Code for nurses with interpretive statements," 1985). Among these rights is the right to anonymity and confidentiality. In order to protect that right, all data were maintained on the secure Research Drive of the host institution. Access to this data was restricted to the PI and two representatives of the departmental research committee who were also members of the Doctoral Dissertation Committee. All data collection, synthesis, and analysis were electronic, so no physical data storage was required. SPSS data analysis software was accessed directly from the host institution; thus no transfer of electronic data was required. All data were completely de-identified prior to any dissemination in the form of publication of results, including this manuscript. 


\section{Chapter 4 Results}

Approximate PSE rates were monitored during the early weeks of the study to determine if pre-study assumptions used to calculate sample size were accurate. Early results of PSE found a rate of less than 3\% rather than the expected rate of approximately $15 \%$. Given the relative rarity of reported safety events, it was agreed by the Dissertation Committee that a sample size of 50 PSE would be the new target sample, and a control sample size of at least 5:1 would be appropriate for this observational study.

The target number of PSE was attained in 5 months. The total sample size at study conclusion was 2,506 cases. After eliminating excluded cases, the final sample size was 1,808 transports, with 50 PSE's recorded. Post-hoc power analysis by G-Power using alpha $=0.05$ resulted in a power of 0.85 . The control group was sampled at a ratio of 8:1 to ensure target ratio was reached. This was accomplished by randomly selecting 40 non-PSE cases for each 2-week period of the study. The final number of control cases was 392. See CONSORT diagram below in Figure 3. 
Figure 3 - CONSORT diagram

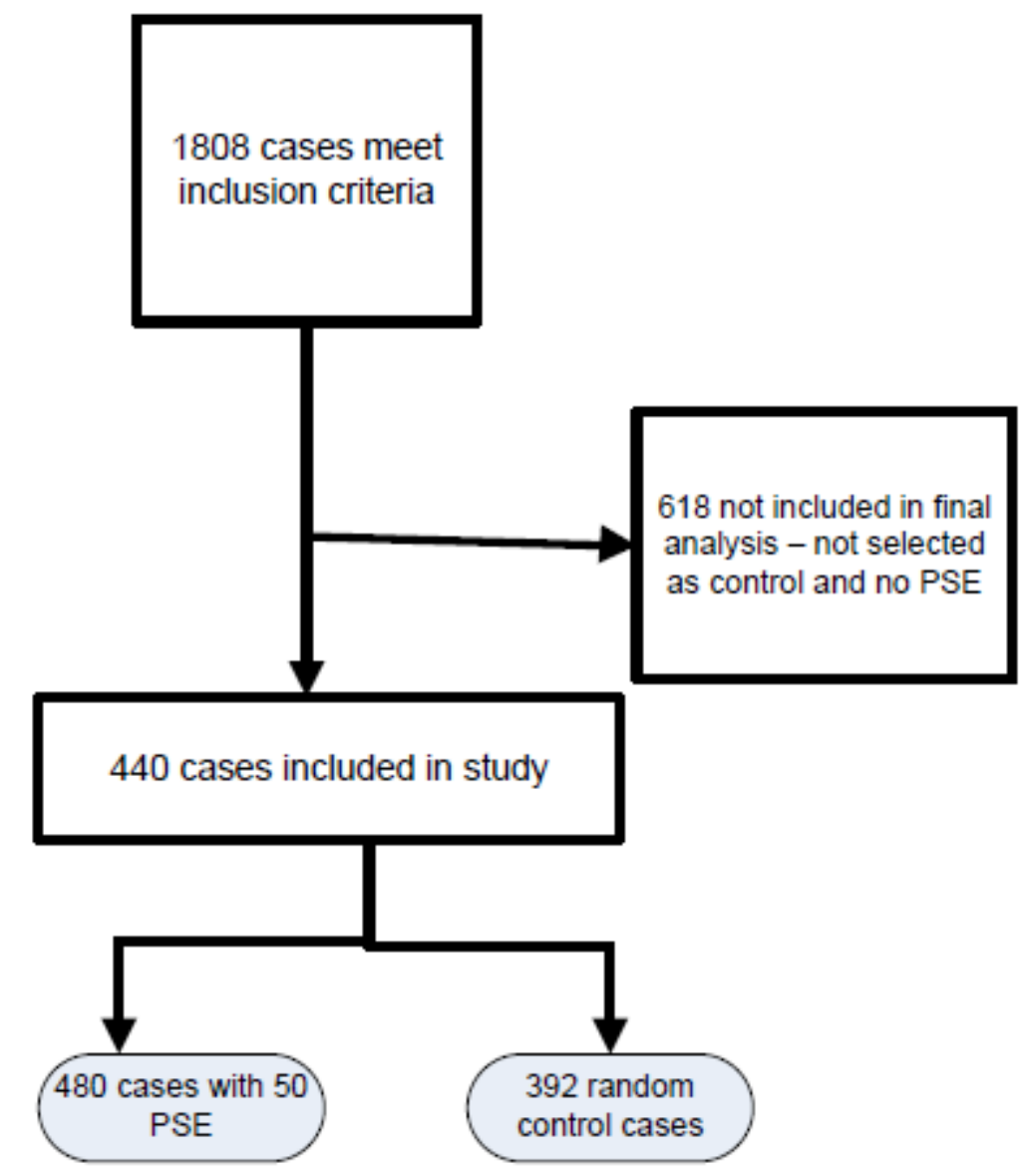

Immediately following data collection, frequencies were run on all collected variables to verify a clean data set. There were no cases with missing data. All data points were verified to be within anticipated parameters for the variable by the PI. Cases were checked to ensure no excluded criteria had been included. The following table contains descriptive statistics for all variables in the equation: 
Table 4 - Descriptive Statistics 1

\begin{tabular}{|c|c|c|c|c|c|c|c|c|c|}
\hline \multicolumn{10}{|c|}{ Descriptive Statistics } \\
\hline & $\mathrm{N}$ & Minimum & Maximum & Mean & Std. Deviation & \multicolumn{2}{|c|}{ Skewness } & \multicolumn{2}{|c|}{ Kurtosis } \\
\hline & Statistic & Statistic & Statistic & Statistic & Statistic & Statistic & Std. Error & Statistic & Std. Error \\
\hline Patient Safety Events & 440 & 0 & 1 & .11 & .312 & 2.516 & .116 & 4.352 & .232 \\
\hline Stability & 440 & 0 & 35 & 5.30 & 7.297 & 1.662 & .116 & 1.971 & .232 \\
\hline Vulnerability & 440 & 0 & 1 & .26 & .437 & 1.117 & .116 & -.756 & .232 \\
\hline Complexity & 440 & 0 & 16 & 4.60 & 2.761 & 1.316 & .116 & 1.811 & .232 \\
\hline Predictability & 440 & 1 & 5 & 2.06 & 1.082 & 1.119 & .116 & .853 & .232 \\
\hline Resiliency & 440 & 15 & 100 & 62.45 & 17.250 & -.514 & .116 & -.141 & .232 \\
\hline Level Clinician 1 & 440 & 2 & 3 & 2.31 & .463 & .829 & .116 & -1.319 & .232 \\
\hline Exp team 1 actual & 440 & 0 & 8 & 3.61 & 2.777 & -.085 & .116 & -1.602 & .232 \\
\hline Mode & 440 & 1 & 3 & 1.32 & .522 & 1.351 & .116 & .855 & .232 \\
\hline Minutes & 440 & 12 & 566 & 47.76 & 41.481 & 7.054 & .116 & 73.910 & .232 \\
\hline Valid N (listwise) & 440 & & & & & & & & \\
\hline
\end{tabular}

\section{Primary Analyses}

Research Question 1 - What are the types and frequencies of patient safety events that occur during inter-facility CCT at a single site that uses RNs and APNs as lead clinicians in ground, rotor and fixed-wing vehicles?

Fifty PSE were reported from 48 cases over the study period. Forty-eight cases had a single reported PSE, 2 cases had 2 PSE reported in the same transport, and 1,760 cases had no reported PSE. The overall rate of PSE was $2.65 \%$, or 26.5 event cases per 1,000 transports.

Of the 50 reported PSE, 34 were adverse events, or $68 \%$ of PSE and $1.88 \%$ overall adverse event rate. Refer to Table 5 below. There were no reported sentinel events during the study period. Five no harm events comprised $10 \%$ of reported PSE, or $0.28 \%$ of overall transports. Two near-miss events comprised $4 \%$ of PSE, or $0.11 \%$ 
overall. Nine reported hazardous conditions made up 18\% of PSE, and an overall hazardous condition rate of $0.50 \%$.

\section{Table 5 - Types and Frequencies of PSE during CCT}

\begin{tabular}{|l|c|c|c|c|}
\hline & Events & $\begin{array}{c}\text { Qualifying } \\
\text { transports }\end{array}$ & $\begin{array}{c}\text { Overall } \\
\text { Rate }\end{array}$ & $\begin{array}{c}\% \text { of } \\
\text { PSE }\end{array}$ \\
\hline PSE Overall & 50 & 1808 & $2.65 \%$ & $100 \%$ \\
\hline Adverse event & 34 & 1808 & $1.88 \%$ & $68.0 \%$ \\
\hline Sentinel event & 0 & 1808 & $0.00 \%$ & $0.0 \%$ \\
\hline No harm event & 5 & 1808 & $0.28 \%$ & $10.0 \%$ \\
\hline Near miss event & 2 & 1808 & $0.11 \%$ & $4.0 \%$ \\
\hline Hazardous condition & 9 & 1808 & $0.50 \%$ & $18.0 \%$ \\
\hline
\end{tabular}

Of the 34 adverse events, new or recurrent hypoxia was the most common event type with 26 reported events. Three equipment failures, two dislodgements, and one each of adverse drug event, delayed care, and wrong destination were the other adverse events.

There were nine reports of hazardous conditions. Verbatim comments of the hazardous conditions were variable and included mechanical issues (4), delays for various reasons (3), and quality concerns (2).

Of the five no harm events, three were related to equipment failure, one was related to a delay due to a risk assessment score, and one was related to a medication administration issue. Of the two reported near-miss events, both were related to equipment issues. However, it was difficult to ascertain the equipment that failed and the impact on patient care.

To summarize, the most common PSE was new or recurrent hypoxia at 26 PSE events across all categories. The next most common was eight equipment failures across 
all categories. There were five delays and four mechanical issues reported across all PSE categories. There were two of each of the following: dislodgement, drug-related concerns, and quality issues. The wrong destination occurred once.

There were no concerns regarding testing of statistical assumptions overall with the exception of inadequate variability of two factors described below. Table 4a details the test for multicollinearity. Tolerances among the all the variables within the model were examined and are presented in Table 6 . All tolerances were greater than 0.10 , ranging between 0.132 and 0.974 indicating that multicollinearity is not a problem and the assumption of independence is met. This team utilizes APNs on all RW and FW transports, so the degree of collinearity there was not surprising, and did not warrant removal from the model.

Table 6 - Collinearity Diagnostics Coefficients $^{\mathrm{a}}$

\begin{tabular}{|c|c|c|c|}
\hline \multirow[b]{2}{*}{ Mod } & & \multicolumn{2}{|c|}{ Collinearity Statistics } \\
\hline & & Tolerance & VIF \\
\hline \multirow[t]{9}{*}{1} & $\begin{array}{l}\text { Stability COMPUTE Stability }=\text { XSBP }+ \text { XHR }+ \text { X2SPO } 2+ \\
\text { XGCS + XPEEP }\end{array}$ & .278 & 3.602 \\
\hline & Vulnerability COMPUTE Vulnerability=XVent + XNPPV & .302 & 3.311 \\
\hline & $\begin{array}{l}\text { Complexity COMPUTE Complexity= Devices + } \\
\text { @\#infusion + @\#vasos + @\#lines + @\#tubes }\end{array}$ & .585 & 1.710 \\
\hline & Predictability COMPUTE Predictability=XDxCat & .966 & 1.035 \\
\hline & Resiliency COMPUTE Resiliency=PatientAge & .974 & 1.026 \\
\hline & LevClinic1 XLevClin1 & .139 & 7.214 \\
\hline & XExp1 & .835 & 1.198 \\
\hline & Minutes XOMins & .743 & 1.346 \\
\hline & ModeCompleted XMode & .132 & 7.586 \\
\hline
\end{tabular}


a. Dependent Variable: PSE XPSE

b. XSBP=MEWS systolic blood pressure, $X H R=M E W S$ heart rate, X2SPO2=MEWS oxygen saturation level, XGCS=transformed Glasgow Coma Scale, XPEEP=positive end-expiratory pressure, @\#infusions=number of intravenous infusions, @\#vasos=number of vasoactive infusions, @\#lines=number of invasive lines, @\#tubes=number of drains and tubes, XLevClin1=licensure level of lead clinician, XExp1=years of experience of the lead clinician, XOminutes=duration of transport

Table 7 details the characteristics of the sample by the variables of interest. Rows labelled Negative PSE refer to critical care transports without PSE. There were a total of 392 transports in this category. Positive PSE refer to the 48 transports with PSE that comprised the sample of 50 PSE.

\section{Table 7 - Between group comparisons}

\begin{tabular}{|c|c|c|c|c|c|c|}
\hline & \multicolumn{6}{|c|}{ Patient Characteristics } \\
\hline & $\begin{array}{l}\text { Stability } \\
\text { (range 0- } \\
51 \text { ) }\end{array}$ & $\begin{array}{l}\text { Vulnerability } \\
\text { (range 0-2) }\end{array}$ & $\begin{array}{l}\text { Complexity } \\
\text { (range 0-26) }\end{array}$ & \multicolumn{2}{|c|}{$\begin{array}{l}\text { Predictability } \\
\text { (nominal range } \\
1-5 \text { ) }\end{array}$} & $\begin{array}{l}\text { Resiliency } \\
\text { (range } \\
14-100 \text { ) }\end{array}$ \\
\hline $\begin{array}{l}\text { Negative } \\
\text { PSE (mean, } \\
\text { SD) }\end{array}$ & $4.60,6.47$ & $0.22,0.41$ & $4.42,2.62$ & \multicolumn{2}{|c|}{$2.09,1.09$} & $\begin{array}{l}62.52 \\
17.36\end{array}$ \\
\hline \multirow[t]{3}{*}{$\begin{array}{l}\text { Positive PSE } \\
\text { (mean, SD) }\end{array}$} & $\begin{array}{l}11.04 \\
10.52\end{array}$ & $0.56,0.50$ & $6.04,3.42$ & \multicolumn{2}{|c|}{$1.83,0.95$} & $\begin{array}{l}61.85 \\
16.45\end{array}$ \\
\hline & \multicolumn{2}{|c|}{ Environmental Factors } & \multicolumn{4}{|c|}{ Nursing Competencies } \\
\hline & $\begin{array}{l}\text { Time } \\
\text { (Minutes) }\end{array}$ & Mode & \multicolumn{2}{|c|}{$\begin{array}{l}\text { Level of Lead } \\
\text { Clinician by licensure }\end{array}$} & \multicolumn{2}{|c|}{$\begin{array}{l}\text { Experience of Lead } \\
\text { Clinician in years }\end{array}$} \\
\hline
\end{tabular}




\begin{tabular}{|c|c|c|c|c|}
\hline $\begin{array}{l}\text { Negative } \\
\text { PSE (mean, } \\
\text { SD) }\end{array}$ & $\begin{array}{l}44.17 \\
26.29 \\
\end{array}$ & $\begin{array}{l}\text { Ground } \\
n=281 \\
R W n=103 \\
F W n=8\end{array}$ & $\begin{array}{l}\text { RN } n=275,70.2 \% \text {, } \\
\text { NP } n=117,29.8 \%\end{array}$ & $2.35,1.17$ \\
\hline $\begin{array}{l}\text { Positive PSE } \\
\text { (mean, SD) }\end{array}$ & $\begin{array}{l}77.08 \\
96.61\end{array}$ & $\begin{array}{l}\text { Ground } n=31 \\
\text { RW } n=13 \\
\text { FW } n=4\end{array}$ & $\begin{array}{l}\text { RN n=29, 60.4\% } \\
N P=19,39.6 \%\end{array}$ & $2.23,1.29$ \\
\hline
\end{tabular}

The following tables $(8-12)$ describe the frequency of PSE of each patient characteristic, broken down into its constituent parts. The composite score for stability was composed of additive MEWS scores for systolic blood pressure, heart rate, and SpO2, plus (15 -Glasgow Coma Scale (GCS)), plus PEEP in cm of H2O. Higher scores indicate less stability or a more precarious patient condition. With the GCS, a higher score indicates improved mental status. Therefore, the GCS, as explained earlier, was coded as "points off" the highest score of 15 to reflect the same scoring approach —a higher score indicated a poorer physiological status.

Table 8 - PSE by components of stability

\begin{tabular}{|c|c|c|c|c|c|c|c|}
\hline \multicolumn{3}{|c|}{ Patient Safety Events } & $\begin{array}{l}\text { SBP (MEWS) } \\
\text { (possible 0-3) }\end{array}$ & $\begin{array}{l}\text { HR (MEWS) } \\
\text { (possible 0-3) }\end{array}$ & $\begin{array}{c}\text { Hypoxia } \\
\text { (possible 0-4) }\end{array}$ & $\begin{array}{c}\text { Points off } \\
\text { Glasgow } \\
\text { Coma Scale } \\
\text { (possible 0- } \\
12 \text { ) }\end{array}$ & $\begin{array}{l}\text { Positive end- } \\
\text { expiratory } \\
\text { pressure } \\
\text { (possible 0- } \\
30 \text { ) }\end{array}$ \\
\hline \multirow[t]{6}{*}{0} & $N$ & Valid & 392 & 392 & 392 & 392 & 392 \\
\hline & & Missing & 0 & 0 & 0 & 0 & 0 \\
\hline & $\mathrm{Me}$ & & .38 & .66 & .17 & 2.09 & 1.31 \\
\hline & & viation & .615 & .971 & .725 & 3.785 & 2.745 \\
\hline & & & 0 & 0 & 0 & 0 & 0 \\
\hline & & & 2 & 3 & 4 & 12 & 15 \\
\hline \multirow[t]{6}{*}{1} & $N$ & Valid & 48 & 48 & 48 & 48 & 48 \\
\hline & & Missing & 0 & 0 & 0 & 0 & 0 \\
\hline & $\mathrm{Me}$ & & .48 & .81 & .83 & 4.71 & 4.21 \\
\hline & & viation & .743 & 1.045 & 1.404 & 5.235 & 4.811 \\
\hline & & & 0 & 0 & 0 & 0 & 0 \\
\hline & & & 2 & 3 & 4 & 12 & 16 \\
\hline
\end{tabular}


Abbreviations: SBP = systolic blood pressure; HR = heart rate; MEWS = modified emergency warning system.

The composite score for vulnerability was composed of dichotomous responses to presence of mechanical ventilation and non-invasive positive pressure ventilation; 0 if not present and 1 if present.

Table 9 - PSE by components of vulnerability

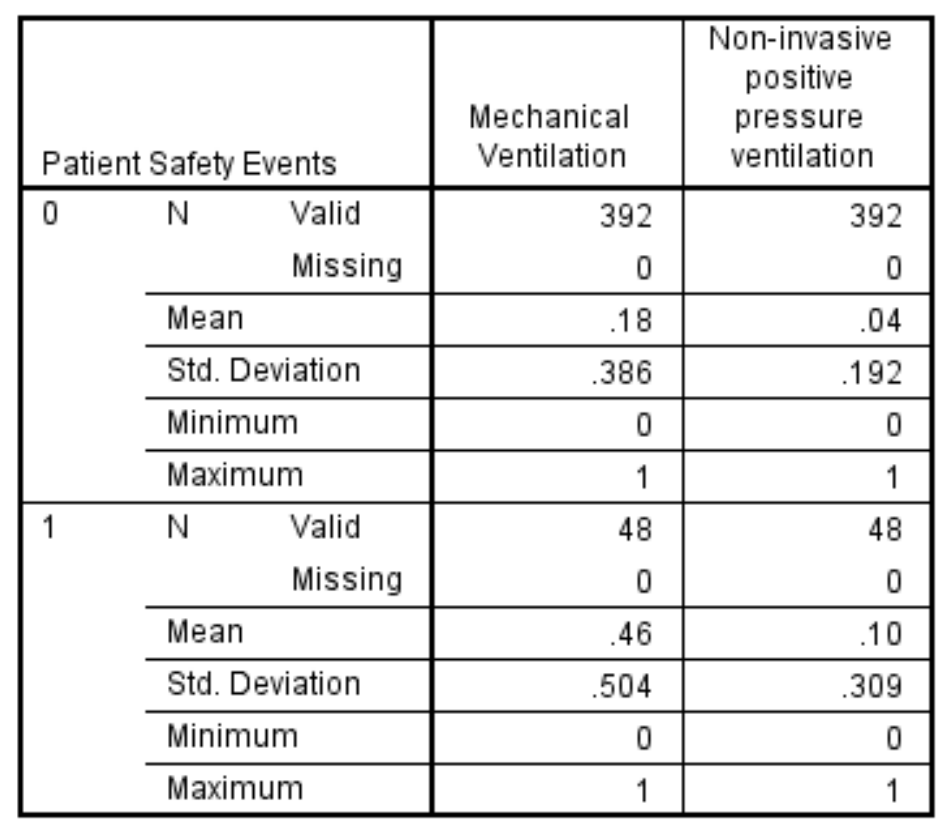

The composite score for complexity was calculated as additive scores of numbers of cardiac assist devices, intravenous infusions, vasoactive intravenous infusions, invasive lines, and all other invasive drains and tubes. 
$\underline{\text { Table } 10 \text { - PSE by components of complexity }}$

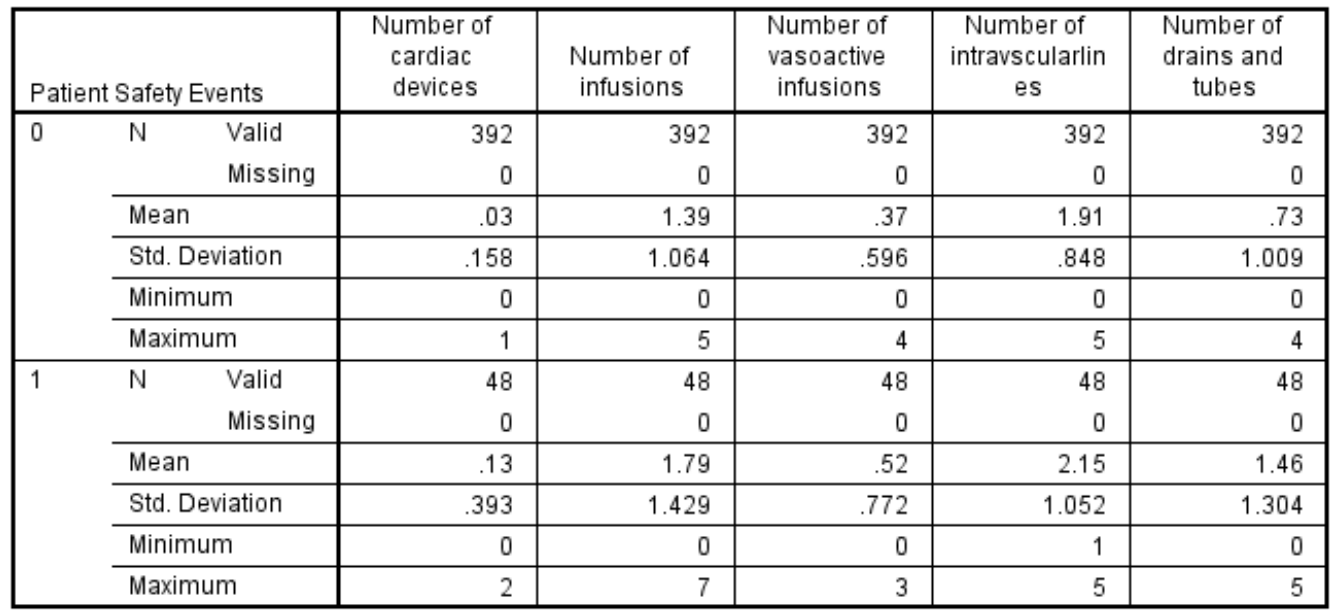

Predictability was measured purely as a function of the patient's primary diagnostic category. Each of the 5 primary diagnostic categories transported by this team were assigned a number alphabetically: (1) Cardiac; (2) Medical); (3) Neurological; (4) Surgical; and (5) Trauma. Generally, these values reflect the population typically transported by the CCT in this setting, an institution consistently ranked high for delivery of cardiac/cardiovascular care. 
Table 11 - PSE by components of predictability

\begin{tabular}{|c|c|c|c|c|c|c|c|}
\hline \multicolumn{3}{|c|}{ Patient Safety Events } & Cardiac & Medical & Neuro & Surgical & Trauma \\
\hline \multirow[t]{6}{*}{0} & $N$ & Valid & 392 & 392 & 392 & 392 & 392 \\
\hline & & Missing & 0 & 0 & 0 & 0 & 0 \\
\hline & \multicolumn{2}{|c|}{ Mean } & .3367 & .40 & .17 & .04 & .06 \\
\hline & \multicolumn{2}{|c|}{ Std. Deviation } & .47320 & .490 & .372 & .204 & .235 \\
\hline & \multicolumn{2}{|c|}{ Minimum } & .00 & 0 & 0 & 0 & 0 \\
\hline & \multicolumn{2}{|c|}{ Maximum } & 1.00 & 1 & 1 & 1 & 1 \\
\hline \multirow[t]{6}{*}{1} & \multirow[t]{2}{*}{$N$} & Valid & 48 & 48 & 48 & 48 & 48 \\
\hline & & Missing & 0 & 0 & 0 & 0 & 0 \\
\hline & \multicolumn{2}{|c|}{ Mean } & 4375 & .38 & .13 & .04 & .02 \\
\hline & \multicolumn{2}{|c|}{ Std. Deviation } & .50133 & .489 & .334 & .202 & .144 \\
\hline & \multicolumn{2}{|c|}{ Minimum } & .00 & 0 & 0 & 0 & 0 \\
\hline & \multicolumn{2}{|c|}{ Maximum } & 1.00 & 1 & 1 & 1 & 1 \\
\hline
\end{tabular}

Resiliency was measured by the patient's age in years at the time of transport.

Notice that the ages and standard deviations are similar between patients who experienced PSE and those who did not in the table,

Table 12 - PSE by components of resiliency

\begin{tabular}{|c|c|c|c|}
\hline \multicolumn{4}{|c|}{ Age } \\
\hline \multirow[t]{6}{*}{0} & $N$ & Valid & 392 \\
\hline & & Missing & 0 \\
\hline & \multicolumn{2}{|c|}{ Mean } & 62.52 \\
\hline & \multicolumn{2}{|c|}{ Std. Deviation } & 17.364 \\
\hline & \multicolumn{2}{|c|}{ Minimum } & 15 \\
\hline & \multicolumn{2}{|c|}{ Maximum } & 100 \\
\hline \multirow[t]{6}{*}{1} & \multirow[t]{2}{*}{$N$} & Valid & 48 \\
\hline & & Missing & 0 \\
\hline & $\mathrm{Me}$ & & 61.85 \\
\hline & \multicolumn{2}{|c|}{ Std. Deviation } & 16.451 \\
\hline & \multicolumn{2}{|c|}{ Minimum } & 25 \\
\hline & \multicolumn{2}{|c|}{ Maximum } & 88 \\
\hline
\end{tabular}


Research Question 2 -_What is the impact of the patient characteristics of stability, vulnerability, complexity, predictability, and resiliency, on frequency of patient safety events?

Prior to evaluating the impact of patient characteristics on PSE, tests of association were completed. Composite scores were used for correlations of patient characteristics to frequency of PSE, where applicable. Other scores were used at face value in biserial correlations. Three of the five patient characteristics, stability, vulnerability, and complexity, showed significant baseline correlations with PSE, as summarized in Table 13. Only predictability had a negative correlation and that correlation was very small $(0.75 \%)$. 
$\underline{\text { Table } 13 \text { - Biserial Correlations of Patient Characteristics }}$

\begin{tabular}{|l|c|c|}
\hline & $\mathrm{R}$ & sig \\
\hline Stability & 0.276 & 0.000 \\
\hline Vulnerability & 0.245 & 0.000 \\
\hline Complexity & 0.184 & 0.000 \\
\hline Predictability Overall & -0.075 & 0.117 \\
\hline Resiliency & 0.012 & 0.800 \\
\hline
\end{tabular}

All patient characteristics and potential moderator variables were then evaluated using logistic regression using simultaneous entry method. Block 0 , testing the null hypothesis with no predictors, showed correlations as described previously for patient characteristics, in addition to significant relationships of time and mode, specifically Fixed Wing, to frequency of PSE. The Classification Table indicated a correct prediction percentage of $89.1 \%$ using this null model.

Block 1 shows the impact of each variable controlling for the effects of others under simultaneous entry. No patient characteristic maintained significance at the $p=0.05$ level. Only the environmental factor of Time remained significant $(p=0.003$, OR 0.630, 95\% CI $1.175-2.261$ per quartile). Extending alpha to the 0.10 level, stability $(p=0.083$, OR $1.059,95 \%$ CI 0.993 - 1.130) was also predictive of PSE. Table 14 below summarizes regression results. 
Table 14 - Summary of regression results

\begin{tabular}{|c|c|c|c|c|c|c|}
\hline & \multicolumn{2}{|c|}{ Block 0} & \multicolumn{4}{|c|}{ Block 1} \\
\hline & $r$ & sig & sig & $B(\exp )$ & $\begin{array}{l}\mathrm{Cl} 95 \\
\text { lower }\end{array}$ & $\begin{array}{l}\mathrm{Cl} 95 \\
\text { upper }\end{array}$ \\
\hline Stability & 0.276 & 0.000 & 0.083 & 1.059 & 0.993 & 1.13 \\
\hline Vulnerability & 0.245 & 0.000 & 0.146 & 2.415 & 0.735 & 7.937 \\
\hline Complexity & 0.184 & 0.000 & 0.674 & 0.971 & 0.846 & 1.114 \\
\hline Predictability Overall & $\begin{array}{c}- \\
0.075\end{array}$ & 0.117 & & & & \\
\hline Predictability Cardiac & & & 0.32 & & & \\
\hline Predictability Medical & & & 0.084 & 0.476 & 0.205 & 1.105 \\
\hline Predictability Neuro & & & 0.085 & 0.388 & 0.132 & 1.139 \\
\hline Predictability Surgical & & & 0.491 & 0.562 & 0.109 & 2.895 \\
\hline Predictability Trauma & & & 0.775 & 0.731 & 0.085 & 6.274 \\
\hline Resiliency & 0.012 & 0.800 & 0.865 & 0.998 & 0.978 & 1.019 \\
\hline
\end{tabular}

a. $\quad$ Sig $=$ significance

b. $\quad \mathrm{B}(\exp )=\log$ odds in logistic regression

c. $r=$ association

Research questions 3 -_Do the nursing competencies of caring practices and clinical judgment, have a mediating or moderating role on the frequency PSE?

The relationship of each hypothesized moderator / mediator variable was tested for independent relationship to the rate of PSE. A classic mediation model requires significant relationships among predictor, mediator, and outcome. Among the nursing competency variables, neither were predictive of PSE at the $\mathrm{p}<0.05$ level, so no mediational model can exist among these variables. The significance of level of clinician on PSE was 0.557. The significance of the lead clinician experience was 0.036 , but when 
all other insignificant variables were removed from the regression and rerun, lead clinician experience became insignificant at 0.277

Each nursing competency was then tested for moderation by using sequential regressions. Each iteration placed a different product-term of nursing competency and patient characteristic in Block 2 of the regression. As seen in Table 15 below, no significant moderation relationship was found.

Table 15 - Moderation by Nursing Competencies of the Lead Clinician

\begin{tabular}{|l|c|c|}
\hline & Licensure - B(exp) (sig) & Experience - B(exp) (sig) \\
\hline Stability & $1.050(0.224)$ & $0.994(0.679)$ \\
\hline Vulnerability & $2.615(0.210)$ & $0.907(0.725)$ \\
\hline Complexity & $1.085(0.475)$ & $0.996(0.826)$ \\
\hline Predictability & $0.000-1.039(0.809-0.999)$ & $0.851-1.589(0.285-0.997)$ \\
\hline Resiliency & $0.987(0.530)$ & $0.990(0.244)$ \\
\hline
\end{tabular}

*variable by diagnostic category

a. $\quad$ Sig $=$ significance

b. $\quad \mathrm{B}(\exp )=\log$ odds in logistic regression

Research question 4 - Do modifiable environmental factors (i.e., time outside of the ICU and mode of transport) influence the frequency of PSE during interfacility transport?

Question 4 was evaluated similarly to question 3, with potential moderators / mediators including the environmental factors of mode of transport and duration of transport. Among the environmental factors, only time was predictive of PSE. Time was then used as the dependent outcome variable in a linear regression. No patient 
characteristic was predictive of time, so no mediational model can exist among the variables.

Each environmental factor was then tested for moderation in similar approach to the nursing competency described previously. As seen in Table 16 below, no significant interaction effects were seen in either factor with any of the patient characteristic predictor variables.

$\underline{\text { Table } 16 \text { - Moderation by Environmental Factors }}$

\begin{tabular}{|c|c|c|}
\hline & Time - B(exp) (sig) & Mode - B(exp) [G, RW, FW] (sig) \\
\hline Stability & $0.999(0.940)$ & $1.034-1.056(0.643,0.432,0.499)$ \\
\hline Vulnerability & $0.869(0.664)$ & $3.238-3.283(0.334,0.165,0.448))$ \\
\hline Complexity & $0.960(0.425)$ & $1.102,1.028(0.721,0.425,0.877)$ \\
\hline Predictability & 0.000-1.039 (0.119-0.999) & {$[0.000-3.235](0.397-1.000)$} \\
\hline Resiliency & $0.997(0.789)$ & $1.018-1.022(0.674,0.388,0.761)$ \\
\hline
\end{tabular}

\section{Secondary Analyses}

Post-hoc analysis was performed using the predictor variables in the regression directly, rather than as a function of their composite score related to their theoretical constructs. Table 17 summarizes the descriptive statistics of the variables in this equation: 
$\underline{\text { Table } 17 \text { - Descriptive Statistics } 2}$

\begin{tabular}{|c|c|c|c|c|c|c|c|c|c|}
\hline \multicolumn{10}{|c|}{ Descriptive Statistics } \\
\hline & $\mathrm{N}$ & Minimum & Maximum & Mean & Std. Deviation & \multicolumn{2}{|c|}{ Skewness } & \multicolumn{2}{|c|}{ Kurtosis } \\
\hline & Statistic & Statistic & Statistic & Statistic & Statistic & Statistic & Std. Error & Statistic & Std. Error \\
\hline Patient Safety Events & 440 & 0 & 1 & .11 & .312 & 2.516 & .116 & 4.352 & .232 \\
\hline SBP (MEWS) & 440 & 0 & 2 & .39 & .630 & 1.395 & .116 & .762 & .232 \\
\hline HR (MEWS) & 440 & 0 & 3 & .67 & .979 & 1.133 & .116 & -.104 & .232 \\
\hline Hypoxia (MEWS-ad) & 440 & 0 & 4 & .24 & .850 & 3.810 & .116 & 13.578 & .232 \\
\hline GCS & 440 & 0 & 12 & 2.38 & 4.045 & 1.541 & .116 & .834 & .232 \\
\hline PEEP & 440 & 0 & 16 & 1.62 & 3.164 & 2.055 & .116 & 4.050 & .232 \\
\hline Mech VEntilation & 440 & 0 & 1 & .21 & .409 & 1.419 & .116 & .013 & .232 \\
\hline XNPPV & 440 & 0 & 1 & .05 & .209 & 4.379 & .116 & 17.257 & .232 \\
\hline XoDevices & 440 & 0 & 2 & .04 & .199 & 5.814 & .116 & 36.498 & .232 \\
\hline \# of infusions & 440 & 0 & 7 & 1.43 & 1.115 & 1.035 & .116 & 1.656 & .232 \\
\hline \# of vasoactives & 440 & 0 & 4 & .38 & .619 & 1.781 & .116 & 4.089 & .232 \\
\hline \# of lines & 440 & 0 & 5 & 1.94 & .874 & 1.148 & .116 & 1.838 & .232 \\
\hline \# of tubes & 440 & 0 & 5 & .81 & 1.068 & 1.237 & .116 & .668 & .232 \\
\hline Diagnostic category & 440 & 1 & 5 & 2.06 & 1.082 & 1.119 & .116 & .853 & .232 \\
\hline Age & 440 & 15 & 100 & 62.45 & 17.250 & -.514 & .116 & -.141 & .232 \\
\hline Level Clinician 1 & 440 & 2 & 3 & 2.31 & .463 & .829 & .116 & -1.319 & .232 \\
\hline Experience Clinician 1 & 440 & 1 & 4 & 2.34 & 1.183 & .115 & .116 & -1.518 & .232 \\
\hline Time groups & 440 & 1 & 4 & 2.48 & 1.133 & .018 & .116 & -1.394 & .232 \\
\hline Mode & 440 & 1 & 3 & 1.32 & .522 & 1.351 & .116 & .855 & .232 \\
\hline Valid N (listwise) & 440 & & & & & & & & \\
\hline
\end{tabular}

a. $\quad$ Std $=$ Standard

Two variables, number of cardiac devices and presence of NPPV, were eliminated from analysis due to insufficient variability to meet the assumptions of regression. When the remainder of the variables were placed directly into the logistic regression, hypoxia, experience of the lead clinician, and duration of transport were significant predictors of PSE at Block 1. Only hypoxia and duration of transport retained significance at Block 1 after removing all insignificant factors from the model.

Table 18 summarizes the significant results of this secondary analysis, followed by Table 19 showing regression results for all variables in the equation: 
Table 18 - Significant results of secondary analysis

\begin{tabular}{|l|c|c|}
\hline & Block 0 sig & Block 1 B(exp) (sig) \\
\hline Hypoxia & 0.025 & $1.860(0.046)$ \\
\hline Time & 0.033 & $1.864(0.025)$ \\
\hline $\begin{array}{l}\text { Experience of lead } \\
\text { clinician }\end{array}$ & 0.277 & $0.592(0.036)$ \\
\hline
\end{tabular}

a. $\quad$ Sig $=$ significance

b. $\quad \mathrm{B}(\exp )=\log$ odds in logistic regression

Table 19 - Regression results all pre-transport variables

\begin{tabular}{|c|c|c|c|c|c|c|c|}
\hline \multicolumn{8}{|c|}{ Variables in the Equation } \\
\hline & & $\mathrm{B}$ & S.E. & Wald & $\mathrm{df}$ & Sig. & $\operatorname{Exp}(\mathrm{B})$ \\
\hline \multirow[t]{22}{*}{ Step $1^{a}$} & PatientAge & -.016 & .019 & .694 & 1 & .405 & .984 \\
\hline & XSBP & -.211 & .675 & .098 & 1 & .755 & .810 \\
\hline & $\mathrm{XHR}$ & -.569 & .350 & 2.641 & 1 & .104 & .566 \\
\hline & $\mathrm{X} 2 \mathrm{SPO} 2$ & .620 & .312 & 3.964 & 1 & .046 & 1.860 \\
\hline & XGCS & .030 & .099 & .089 & 1 & .765 & 1.030 \\
\hline & XVent & -1.631 & 1.079 & 2.287 & 1 & .130 & .196 \\
\hline & XPEEP & .059 & .095 & .384 & 1 & .535 & 1.061 \\
\hline & @\#infusion & .188 & .286 & .433 & 1 & .511 & 1.207 \\
\hline & @\#vasos & .375 & .500 & .563 & 1 & .453 & 1.455 \\
\hline & @\#lines & -.332 & .302 & 1.208 & 1 & .272 & .717 \\
\hline & Q \#tubes & -.207 & .307 & .456 & 1 & .499 & .813 \\
\hline & XDxCat & & & .694 & 3 & .875 & \\
\hline & XDxCat(1) & -.502 & .696 & .520 & 1 & .471 & .605 \\
\hline & XDxCat(2) & -.512 & .889 & .331 & 1 & .565 & .599 \\
\hline & XDxCat(3) & -18.999 & 16959.304 & .000 & 1 & .999 & .000 \\
\hline & Xminutes & .623 & .279 & 4.998 & 1 & .025 & 1.864 \\
\hline & ModeCompleted & & & .986 & 2 & .611 & \\
\hline & ModeCompleted(1) & .058 & 1.447 & .002 & 1 & .968 & 1.060 \\
\hline & ModeCompleted(2) & 1.232 & 1.757 & .492 & 1 & .483 & 3.427 \\
\hline & LevClinic1 & .890 & 1.516 & .345 & 1 & .557 & 2.436 \\
\hline & XExp1 & -.524 & .249 & 4.418 & 1 & .036 & .592 \\
\hline & Constant & -1.201 & 3.450 & .121 & 1 & .728 & .301 \\
\hline
\end{tabular}

a. $\quad$ Sig $=$ significance

b. $\quad \mathrm{B}(\exp )=\log$ odds in logistic regression

Figures 4 and 5 display the frequency of PSE as a function of duration of transport (minutes). While all cases are clustered generally around the 30 to 45 -minute 
range, those cases with PSE can be visually noted to be clustered in the 40 to 60 -minute range, with many more in the greater than 60 -minute range than in the overall distribution. Figure 5 even more dramatically shows the higher frequency during longer transports by placing time into quartiles. Quartiles of time were 0-30 minutes (quartiles 1), 31-37 minutes (quartile 2), 38-54 minutes (quartile 3), and greater than 54 minutes (quartile 4). Cases without a PSE decrease for each quartile of time, while cases with PSE increase with each quartile of time.

\section{Figure 4 - Patient Safety Events per duration of transport (in minutes)}

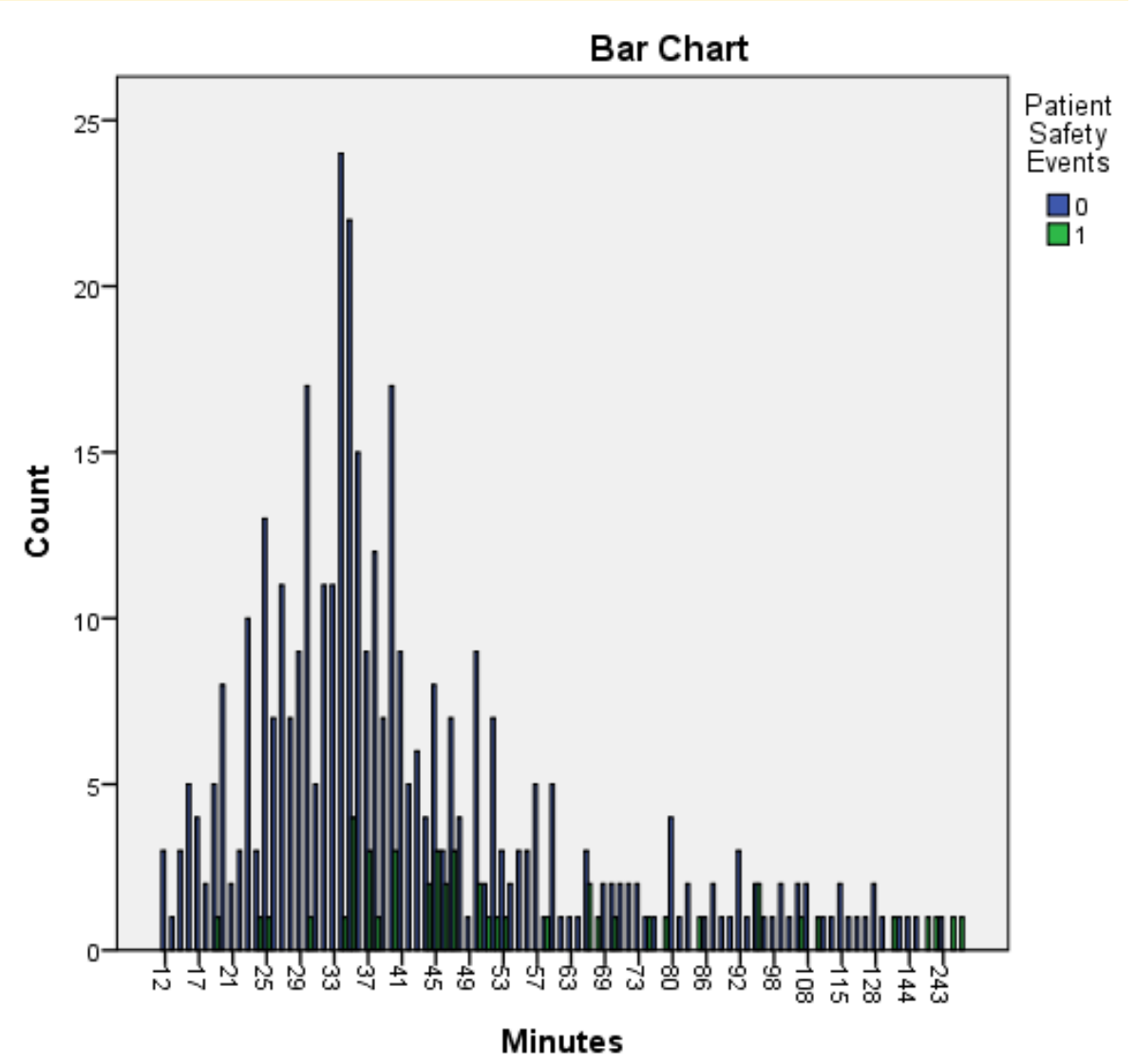


Figure 5 - Patient Safety Events per duration of transport (quartile)

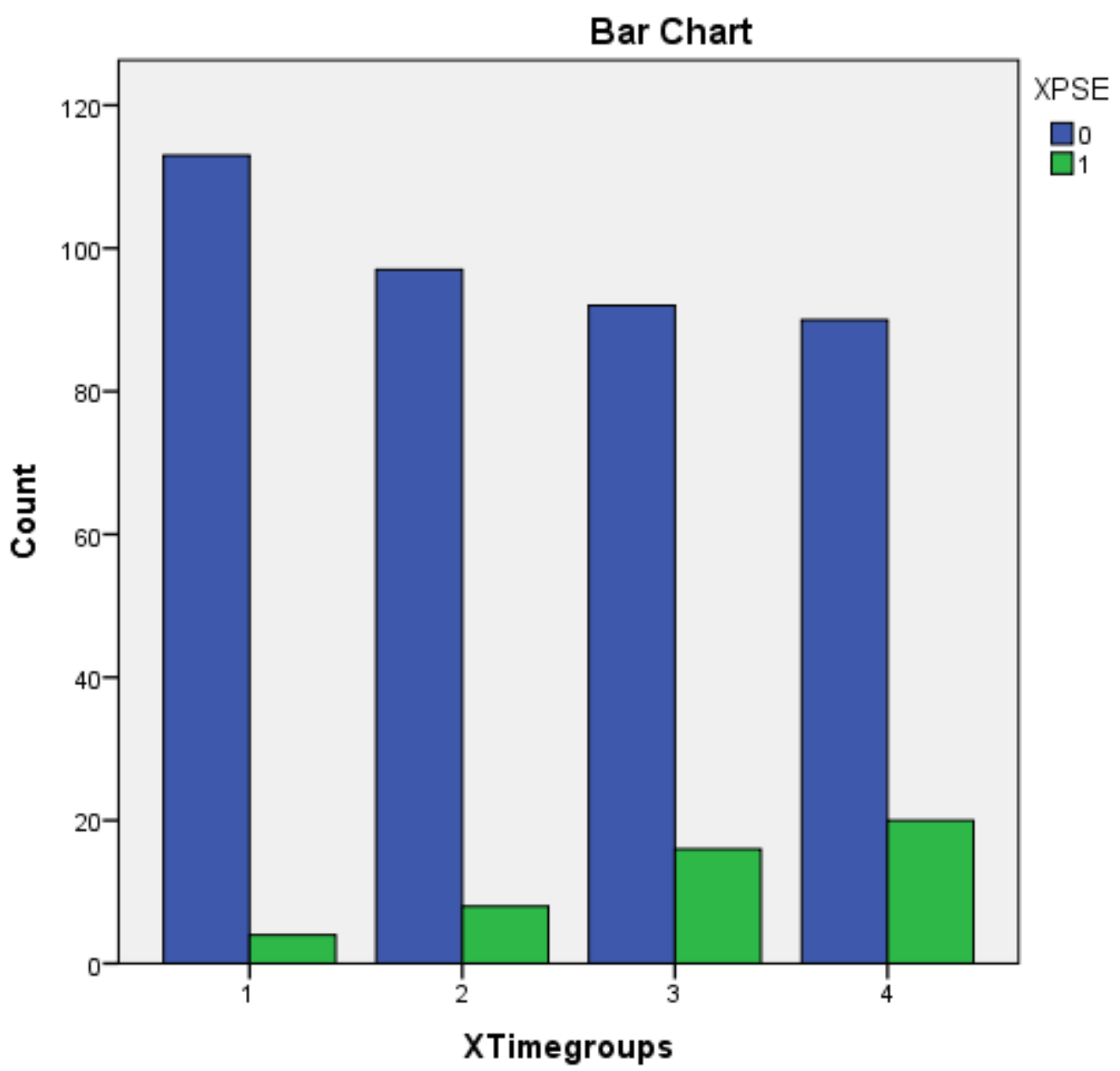

Adverse events were identified as the most frequent type of PSE. Restricting the cases to only those with PSE, the distribution of PSE to time groups in the following figure graphically shows the difference in frequency and number of PSE as a function of time quartiles. Only in the top quartile (transports greater than 60 minutes) do cases appear with more than 1 adverse event. 
Figure 6-Adverse events per time quartile

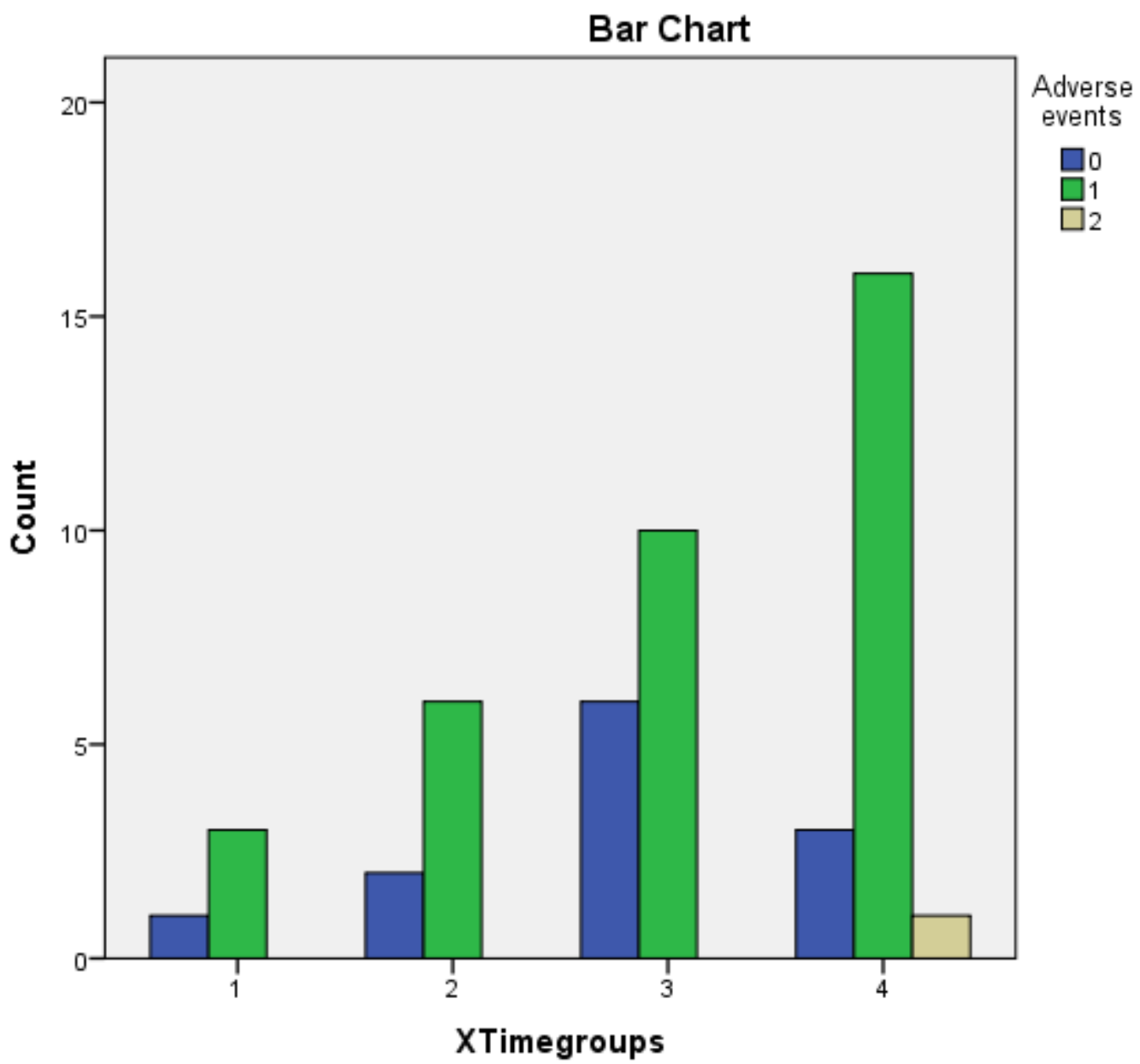

Mode of transport is commonly described in the literature as associated with more or less patient events. This study found that it was actually duration of transport, rather than mode of transport, that remained predictive for PSE when all factors were considered and controlled for. Table 20 below summarizes the duration of transport in quartiles as a function of each mode of transport. In this table, mode 1 is ground, mode 2 
is helicopter, and mode 3 is fixed wing aircraft. All fixed wing flights were in time quartile 4. Ground and helicopter transports were more evenly distributed among the time categories. The mean duration of ground transport was 44 minutes; the mean duration of helicopter transport was 43 minutes; and the mean duration of fixed wing transport was 198 minutes. The overall mean duration of transport across all modes was 48 minutes.

Table 20 - Duration of transport as a function of mode of transport

\begin{tabular}{|c|c|c|c|c|c|c|c|}
\hline \multicolumn{8}{|c|}{ Mode * Time groups Crosstabulation } \\
\hline & & & \multicolumn{4}{|c|}{ Time groups } & \multirow[b]{2}{*}{ Total } \\
\hline & & & 1 & 2 & 3 & 4 & \\
\hline \multirow[t]{12}{*}{ Mode } & 1 & Count & $81 \mathrm{a}, \mathrm{b}$ & $81 b$ & $79 a, b$ & $71 \mathrm{a}$ & 312 \\
\hline & & $\%$ within Mode & $26.0 \%$ & $26.0 \%$ & $25.3 \%$ & $22.8 \%$ & $100.0 \%$ \\
\hline & & $\%$ within Time groups & $69.2 \%$ & $77.1 \%$ & $73.1 \%$ & $64.5 \%$ & $70.9 \%$ \\
\hline & & $\%$ of Total & $18.4 \%$ & $18.4 \%$ & $18.0 \%$ & $16.1 \%$ & $70.9 \%$ \\
\hline & 2 & Count & $36 a$ & $24 a$ & $29 a$ & $27 a$ & 116 \\
\hline & & $\%$ within Mode & $31.0 \%$ & $20.7 \%$ & $25.0 \%$ & $23.3 \%$ & $100.0 \%$ \\
\hline & & $\%$ within Time groups & $30.8 \%$ & $22.9 \%$ & $26.9 \%$ & $24.5 \%$ & $26.4 \%$ \\
\hline & & $\%$ of Total & $8.2 \%$ & $5.5 \%$ & $6.6 \%$ & $6.1 \%$ & $26.4 \%$ \\
\hline & 3 & Count & $0 a$ & $0 a$ & $0 a$ & $12 b$ & 12 \\
\hline & & $\%$ within Mode & $0.0 \%$ & $0.0 \%$ & $0.0 \%$ & $100.0 \%$ & $100.0 \%$ \\
\hline & & $\%$ within Time groups & $0.0 \%$ & $0.0 \%$ & $0.0 \%$ & $10.9 \%$ & $2.7 \%$ \\
\hline & & $\%$ of Total & $0.0 \%$ & $0.0 \%$ & $0.0 \%$ & $2.7 \%$ & $2.7 \%$ \\
\hline \multirow[t]{4}{*}{ Total } & & Count & 117 & 105 & 108 & 110 & 440 \\
\hline & & $\%$ within Mode & $26.6 \%$ & $23.9 \%$ & $24.5 \%$ & $25.0 \%$ & $100.0 \%$ \\
\hline & & $\%$ within Time groups & $100.0 \%$ & $100.0 \%$ & $100.0 \%$ & $100.0 \%$ & $100.0 \%$ \\
\hline & & $\%$ of Total & $26.6 \%$ & $23.9 \%$ & $24.5 \%$ & $25.0 \%$ & $100.0 \%$ \\
\hline
\end{tabular}
a. Mode 1 = ground, 2 = rotor wing, 3 = fixed wing
b. Time quartile $1=0-30$ minutes, $2=31-37$ minutes, $3=38-54$ minutes, $4=>54$ minutes 
In summary, primary analyses found the null hypothesis model (Model 0) began with an overall predicted percentage correct estimation of $89.1 \%$. Stability, complexity, and vulnerability were significantly correlated with frequency of PSE. Logistic regression with simultaneous entry resulted in only stability remaining significant, and that only at the $p<0.10$ level. This model had a predictive value of $90.0 \%$, a significant omnibus test of the model confirmed with an insignificant Hosmer and Lemeshow test $(\mathrm{p}=0.911)$, and a pseudo r-square value (using Nagelkerke's R Square) of 0.199.

Secondary analysis found pre-transport hypoxia, a component of stability, and time to be the most consistent predictors of PSE. Odds of a patient safety event during transport were 1.86 times greater for patients who suffered pre-transport hypoxia, and 1.86 times greater for patients with greater transport times. 


\section{Chapter 5: Conclusions, Recommendations, and Implications}

\section{Discussion}

This study found an overall rate of patient safety events of $2.65 \%$, with an adverse event rate of $1.88 \%$. This rate is similar to the MacDonald (2008) study that found a $1.15 \%$ adverse event rate with taxonomy and definitions very similar to those used here. As discussed previously, one difficulty in comparing studies was the lack of formalized taxonomy of PSE and the mixture of safety and quality events reported in the majority of studies. Similar findings to the MacDonald study support the proposition that standardized taxonomy is required for adequate benchmarking and improvement of patient safety across all CCT.

Adverse events were the most common type of PSE found, and new or recurrent hypoxia was the most common type of adverse event. New or recurrent hypoxia meets the definition of adverse event, and is now specifically tracked through reporting of Air Medical Physician Association metrics to accreditation bodies, but was not specifically tracked in most studies in the literature. For example, Singh $(2009,2014)$ tracked interventions related to critical events rather than the alteration in oxygen saturation that triggered the intervention, i.e. needle decompression and airway maneuvers were tracked, but the hypoxic states or pathologies that triggered the responses were not tracked. Of note, the hypoxic adverse event was accepted as reported in this study. Providing the inclusion criteria was met, no secondary analysis was done to discriminate if the new or recurrent hypoxia was a progression of the patient's current illness, i.e. a quality event, or 
related to inadequate planning, execution of the treatment plan, or other safety-related cause.

Mechanical equipment failures were the next most reported PSE at $16 \%$ of events and this is also consistent with other studies (Droogh et al., 2012; Flabouris et al., 2006; Wiegersma et al., 2011). Despite significant recent improvements in transport equipment technology, equipment failure remains a frequent source of frustration for CCT teams. This study found equipment failure a factor in adverse events, hazardous conditions, and near-misses. The value of $16 \%$ is consistent with the literature where equipment failures ranged from $7.5 \%$ to $37 \%$. Both transports with two reported PSE included an equipment failure suggesting that equipment failure may lead to additional PSE.

Regression analysis identified no patient characteristics significant at the $\mathrm{p}<0.05$ level, and stability as the only significant predictor of intra-transport PSE at the $\mathrm{p}<0.10$ level. Not surprisingly, post-hoc analysis also found the only significant predictor of adverse event was hypoxia, a component of stability. No significant mediator or moderator influences were found in primary analyses; however, experience of the lead clinician was found to have a significant primary effect on pre-transport hypoxia in secondary analysis. This finding is suggestive that patients at increased risk for PSE as a result of instability, specifically pre-transport hypoxia, may benefit from selection of a more experienced lead clinician, but further study is warranted since experience level of the lead clinician did not retain significance when all other insignificant factors were removed from the regression model. Team members' total team experience was not 
evaluated and that may have been a critical factor in determining if a team is experienced, rather than focusing on the lead clinician.

Duration of transport and mode of transport dominate the literature as primary means of avoiding safety events and negative quality events during transport. Though environmental factors were not treated as predictor variables in this study, secondary analysis did find that duration of transport was significantly associated with frequency of PSE $(p=0.000)$. Numerous permutations of the variables were run, grouping variables differently, and time and hypoxia consistently showed the most predictive power for PSE. Regression analysis found that neither duration of transport nor mode of transport played a moderating role in the relationship between any patient characteristics and frequency of PSE, possibly as a result of time's strong main effects. Future studies may wish to study further the direct effects of duration of transport on rate of PSE in the setting of other significant predictors.

\section{Limitations}

While this study added to the existing knowledge about inter-facility transport, there are several limitations as a result of threats to both internal and external validity. Threats to internal validity came from instrumentation, sampling, and mode / clinician selection bias. The records used in this study were reports generated by clinicians. Clinicians may not self-report PSE, and data suggest that self-reports of near misses are least likely to be reported. However, this project used processes that have been accepted by peers and experts in other reports and is a reasonable initial study for identifying PSE during inter- 
facility transport in the U.S., particularly in determining new information about the influence of the role of the APN in CCT on frequency of PSE. Using consecutive samples over a few months may not represent the full occurrence of PSE in a year-long or even several-year sampling. This study has the increased potential for sampling bias related to the study timing occurring entirely during the winter months in northeast Ohio, where weather may be a factor related to PSE, both independently and indirectly through its effects on staff, crew configuration, mode selection, and time outside the ICU. However, this is an early study that provides information about the feasibility of collecting this type of data and the initial applicability of applying a standard tool about PSE in CCT. It is a reasonable approach for an early study.

Another limitation is that transport mode was selected based on the assessment of the referring physician, an RN Clinical Coordinator, and the receiving physician; the mode of transportation is not randomly assigned. Patients transported by helicopter tend to be further in distance and higher acuity patients, and always have a Licensed Independent Provider (APN or physician) leading the team, while patients transported by ground tend to be closer in distance (though not necessarily time), lower acuity, and are routinely but not exclusively led by a Registered Nurse. A Licensed Independent Provider always leads patients transported by jet, but the level of acuity is highly variable.

Threats to external validity come from team composition, clinician / mode selection method, and mean patient acuity in this setting. Few CCT teams offer multi-modal service and multiple levels of clinician based on patient need, thus limiting generalizability. Few teams offer advanced practice clinicians or physicians, further 
limiting generalizability. Finally, this large quaternary institution is established as a referral destination when other facilities cannot offer further possible intervention, elevating the acuity level beyond those of typical CCT teams across the country. However, the very uniqueness of this setting and CCT team composition is a compelling reason for further investigation in that there is a large volume of transports (greater than 500/month) and variety of clinicians to provide important new information to CCT.

As stated in Chapter 1, this study makes several assumptions that threaten internal validity. It is assumed that clinicians accurately and honestly record patient data, and report the occurrence of patient safety events similarly. The air medical industry in general, and this CCT team specifically, maintains a stated support for a culture of safety. Culture of safety provides mechanisms to identify hazardous conditions and patient events without fear of reprisals to facilitate continuous quality and safety improvement. The PI does not have a day-to-day oversight of PSE. Patient safety events are identified and managed by a Quality improvement officer and team and this structure has been in place for several years.

Implications for Nursing

This study had some findings that were unique, and some that were quite consistent with those of other studies. Nurse educators may wish to incorporate these preliminary findings into transport nursing education. One of the most commonly cited reasons for using helicopter transport on complex patients is to decrease the time outside the ICU, even when no time-sensitive intervention is waiting at the receiving institution. 
Experienced clinicians in transport recognize that the longer you have an unstable patient outside the hospital, the higher the likelihood something will go wrong. Further studies should focus on validating the influence of time outside the ICU, better discriminating which pre-transport variables, such as hypoxia and mechanical ventilation, present increased risk as a factor of time, not merely as a factor of their current hemodynamic status.

Pre-transport hypoxia and increased duration of transport were the strongest predictors of intra-transport PSE in secondary analysis. Experience of the lead clinician may moderate the increased risk of intra-transport PSE resulting from pre-transport hypoxia, but this was not conclusive. The ability to vary the level or experience of the lead clinician based on patient characteristics is not a common practice throughout the country. CCT teams tend to have defined crew configurations, a one-size-fits-all philosophy concerning the appropriateness of crew configuration to each mission, and a standard operating procedure of sending the closest available transport team. This study indicates that it may not be enough to stratify patients between BLS, ALS, and critical care, but patients may be better served by further stratification into levels of critical care. The newest $\left(10^{\text {th }}\right.$ edition $)$ standards from the Commission for Accreditation of Medical Transport Systems (CAMTS) has begun to recognize these differences, and accredit agencies at different levels of critical care capability. If patients are triaged accordingly, this study lends early support to the premise that different levels of critical care agency may be more appropriate for different patients. Future studies should further investigate 
the mitigating role of clinician experience, and include the degree of experience of the second clinician, not evaluated in this study.

Portable transport equipment was recognized as a significant issue for patient safety and quality in the earliest reports of CCT, and continue to be concerning despite numerous advances in technology. The overall strategy for mitigation of risk during transport is to reproduce the stable conditions inside the ICU to every extent possible during transport. Professional guidelines indicate the level of care provided to the patient should not decrease during transport. Failure of transport monitors to display waveforms, or failure of transport pumps to administer medications serves to decrease the level of care by lowering the capability to monitor or provide intervention. Higher standards in transport equipment manufacture, and lower failure rates, should be advocated.

The cost of decreasing time outside the ICU is not inexpensive. Helicopter transport between two facilities may cost 10-times more than a Mobile ICU for the same transport. Increasing insurance scrutiny is pushing the transport industry to utilize helicopter transport less frequently without a clear, evidence-based rationale. While it is hoped that increasing the level and experience of transport clinicians may mitigate the impact of time, this hypothesis has not yet been clearly substantiated in research. Public policy should address this inequity in the form of CMS reimbursement for air transport of at-risk patients. Continued research should address matching pre-transport patient characteristics with transport resources, and public policy must be encouraged to support the premise of patient safety through evidence-based reimbursement practices. 
Conclusion

This study was a descriptive correlational retrospective review of charts to determine the incidence of PSE in CCT (purpose). Significant findings in primary analyses included a PSE rate of 2.65\%. Intra-transport hypoxia was the most common PSE. Pre-transport hypoxia and duration of transport were the strongest predictors of intra-transport PSE in secondary analysis. These findings suggest that risk for hypoxia should be considered when training and assigning CCT teams. Additional findings suggest that the experience of the lead clinician for a CCT team may moderate the frequency of PSE related to new or recurrent hypoxia in the critically ill adult, particularly during longer transports. Neither mode of transport nor licensure of the lead clinician (RN versus APN) was associated with PSE in this study. These findings may have implications for policy and reimbursement. 
Figure 1 - Research Model

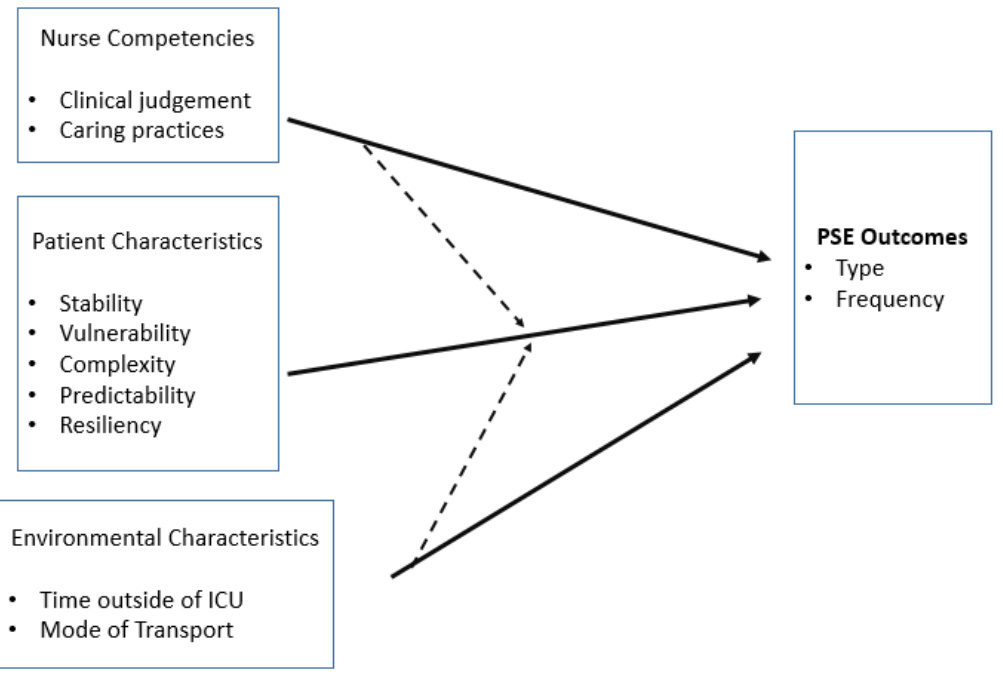

Research Model Based on Adaptation of AACN Synergy Model 
Figure 2 - Theoretical Framework

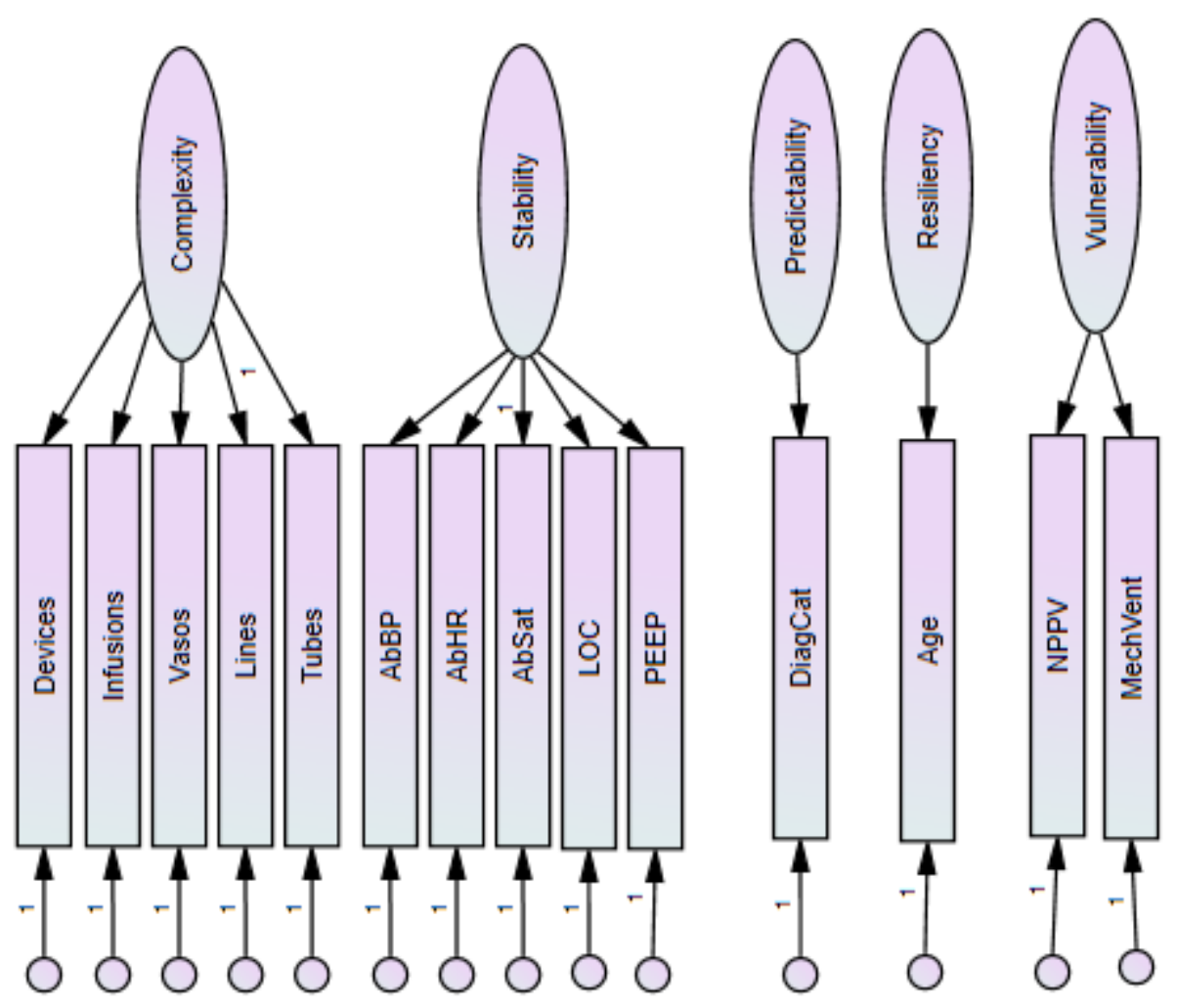


Figure 3 - CONSORT Diagram

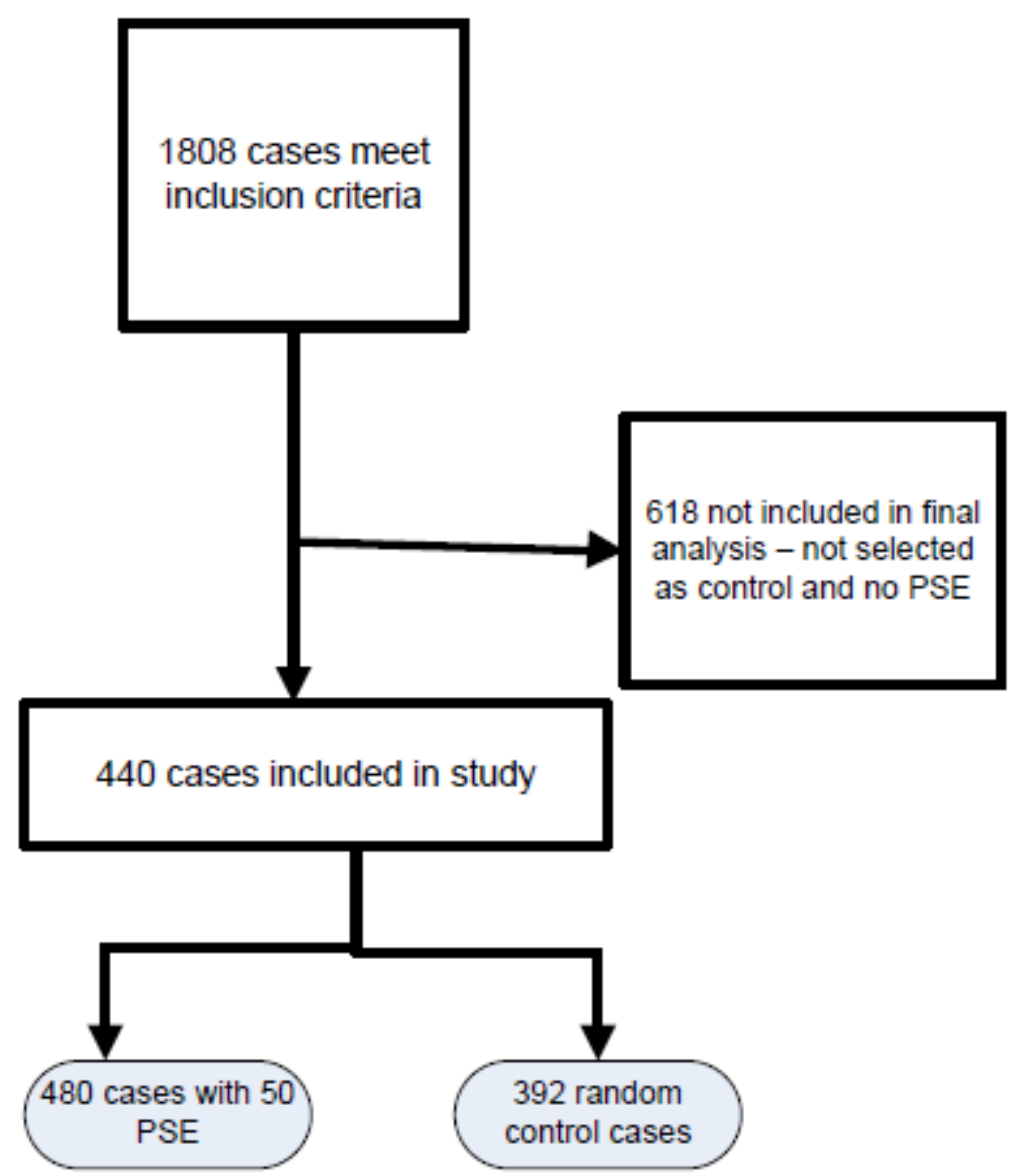




\section{Figure 6 - Patient Safety Event / Quality Reporting Record}

1. Did the patient have an advanced airway?

2. If the patient had an advanced airway, Was the patient supported by a mechanical ventilator during transport?

3. If the patient had an advanced airway, Was waveform capnography utilized during transport?

(Documentation of capnography plus at least 1 of the following: direct visualization, chest radiography, or symmetric breath sounds)

4. If the patient had an advanced airway, Was confirmation of tracheal tube placement documented in the CCT chart (regardless of whether or not tracheal tube was placed by СCT)?

5. If the patient had an advanced airway, Was the advanced airway placed by CCT?

6. If the patient had an advanced airway placed by CCT, was placement successful with first attempt?

(First attempt is defined as the insertion of a laryngoscope or in the insertion of any bougie or airway device past the lips.)

7. If the patient had an advanced airway placed by CCT, was placement successful with first attempt without hypoxia/hypotension?

(Hypoxia is defined as oxygen saturation newly falling below 90\%. Hypotension is defined as SBP in adults $<90 \mathrm{mmHg}$ and $S B P<5$ percentile in children $<16$ years of age.)

8. Reliable pain assessment completed using an age-appropriate pain scale?

9. Unplanned dislodgement of therapeutic devices during transport?

(IO, IV, central venous line, arterial line, advanced airway, chest tube, and tracheostomy tubes. This does NOT include intravenous or peripheral intravenous devices that infiltrate without 
obvious dislodgement.)

10. Hypoxia during transport?

(Define as the pulse ox reading dropping below $90 \%$. However if the patient is chronically low or is $<90 \%$ when contact is made, the patient is ONLY included when the saturation is corrected to be $>90 \%$ and falls again.)

11. CPR performed during transport?

12. Standardized patient care handoff utilized?

13. Did the patient have altered mental status?

(GCS $<15$ or focal neurologic deficit with suspicion of stroke.)

14. If the patient had altered mental status, was a blood glucose check completed? (GCS $<15$ or focal neurologic deficit with suspicion of stroke. A blood glucose check includes those checks by the transport team or prior to transport team arrival if reviewed and documented by the transport team.)

15. Diagnosis of Aortic Emergency?

16. Appropriate management of blood pressure for aortic emergencies? (Known or suspected aortic dissection with $H R<60$ and SBP $<120 \mathrm{mmHg}$ OR documented interventions during transport aimed at achieving these parameters.)

17. Diagnosis of hemorrhagic stroke?

18. Appropriate management of blood pressure for hemorrhagic stroke? (Hemorrhagic stroke is defined as non-traumatic, ICH identified on CT or MRI with goal $S B P<160$ or $20 \%$ less than initial MAP for initial SBP $>200$ at transfer of care to the receiving hospital)

19. Diagnosis of hemorrhagic shock? 
20. Appropriate management of hemorrhagic shock?

(Defined as hemorrhage control measure are initiate if applicable, IV administration of blood products if available, and IV fluid resuscitation meeting the following: 1. Signs of adequate tissue perfusion; 2 . SBP $>=70+2 x$ age (years) or $>=90$ or MAP $>65$; 3 . Maximum of 2 liters in adults of $40 \mathrm{cc} / \mathrm{kg}$ in children $<16$ years of age.)

\section{Transport-related patient injuries?}

\section{Transport-related crew injuries?}

\section{Adverse drug event during transport?}

24. Medical equipment failure during transport?

(Examples: IV pumps, ventilator malfunction, monitor, empty medical gas tanks, etc.)

\section{Patient near-miss or precursor adverse events?}

(Near-miss events are deviations from generally accepted performance standards that occurred but did not "reach" the patient. Precursor adverse events are deviations from generally accepted performance standards that reach the patient but result in NO harm or minimal, temporary patient harm. Excluded are injuries and deaths related to the medical/surgical conditions themselves. Examples: patient falls, loose pieces of transport equipment that fall and strike the patient, injuries suffered in a transport vehicle accident, etc.)

\section{Hazardous Condition?}

(Any circumstance or condition that increases the probability of an adverse event)

27. Was this trip delayed or cancelled due to a risk assessment score? (If yes, file SIRF.)

\section{Medication administration error during transport?}


$\underline{\text { Figure } 8 \text { - Combined data collection record }}$

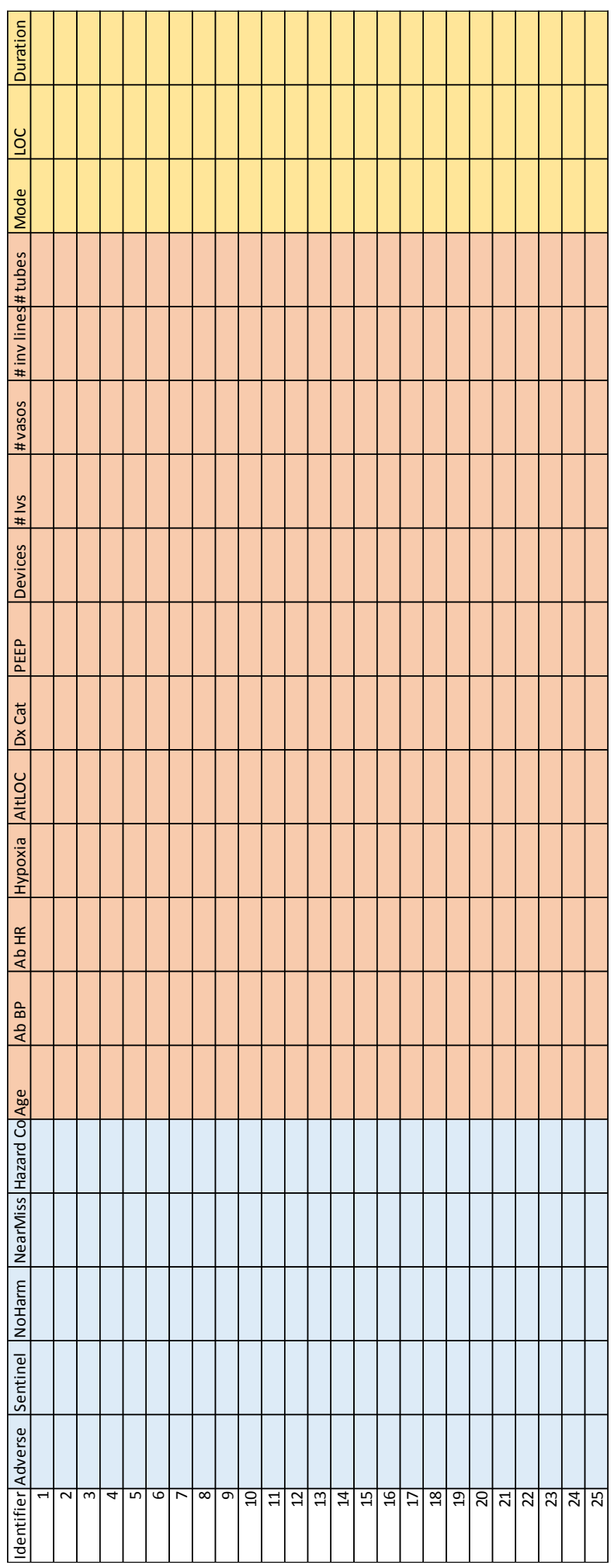


References

. (2013). In P. Velentgas, N. A. Dreyer, P. Nourjah, S. R. Smith, \& M. M. Torchia (Eds.), Developing a Protocol for Observational Comparative Effectiveness Research: A User's Guide. Rockville (MD).

Alligood, M. R., \& Marriner-Tomey, A. (2010). Nursing theorists and their work (7th ed.). Maryland Heights, Mo.: Mosby/Elsevier.

Andrews, L. B., Stocking, C., Krizek, T., Gottlieb, L., Krizek, C., Vargish, T., \& Siegler, M. (1997). An alternative strategy for studying adverse events in medical care. Lancet, 349(9048), 309-313. doi:10.1016/S0140-6736(96)08268-2

Anthes, A. M., Harinstein, L. M., Smithburger, P. L., Seybert, A. L., \& Kane-Gill, S. L. (2013). Improving adverse drug event detection in critically ill patients through screening intensive care unit transfer summaries. Pharmacoepidemiol Drug Saf, 22(5), 510-516. doi:10.1002/pds.3422

Association, A. H. (1999). Hospital Statistics. Retrieved from Chicago:

Baron, R. M., \& Kenny, D. A. (1986). The moderator-mediator variable distinction in social psychological research: conceptual, strategic, and statistical considerations. J Pers Soc Psychol, 51(6), 1173-1182. Retrieved from http://www.ncbi.nlm.nih.gov/pubmed/3806354

Brennan, T. A., \& Leape, L. L. (1991). Adverse events, negligence in hospitalized patients: results from the Harvard Medical Practice Study. Perspect Healthc Risk 
Manage, 11(2), 2-8. Retrieved from

http://www.ncbi.nlm.nih.gov/pubmed/10109934

Brennan, T. A., Leape, L. L., Laird, N. M., Hebert, L., Localio, A. R., Lawthers, A.

G., . . Hiatt, H. H. (1991). Incidence of adverse events and negligence in hospitalized patients. Results of the Harvard Medical Practice Study I. $N$ Engl $J$ Med, 324(6), 370-376. doi:10.1056/NEJM199102073240604

Bryant, M. T. (2004). The portable dissertation advisor. Thousand Oaks, Calif.: Corwin Press.

Burns, N., \& Grove, S. K. (2009). The practice of nursing research : appraisal, synthesis, and generation of evidence (6th ed.). St. Louis, Mo.: Saunders/Elsevier.

Chang, A., Schyve, P. M., Croteau, R. J., O'Leary, D. S., \& Loeb, J. M. (2005). The JCAHO patient safety event taxonomy: a standardized terminology and classification schema for near misses and adverse events. Int J Qual Health Care, 17(2), 95-105. doi:10.1093/intqhe/mzi021

Classen, D. C., Resar, R., Griffin, F., Federico, F., Frankel, T., Kimmel, N., . . James, B. C. (2011). 'Global trigger tool' shows that adverse events in hospitals may be ten times greater than previously measured. Health Aff (Millwood), 30(4), 581-589. doi:10.1377/hlthaff.2011.0190

Code for nurses with interpretive statements. (1985). ANA Publ(G-56), 1-17. Retrieved from http://www.ncbi.nlm.nih.gov/pubmed/3849268 
Commission, T. J. (2015, July 1, 2015). Patient Safety Systems (PS). Retrieved from http://www.jointcommission.org/patient safety systems chapter for the hospita 1 program/

Cook, D., Brower, R., Cooper, J., Brochard, L., \& Vincent, J. L. (2002). Multicenter clinical research in adult critical care. Crit Care Med, 30(7), 1636-1643. Retrieved from http://www.ncbi.nlm.nih.gov/pubmed/12130991

Coombs, M., Chaboyer, W., \& Sole, M. L. (2007). Advanced nursing roles in critical care--a natural or forced evolution? J Prof Nurs, 23(2), 83-90. doi:10.1016/j.profnurs.2006.07.003

The Critical Care Transport Standards Project. (2012). Retrieved from Association for Critical Care Transport website:

http://www.nasemso.org/Projects/GovernmentAffairs/documents/AACTMedPAC Sept2012.pdf Retrieved from http://www.nasemso.org/Projects/GovernmentAffairs/documents/AACTMedPAC $\underline{\text { Sept2012.pdf }}$

Croft, L. D., Harris, A. D., Pineles, L., Langenberg, P., Shardell, M., Fink, J. C., . . Gown, B. P. I. (2015). The Effect of Universal Glove and Gown Use on Adverse Events in Intensive Care Unit Patients. Clin Infect Dis. doi:10.1093/cid/civ315

Doring, B. L., Kerr, M. E., Lovasik, D. A., \& Thayer, T. (1999). Factors that contribute to complications during intrahospital transport of the critically ill. J Neurosci Nurs, 31(2), 80-86. Retrieved from http://www.ncbi.nlm.nih.gov/pubmed/14964607 
Droogh, J. M., Smit, M., Hut, J., de Vos, R., Ligtenberg, J. J., \& Zijlstra, J. G. (2012). Inter-hospital transport of critically ill patients; expect surprises. Crit Care, 16(1), R26. doi:10.1186/cc11191

Edge, W. E., Kanter, R. K., Weigle, C. G., \& Walsh, R. F. (1994). Reduction of morbidity in interhospital transport by specialized pediatric staff. Crit Care Med, 22(7), 1186-1191. Retrieved from http://www.ncbi.nlm.nih.gov/pubmed/8026211

Fairchild, A. J., \& MacKinnon, D. P. (2009). A general model for testing mediation and moderation effects. Prev Sci, 10(2), 87-99. doi:10.1007/s11121-008-0109-6

Fanara, B., Manzon, C., Barbot, O., Desmettre, T., \& Capellier, G. (2010). Recommendations for the intra-hospital transport of critically ill patients. Crit Care, 14(3), R87. doi:10.1186/cc9018

Flabouris, A., Runciman, W. B., \& Levings, B. (2006). Incidents during out-of-hospital patient transportation. Anaesth Intensive Care, 34(2), 228-236. Retrieved from http://www.ncbi.nlm.nih.gov/pubmed/16617646

Fried, M. J., Bruce, J., Colquhoun, R., \& Smith, G. (2010). Inter-hospital transfers of acutely ill adults in Scotland. Anaesthesia, 65(2), 136-144. doi:10.1111/j.13652044.2009.06165.x

Gillman, L., Leslie, G., Williams, T., Fawcett, K., Bell, R., \& McGibbon, V. (2006). Adverse events experienced while transferring the critically ill patient from the emergency department to the intensive care unit. Emerg Med J, 23(11), 858-861. doi:10.1136/emj.2006.037697 
Greene, M. J. (2014). 2014 critical care transport workplace and salary survey. Air Med J, 33(6), 257-264. doi:10.1016/j.amj.2014.09.008

Griffin FA, R. R. (2009). IHI Global Trigger Tool for Measuring Adverse Events Cambridge, MA: Institute for Healthcare Improvement.

Hardin, S. R., \& Kaplow, R. (2005). Synergy for clinical excellence : the AACN synergy model for patient care. Sudbury, Mass.: Jones and Bartlett.

Hulley, S. B. (2007). Designing clinical research (3rd ed.). Philadelphia, PA: Lippincott Williams \& Wilkins.

Ilan, R., \& Fowler, R. (2005). Brief history of patient safety culture and science. J Crit Care, 20(1), 2-5. Retrieved from http://www.ncbi.nlm.nih.gov/pubmed/16015510

James, J. T. (2013). A new, evidence-based estimate of patient harms associated with hospital care. J Patient Saf, 9(3), 122-128. doi:10.1097/PTS.0b013e3182948a69

Kanter, R. K., \& Tompkins, J. M. (1989). Adverse events during interhospital transport: physiologic deterioration associated with pretransport severity of illness. Pediatrics, 84(1), 43-48. Retrieved from http://www.ncbi.nlm.nih.gov/pubmed/2740177

Kaplan, H. S., Battles, J. B., Van der Schaaf, T. W., Shea, C. E., \& Mercer, S. Q. (1998). Identification and classification of the causes of events in transfusion medicine. Transfusion, 38(11-12), 1071-1081. Retrieved from http://www.ncbi.nlm.nih.gov/pubmed/9838940 
Kohn, L. T., Corrigan, J., Donaldson, M. S., \& Institute of Medicine (U.S.). Committee on Quality of Health Care in America. (1999). To err is human : building a safer health system. Washington, D.C.: National Academy Press.

Kohn, L. T., Corrigan, J., Donaldson, M. S., \& Institute of Medicine (U.S.). Committee on Quality of Health Care in America. (2000). To err is human building a safer health system. Retrieved from http://books.nap.edu/books/0309068371/html/

Kue, R., Brown, P., Ness, C., \& Scheulen, J. (2011). Adverse clinical events during intrahospital transport by a specialized team: a preliminary report. Am J Crit Care, 20(2), 153-161; quiz 162. doi:10.4037/ajcc2011478

Lahner, D., Nikolic, A., Marhofer, P., Koinig, H., Germann, P., Weinstabl, C., \& Krenn, C. G. (2007). Incidence of complications in intrahospital transport of critically ill patients--experience in an Austrian university hospital. Wien Klin Wochenschr, 119(13-14), 412-416. doi:10.1007/s00508-007-0813-4

Lee, L. L., Yeung, K. L., Lo, W. Y., Lau, Y. S., Tang, S. Y., \& Chan, J. T. (2008). Evaluation of a simplified therapeutic intervention scoring system (TISS-28) and the modified early warning score (MEWS) in predicting physiological deterioration during inter-facility transport. Resuscitation, 76(1), 47-51. doi:10.1016/j.resuscitation.2007.07.005

Ligtenberg, J. J., Arnold, L. G., Stienstra, Y., van der Werf, T. S., Meertens, J. H., Tulleken, J. E., \& Zijlstra, J. G. (2005). Quality of interhospital transport of critically ill patients: a prospective audit. Crit Care, 9(4), R446-451. doi:10.1186/cc3749 
Lovell, M. A., Mudaliar, M. Y., \& Klineberg, P. L. (2001). Intrahospital transport of critically ill patients: complications and difficulties. Anaesth Intensive Care, 29(4), 400-405. Retrieved from http://www.ncbi.nlm.nih.gov/pubmed/11512652

Maass, C., Kuske, S., Lessing, C., \& Schrappe, M. (2015). Are administrative data valid when measuring patient safety in hospitals? A comparison of data collection methods using a chart review and administrative data. Int J Qual Health Care, 27(4), 305-313. doi:10.1093/intqhe/mzv045

MacDonald, R. D., Banks, B. A., \& Morrison, M. (2008). Epidemiology of adverse events in air medical transport. Acad Emerg Med, 15(10), 923-931. doi:10.1111/j.1553-2712.2008.00241.x

Markakis, C., Dalezios, M., Chatzicostas, C., Chalkiadaki, A., Politi, K., \& Agouridakis, P. J. (2006). Evaluation of a risk score for interhospital transport of critically ill patients. Emerg Med J, 23(4), 313-317. doi:10.1136/emj.2005.026435

Marriner-Tomey, A., \& Alligood, M. R. (2002). Nursing theorists and their work (5th ed.). St. Louis, Mo.: Mosby.

Miranda, D. R., de Rijk, A., \& Schaufeli, W. (1996). Simplified Therapeutic Intervention Scoring System: the TISS-28 items--results from a multicenter study. Crit Care Med, 24(1), 64-73. Retrieved from http://www.ncbi.nlm.nih.gov/pubmed/8565541

Nightingale, F. (1860). Notes on nursing what it is, and what it is not (New ed.). London: Harrison. 
Nightingale, F. (1863). Notes on hospitals (3d ed.). London,: Longman, Green, Longman, Roberts, and Green.

Ott, L. K., Hoffman, L. A., \& Hravnak, M. (2011). Intrahospital Transport to the Radiology Department: Risk for Adverse Events, Nursing Surveillance, Utilization of a MET and Practice Implications. J Radiol Nurs, 30(2), 49-52. doi:10.1016/j.jradnu.2011.02.001

Papson, J. P., Russell, K. L., \& Taylor, D. M. (2007). Unexpected events during the intrahospital transport of critically ill patients. Acad Emerg Med, 14(6), 574-577. doi:10.1197/j.aem.2007.02.034

Parmentier-Decrucq, E., Poissy, J., Favory, R., Nseir, S., Onimus, T., Guerry, M. J., . . . Mathieu, D. (2013). Adverse events during intrahospital transport of critically ill patients: incidence and risk factors. Ann Intensive Care, 3(1), 10. doi:10.1186/2110-5820-3-10

Patterson, P. D., Lave, J. R., Weaver, M. D., Guyette, F. X., Arnold, R. M., Martin-Gill, C., ... Yealy, D. M. (2014). A comparative assessment of adverse event classification in the out-of-hospital setting. Prehosp Emerg Care, 18(4), 495-504. doi:10.3109/10903127.2014.916022

Perrow, C. (1984). Normal accidents : living with high-risk technologies. New York: Basic Books.

Peterson, S. J., \& Bredow, T. S. (2009). Middle range theories : application to nursing research (2nd ed.). Philadelphia: Wolters Kluwer Health/Lippincott Williams \& Wilkins. 
Physicians, A. C. o. E. (2006). Interfacility transportation of the critical care patient and its medical direction. Ann Emerg Med, 47(3), 305. doi:10.1016/j.annemergmed.2005.11.006

Prevention, C. f. D. C. a. (1999). (47(25)).

Quenot, J. P., Milesi, C., Cravoisy, A., Capellier, G., Mimoz, O., Fourcade, O., \& Gueugniaud, P. Y. (2012). Intrahospital transport of critically ill patients (excluding newborns) recommendations of the Societe de Reanimation de Langue Francaise (SRLF), the Societe Francaise d'Anesthesie et de Reanimation (SFAR), and the Societe Francaise de Medecine d'Urgence (SFMU). Ann Intensive Care, 2(1), 1. doi:10.1186/2110-5820-2-1

Reason, J. (1990). The contribution of latent human failures to the breakdown of complex systems. Philos Trans R Soc Lond B Biol Sci, 327(1241), 475-484. Retrieved from http://www.ncbi.nlm.nih.gov/pubmed/1970893

Reason, J. (1995). Understanding adverse events: human factors. Qual Health Care, 4(2), 80-89. Retrieved from http://www.ncbi.nlm.nih.gov/pubmed/10151618

Reason, J. (2000). Human error: models and management. BMJ, 320(7237), 768-770. Retrieved from http://www.ncbi.nlm.nih.gov/pubmed/10720363

Reimer, A. P., Schiltz, N., Koroukian, S. M., \& Madigan, E. A. (2016). National Incidence of Medical Transfer: Patient Characteristics and Regional Variation. $J$ Health Hum Serv Adm, 38(4), 509-528. Retrieved from http://www.ncbi.nlm.nih.gov/pubmed/27079058 
Reis, A. M., \& Cassiani, S. H. (2011). Adverse drug events in an intensive care unit of a university hospital. Eur J Clin Pharmacol, 67(6), 625-632. doi:10.1007/s00228010-0987-y

Resar, R. K., Rozich, J. D., Simmonds, T., \& Haraden, C. R. (2006). A trigger tool to identify adverse events in the intensive care unit. Jt Comm J Qual Patient Saf, 32(10), 585-590. Retrieved from http://www.ncbi.nlm.nih.gov/pubmed/17066996

Ringdal, M., Chaboyer, W., \& Warren Stomberg, M. (2016). Intrahospital transports of critically ill patients: critical care nurses' perceptions. Nurs Crit Care, 21(3), 178184. doi:10.1111/nicc. 12229

Rothschild, J. M., Landrigan, C. P., Cronin, J. W., Kaushal, R., Lockley, S. W., Burdick, E., . . Bates, D. W. (2005). The Critical Care Safety Study: The incidence and nature of adverse events and serious medical errors in intensive care. Crit Care Med, 33(8), 1694-1700. Retrieved from http://www.ncbi.nlm.nih.gov/pubmed/16096443

Schwebel, C., Clec'h, C., Magne, S., Minet, C., Garrouste-Orgeas, M., Bonadona, A., .. . Group, O. S. (2013). Safety of intrahospital transport in ventilated critically ill patients: a multicenter cohort study*. Crit Care Med, 41(8), 1919-1928. doi:10.1097/CCM.0b013e31828a3bbd

Services, C. f. M. M. (2015). Details for Title: Case Mix Index. Retrieved from http://www.cms.gov/Medicare/Medicare-Fee-for-ServicePayment/AcuteInpatientPPS/Acute-Inpatient-Files-for-DownloadItems/CMS022630.html 
Seymour, C. W., Kahn, J. M., Schwab, C. W., \& Fuchs, B. D. (2008). Adverse events during rotary-wing transport of mechanically ventilated patients: a retrospective cohort study. Crit Care, 12(3), R71. doi:10.1186/cc6909

Silva, M. C. (1983). The American Nurses' Association's position statement on nursing and social policy: philosophical and ethical dimensions. $J$ Adv Nurs, 8(2), 147151. Retrieved from http://www.ncbi.nlm.nih.gov/pubmed/6551394

Singh, J. M., MacDonald, R. D., \& Ahghari, M. (2014). Critical events during land-based interfacility transport. Ann Emerg Med, 64(1), 9-15 e12. doi:10.1016/j.annemergmed.2013.12.009

Singh, J. M., MacDonald, R. D., Bronskill, S. E., \& Schull, M. J. (2009). Incidence and predictors of critical events during urgent air-medical transport. CMAJ, 181(9), 579-584. doi:10.1503/cmaj.080886

Smith, C. M. (2005). Origin and uses of primum non nocere--above all, do no harm! $J$ Clin Pharmacol, 45(4), 371-377. doi:10.1177/0091270004273680

Steel, K., Gertman, P. M., Crescenzi, C., \& Anderson, J. (1981). Iatrogenic illness on a general medical service at a university hospital. $N$ Engl J Med, 304(11), 638-642. doi:10.1056/NEJM198103123041104

Swickard, S., Swickard, W., Reimer, A., Lindell, D., \& Winkelman, C. (2014). Adaptation of the AACN Synergy Model for Patient Care to critical care transport. Crit Care Nurse, 34(1), 16-28; quiz 29. doi:10.4037/ccn2014573

Systems, C. f. A. o. M. T. (2012). 9th Edition Accreditation Standards. 
Thomas, E. J., \& Petersen, L. A. (2003). Measuring errors and adverse events in health care. J Gen Intern Med, 18(1), 61-67. Retrieved from http://www.ncbi.nlm.nih.gov/pubmed/12534766

Thomas, E. J., Studdert, D. M., Burstin, H. R., Orav, E. J., Zeena, T., Williams, E. J., . . . Brennan, T. A. (2000). Incidence and types of adverse events and negligent care in Utah and Colorado. Med Care, 38(3), 261-271. Retrieved from http://www.ncbi.nlm.nih.gov/pubmed/10718351

Vaughan, D. (1996). The Challenger launch decision : risky technology, culture, and deviance at NASA. Chicago: University of Chicago Press.

Venkategowda, P. M., Rao, S. M., Mutkule, D. P., \& Taggu, A. N. (2014). Unexpected events occurring during the intra-hospital transport of critically ill ICU patients. Indian J Crit Care Med, 18(6), 354-357. doi:10.4103/0972-5229.133880

Voigt, L. P., Pastores, S. M., Raoof, N. D., Thaler, H. T., \& Halpern, N. A. (2009). Review of a large clinical series: intrahospital transport of critically ill patients: outcomes, timing, and patterns. J Intensive Care Med, 24(2), 108-115. doi: $10.1177 / 0885066608329946$

Wiegersma, J. S., Droogh, J. M., Zijlstra, J. G., Fokkema, J., \& Ligtenberg, J. J. (2011). Quality of interhospital transport of the critically ill: impact of a Mobile Intensive Care Unit with a specialized retrieval team. Crit Care, 15(1), R75. doi:10.1186/cc10064 
Wilson, R. M., Runciman, W. B., Gibberd, R. W., Harrison, B. T., Newby, L., \& Hamilton, J. D. (1995). The Quality in Australian Health Care Study. Med J Aust, 163(9), 458-471. Retrieved from http://www.ncbi.nlm.nih.gov/pubmed/7476634 